Portland State University

PDXScholar

5-7-1992

\title{
Personal Values, Work Values, and Job Interests of Nursing Students
}

Stella Beach Bellarts

Portland State University

Follow this and additional works at: https://pdxscholar.library.pdx.edu/open_access_etds

Part of the Educational Leadership Commons

Let us know how access to this document benefits you.

\section{Recommended Citation}

Bellarts, Stella Beach, "Personal Values, Work Values, and Job Interests of Nursing Students" (1992). Dissertations and Theses. Paper 4669.

https://doi.org/10.15760/etd.6556

This Thesis is brought to you for free and open access. It has been accepted for inclusion in Dissertations and Theses by an authorized administrator of PDXScholar. Please contact us if we can make this document more accessible: pdxscholar@pdx.edu. 
AN ABSTRACT OF THE DISSERTATION OF Stella Beach Bellarts for the Doctor of Education in Educational Leadership: Postsecondary Education presented May 7, 1992.

Title: Personal Values, Work Values, and Job Interests of Nursing students

APPROVED BY MEMBERS OF THE DISSERTATION COMMITTEE:

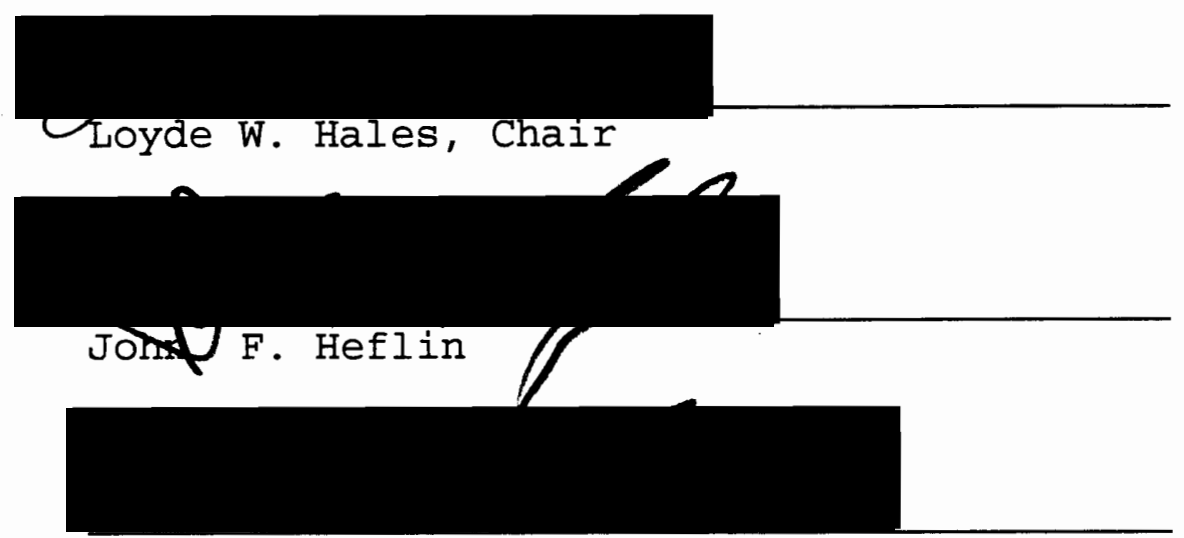

Mary K. Kinnick

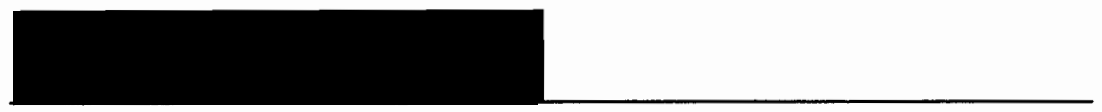

Kenneth D. Peterson

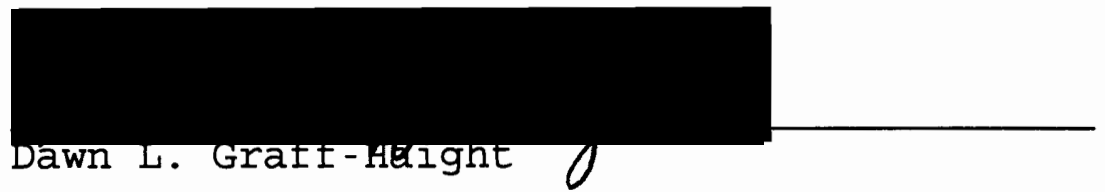

The purposes of this study were to (1) describe the personal values and work values of nursing students in the last year of their present educational preparation, (2) to 
investigate the relationships between values, both personal and work, and selected demographic variables (type of educational institution, present educational preparation, job interests, and age), and (3) to examine the correlations between students' personal values and work values.

Using the profile of Life Values (PLV) and the ohio Work Values Inventory (OWVI), the personal and work values of 452 student nurses were examined, first as a total sample for means and standard deviations, then by selected demographic variables with MANOVA, ANOVA, and Scheffe at the .10 level of significance. In the sample were 43 students from graduate nursing programs, 143 students from baccalaureate nursing programs, and 266 students from associate degree programs, from both public and private educational institutions in two northwestern states.

The order of the means for the total sample on the PLV scales from the highest to lowest were Considerate, Intellectual, Achievement, Recognition, Creative, Artistic, and Integrity. The order of the means for the total sample on the OWVI scales from highest to lowest were Task Satisfaction, Self Realization, Altruism, Securiy, Money, Independence, Ideas/Data Orientation, Object Orientation, Control, Prestige, and Solitude.

In comparing the values on the PLV and OWVI by type of educational institution, the means were significantly higher for students enrolled in private educational institutions than 
for students from public educational institutions. When the values on the PLV and OWVI scales were compared by educational preparation, significant differences were found on the means, with graduate students placing more values on Intellectual, baccalaureate degree students placing more value on Recognition, Control, Independence, and Object Orientation, and associate degree students placing more value on Integrity, Security, and Money. When the means on the PLV and OWVI scales were examined by job interest, students interested in pediatrics placed more importance on Considerate, Achievement, and Intellectual; students interested in specialty areas, such as the operating room or emergency room placed more value on Object Orientation, just as students interested in critical care and pediatrics placed more value on object Orientation than did the students interested in medical/surgical nursing, geriatrics, obstetrics, mental health, nurse practitioner or clinical specialist role. In the final comparison of the PLV and OWVI values with age, the 40-54 age group placed more value on Intellectual while the 20-29 age group placed more value on Recognition, Security, Control, Money, and Prestige. Using Chi-square as the inferential test, educational preparation and job interests were found to be related. Graduate students were primarily interested in the nurse practitioner or clinical specialist role; students receiving a baccalaureate degree expressed more interest in critical care and pediatrics; students receiving an associate degree 
expressed more interest in medical/ surgical nursing and geriatrics.

In examining the correlations between the PLV and OWVI, 58 of the 77 coefficients were significant at the .05 level. The correlations of the two instruments demonstrated a logical relationship exists between the instruments.

These findings have implications for nursing education. The educational foundation for nursing is based on the fostering of personal well-being and continuing growth through interpersonal interactions. The nursing curriculum needs to be reviewed periodically for differientation, interpretation, and clarification of values. In order to provide an education that is conducive to recognition of values, the faculty need to be aware of their own values, be able to recognize how their values relate to teaching, student learning, and professional practice, and periodically evaluate how they use values in the process. Teaching by relating values to subject matter, human differences, and practice enables student nurses to recognize and understand their own values as well as the values of other people. These findings have implications for further research, as values of faculty and students are in some ways related to age, specific interests, and educational preparation. 


\title{
PERSONAL VALUES, WORK VALUES, AND JOB INTERESTS OF NURSING STUDENTS
}

\author{
by
}

STELLA BEACH BELLARTS

A dissertation submitted in partial fulfillment of the requirements for the degree of

\author{
DOCTOR OF EDUCATION \\ in \\ EDUCATIONAL LEADERSHIP: POSTSECONDARY EDUCATION
}

Portland State University

1992 
TO THE OFFICE OF GRADUATE STUDIES:

The members of the Committee approve the dissertation of Stella Beach Bellarts presented May 7, 1992.

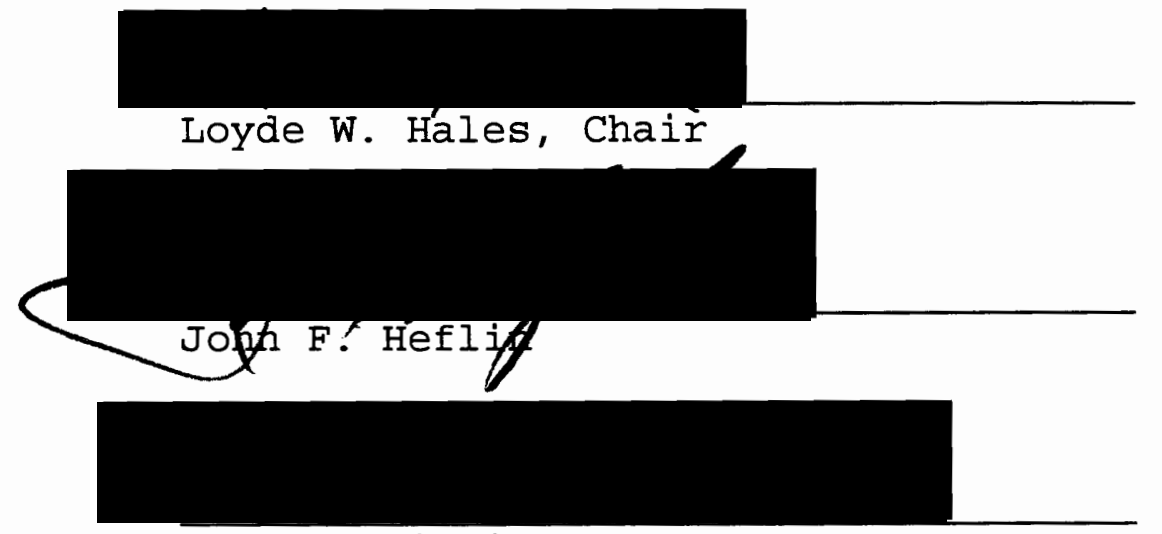

Mary K. Kinnick

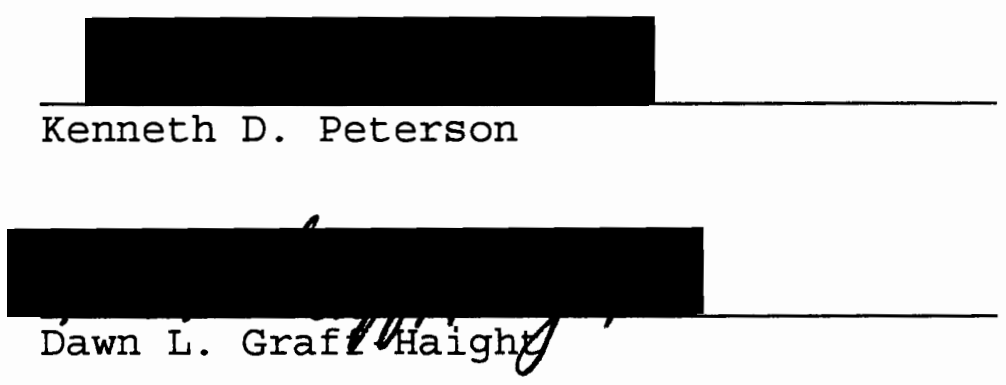

APPROVED :
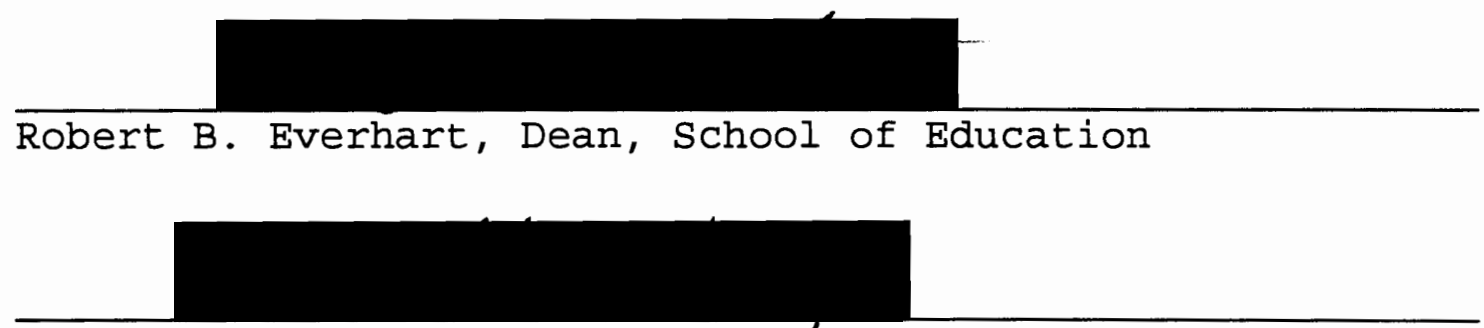
William Savery, Vice Provgst for Graduate studies
and Research 


\section{ACKNOWLEDGEMENTS}

Special appreciation is extended to Dr. Loyde Hales for his constant encouragement, support, and invaluable assistance as research advisor. A sincere thank you is extended to Dr. John Heflin, Dr. Mary Kinnick, Dr. Kenneth Peterson, and Dr. Dawn Graff-Haight for their helpful recommendations and criticisms as readers. Special acknowledgement is extended to Dr. Loyde Hales and those in the computer center for their assistance with computer programming and analysis of the data. Appreciation is extended to the Community Colleges and Universities, for their willingess to endorse this study. Sincere appreciation is due the students who particupated in this study.

My thanks also go to colleagues, friends, and family who gave me support throughout all stages of this study.

s.b.b. 
TABLE OF CONTENTS

PAGE

ACKNOWLEDGEMENTS $\ldots \ldots \ldots \ldots \ldots \ldots \ldots \ldots \ldots \ldots \ldots \ldots \ldots \ldots \ldots \ldots$

LIST OF TABLES $\ldots \ldots \ldots \ldots \ldots \ldots \ldots \ldots \ldots \ldots \ldots \ldots \ldots \ldots \ldots \ldots \ldots$

CHAPTER

I INTRODUCTION $\ldots \ldots \ldots \ldots \ldots \ldots \ldots \ldots \ldots \ldots \ldots \ldots$

Background $\ldots \ldots \ldots \ldots \ldots \ldots \ldots \ldots \ldots \ldots$

Problem Statement $\ldots \ldots \ldots \ldots \ldots \ldots \ldots \ldots, 8$

Statistical Hypotheses .............. 10

Assumptions . . . . . . . . . . . . . 11

Delimitations of the study $\ldots \ldots \ldots \ldots \ldots \ldots 12$

Definitions ................... 12

Significance of this study .......... 19

Overview of the study $\ldots \ldots \ldots \ldots \ldots \ldots \ldots 20$

II REVIEW OF THE LITERATURE $\ldots \ldots \ldots \ldots \ldots \ldots \ldots \ldots 21$

Theoretical Foundation for values ....... 22

Historical Perspectives ............ 26

Classifications of values ............ 30

Values of Students in Elementary and

Secondary Education ............... 32

Values and Occupational Choice ........ 38

Values Among College Students ......... 40

Values of Employed Adults ........... 46 
Studies of Nurses' Values .............. 53

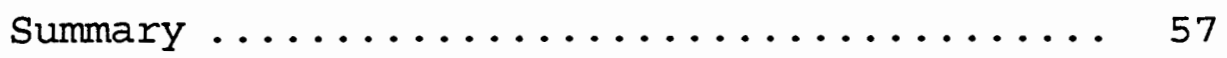

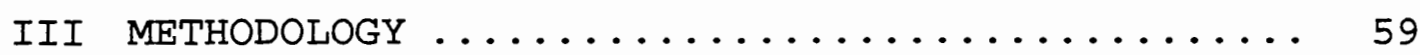

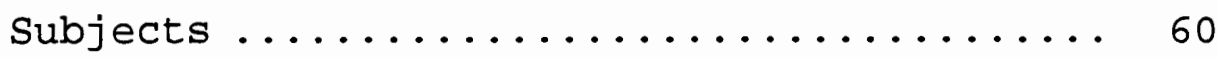

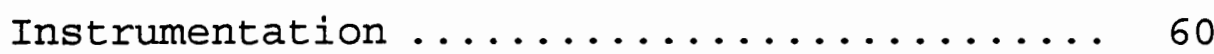

Data Gathering Procedure .............. 66

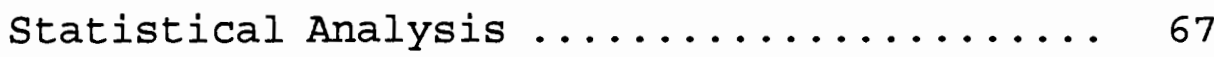

IV PRESENTATION OF THE FINDINGS ............... 72

Characteristics of Sample ............. 72

Professional Interest Areas ............. 86

Analysis of the Profile of Life Values ..... 91

Analysis of the Ohio Work Values Inventory . 96

Analysis of Personal Values by Type of

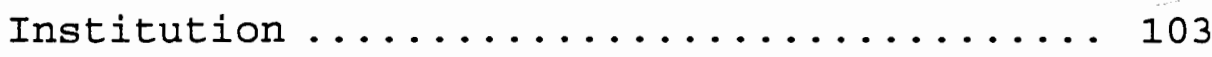

Analysis of Personal Values by Educational

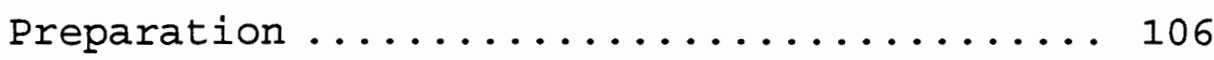

Analysis of work Values by Type of

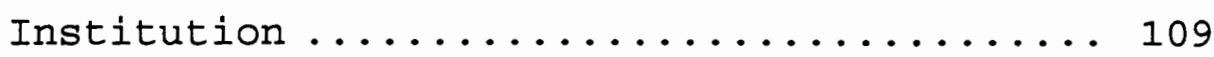

Analysis of Work Values by Educational

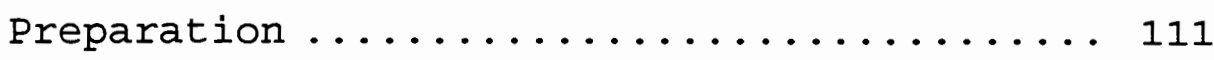

Relationships Between Personal Values and

Job Interests .......................... 116

Relationship Between Work Values and Job

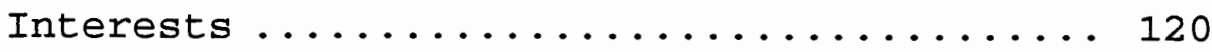


Analysis of Personal Values by Age Group ... 124 Analysis of Work Values by Age Group ...... 127 Relationships Between Personal Values and

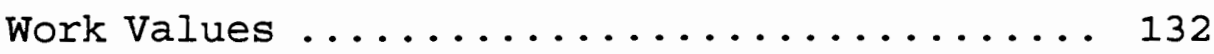
Relationship Between Educational Preparation

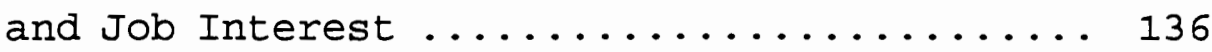
Measurement Characteristics of the

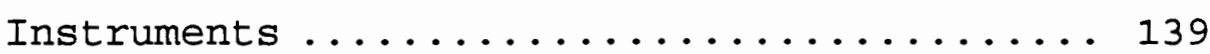
Values by Rank order .................... 144

V SUMMARY, CONCLUSIONS, AND RECOMMENDATION ..... 157

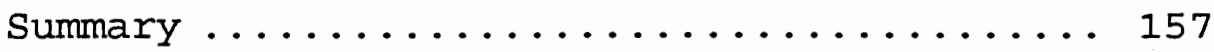

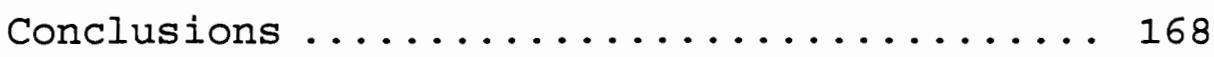
Implications for Nursing Education ....... 188 Limitations of the study ............. 189 Recommendation for Future Research ....... 190

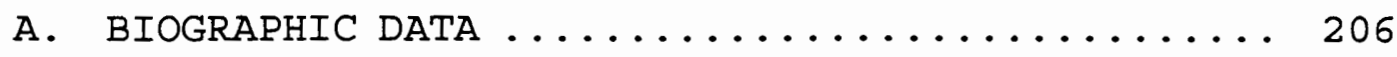

B. OHIO WORK VALUES INVENTORY .............. 209

C. PROFILE OF LIFE VALUES ................ 216

D. SAMPLE LETTER FROM RESEARCHER TO COLLEGES

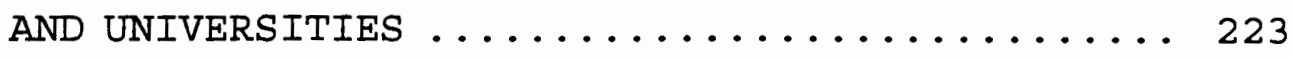

E. SAMPLE LETTERS FROM RESEARCHER TO STUDENTS .... 229 


\section{LIST OF TABLES}

TABLE

PAGE

I Coefficient Alphas for PLV Subscales ........ 65

II Measures Used to Analyze Data ............. 68

III Gender of Nursing students ............... 74

IV Ages of Nursing students ............... 76

V Present Educational Program .............. 77

VI Type of Educational Institution ........... 77

VII Level of Prior Educational Preparation ........ 78

VIII Years of Employment as a Registered Nurse ..... 81

IX Years of Employment as a Iicensed Vocational

Nurse, Paramedic, or Nursing Assistant ....... 82

$\mathrm{X}$ Years of Employment in Other Fields .......... 83

XI Full-Time and Part-Time Employment ........... 84

XII Statistical Summary of Prior Employment ....... 85

XIII Intended work setting ................. 87

XIV Practice Interest for Employment ........... 88

XV Critical Care Nursing Interest ............. 89

XVI Mental Health Interests .................. 89

XVII Nurse Practitioner Interests .............. 90

XVIII Interests in Other Specialities ............ 91

XIX Scales for Profife of Life Values ............ 92

XX Means, Standard Deviations, and

Coefficient Alphas for Personal Values ......... 93 
XXI Assignment of Ohio Work Values Inventory

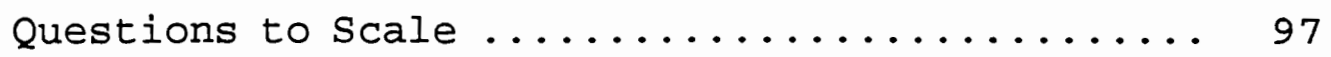

XXI Means, Standard Deviations, and Coefficient Alphas for Ohio Work Values Inventory scales ... 98

XXIII Means and Standard Deviations on Personal Values by Type of Educational Institution .......... 104 XXIV Analysis of Variance for Personal Values by

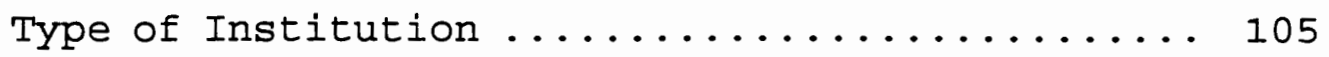

XXV Means and Standard Deviations for Personal Values by Educational Preparation .............. 106

XXVI Analysis of Variance for Personal Values by Educational Preparation .................. 107

XXVII Post Hoc Comparisons: Personal Values with

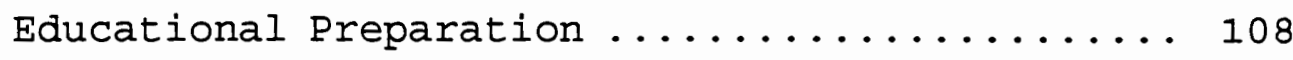

XXVIII Means and Standard Deviations for Work Values by Type of Educational Institution .......... 110

XXIX Analysis of Variance for work values by

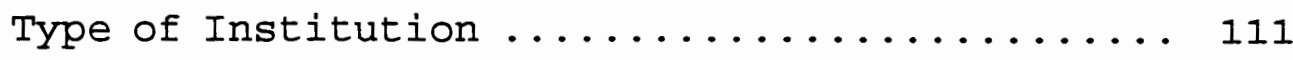

XXX Means and Standard Deviations for Work Values

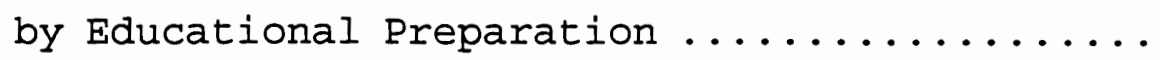

XXXI Analysis of Variance on work Values by

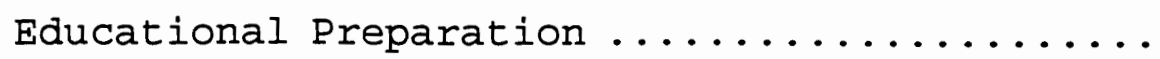

XXXII Post Hoc Comparisons: Work Values with

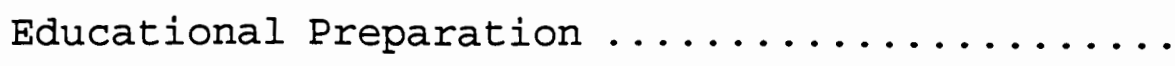


XXXIII Means and Standard Deviations for Personal

Values by Job Interest ................ 117

XXXIV Analysis of Variance for Personal Values by

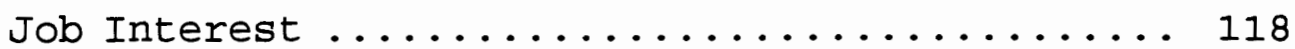

XXXV Significant Pairwise Mean Comparisons on

Job Interest for Personal Values ........... 119

XXXVI Means and Standard Deviations for Work

Value Scales by Job Interest ............. 121

XXXVII Analysis of Variance for work Values

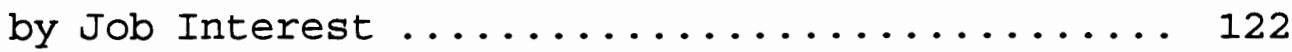

XXXVIII Significant Pairwise Mean Comparisons on Job

Interests for Work Values .............. 123

XXXIX Means and Standard Deviations of Personal Values

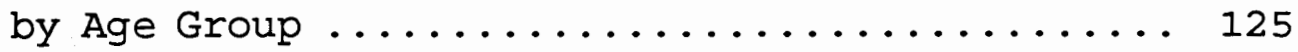

XXXX Analysis of Variance of Personal Values

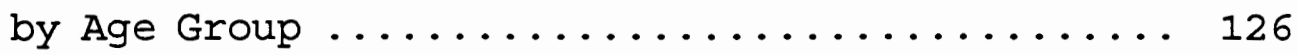

XXXXI Significant Pairwise Mean Comparisons by Age Group for Personal Values ............ 127

XXXXI Means and Standard Deviations for Work Values

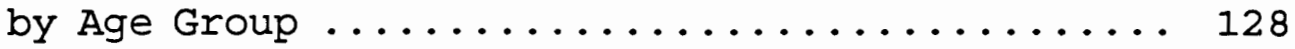

XXXXIII Analysis of Variance of Work Values

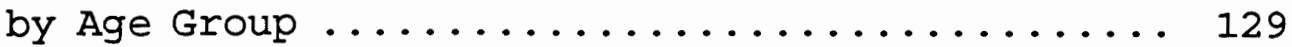

XXXXIV Significant Pairwise Mean Comparisons on Age Group for work Values ................. 130 
TABLES

PAGE

XXXXV Correlation Coefficients with Probabilities

Between Personal Values and Work Values....... 132

XXXXVI Frequency of Employment Interests by

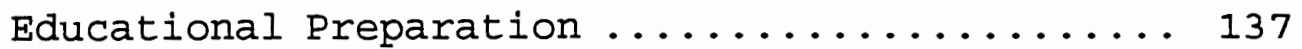

XXXXVII Frequency of Employment Interests by Associate and Baccalaureate Degree Students .......... 139

XXXXVIII Intercorrelation of scale for Profile of Life

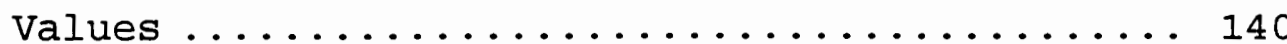

XXXXIX Factor Analysis of Personal Values

for student Nurses..................... 142

I Intercorrelation of Scales for Ohio Work

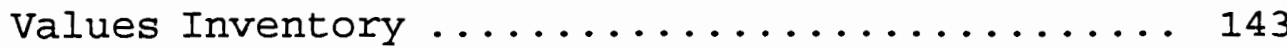

LI Factor Analysis of Work Values

for student Nurses .................... 144

LII Rank Order of Personal Values by Means ....... 146

LIII Personal Values Rank Ordered by Means for Job Interests ..................... 148

LIV Spearman Correlation Coefficients Between Type of Educational Institution, Educational

Preparation, and Age on Personal Values Ranking. 149

LV Spearman Correlation Coefficient by Personal

Value Ranking and Job Interest ........... 150

LVI Rank Order of Work Values by Means ......... 152

LVII Work Values with Job Interests Ordered

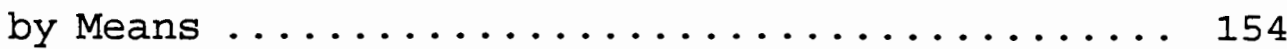


LVIII Spearman Correlation Coefficients Between Type of Educational Institution, Educational Preparation and Age on Work Values Ranking .... 155

IIX Spearman Correlation Coefficients on Work Value Ranking by Job Interests ............... 156

LX Means and Rank Order on Ohio Work Values Inventory Scales for Educators/Administrators ......... 174

IXI Means and Rank Order on Ohio Work Values Inventory by Educational Preparation for Hales Study and the

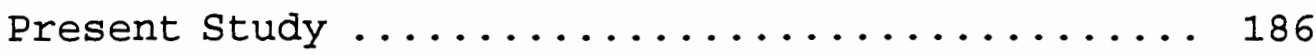


CHAPTER I

INTRODUCTION

Personal values and work values have received increased attention in the nursing curriculum and job market in recent years. Often stated reasons for this attention have been related to rapid changes in health care, changes in the nurse practice role, nursing shortages, and ethical issues that have surfaced and affected the personal values of the individual. These issues raise questions as to what is the significance of personal and work values among student nurses today. What are the personal values of student nurses? What are the work values of student nurses? Is there a difference in the personal values and work values among the student nurses in the differing nursing education programs? How are the values related to future job interests? Age? Is there a difference in the personal and work values of students with previous work experience and those without previous work experience?

\section{BACKGROUND}

The values of professional nursing have changed during this century. In 1900, two essential personal values for nurses were obedience and submissiveness to rules based on an authoritarian milieu (Robb, 1900; Vien, 1989). These values 
persisted well into the 1960's when ethical standards for professional nursing practice began to reflect different opinions. In the latter 1960's and early 1970's, changes were made in the professional nursing organization's professional code. Statements about nurses' accountability, responsibility, and competence replaced previous values of obedience and dependence (Kelly, 1981; Vien, 1989).

Nurse educators then considered altering their teaching strategies to model the developing changes in the professional practice role. The impact of the American Association of Colleges of Nursing (AACN) Report: Essentials of College and University Education for Professional Nursing (Edwards and panel, 1986) on higher education in nursing contributed to some of the more recent and major changes in university nursing curriculum. This report included a recommendation to emphasize processes that foster development of values, attitudes, personal qualities, and professional behavior. Just how much impact this has made on the various programs in nursing education has not been studied.

In the AACN Report (Edwards and panel, pp. 6-7), a number of values were listed: altruism, equality, esthetics, freedom, human dignity, justice, and truth. In conjunction with the listing of values were examples of personal qualities and attitudes (36) that are characteristics that support the values that enhance the educational preparation of the nurse, i. e., caring, commitment, self esteem, creativity, 
independence, empathy, morality, and inquisitiveness. In developing this list, a number of universities with schools of nursing were contacted regarding their thoughts on essential characteristics for personal qualities, attitudes, and values for higher education nursing preparation. Several forums were convened to discuss these issues. Little formal research investigated the relationship of the values, attitudes, and personal qualities listed in the report.

Studies on the role of values in personalities (Allport, Vernon, and Lindzey, 1960), value activities (Shorr, 1963), interpersonal values (Gordon, 1960), personal values (Scott, 1960), and moral and ethical values (Edel, 1963; Rescher, 1982) have been done. Each researcher has investigated one or more of the listed personal qualities in the AACN report. None have included all the personal values, personal qualities, and attitudes stated in the report, a potential area for further study.

With the development of the critical care units in the 1960's and the changing values in nursing practice came more recognition of the participatory processes used for decision making among health care team members. More concern surfaced regarding issues and values, that of the client/patient, the family, nurse, physician, and other health care members. These changes lead to the question: Are student nurses, in the various educational programs (Associate Degree, Baccalaureate Degree, and Graduate Degree), similarly prepared 
to deal with issues on values, attitudes, and personal qualities? Or does their preparation differ?

In the last five years, a major shortage of nurses has been reported. Nursing journals and help wanted sections in most newspapers list many job offerings for nursing positions. This raises questions as to why a shortage is so highly publicized. Is this shortage of Registered Nurses due to the fact women have more opportunities in other fields with greater economic advantages? Or, is it because Registered Nurse staffing ratios have improved? Or, is it because personal qualities and values have changed in the female population?

The definition of the term values varies among disciplines, as well as within disciplines. From an economic point of view, values are seen as an application of preference for societal resources. From the social disciplines, values are viewed as judging something as being desirable or useful (Omery, 1989; Rescher, 1982, p. 1). For educational purposes, Krathwohl, Bloom, and Masia (1964) described values as being a social product that has been internalized or accepted for use by an individual as his/her criterion of worth. Values are formed at different levels, the lowest being a belief with the highest being a commitment to the value. The term attitude is often mingled with values; still, more specifically, the term implies the individual has and uses 
general sets of valuing in their behavior (Krathwohl, Bloom and Masia, 1964, p. 140).

The common theme among the definitions for values is, values pertain to the affective disposition of human behavior, elude to the idea that personal values are organized in a hierarchial order with motivational worth, and are expressed as behaviors or verbalized standards of conduct (Omery, 1989). According to Raths, Harmin and Simon's (1978), a value must meet certain criteria.

It must be freely chosen, without pressure. It must be chosen from many alternatives. It must be chosen after reflection, have been prized and cherished, affirmed to others, incorporated into actual behavior, and been repeated in one's life. (p. 47)

Several theories have contributed to research on values. According to Rescher (1969), in the 1800's Brentano saw the basis of valuation being grounded in man's emotions. Spranger (1928) contended there were six types of men: theoretical, economic, aesthetic, social, political, and religious. Each could be identified by their dominant interests, but each did not belong exclusively to any one type. Spranger's theory had implications of values across personality types. Theories, such as, Combs and Snygg's (1949) self theory on enhancement and preservation of the self concept, Roe's (1956) occupational choice theory of person or non-person directed choice, Maslow's (1954) personality needs theory based on a hierarchy of needs, and Horney's (1945) personality theory, 
have been used as rational basis for studying personal qualities and values.

In the literature, authors, such as Krathwohl, Bloom, and Masia (1964), Katz (1963), and Perrone (1965), have discussed values and the role they play in work. They believe work values are perceived as being the most permanent personal values; interests and attitudes are perceived as being less influential. The formation of values as they relate to work are found to begin in early childhood. These same values continue to exert an influence on the person throughout adult life (Gribbons and Lohnes, 1965; Hales and Fenner, 1972). "Professional values are seen as a reflection and expansion of personal values" (Fromer, 1981, p. 15). Both personal values and work values are influenced by the socioeconomic environment (Raths et al., 1978).

A number of studies have been made on work values of students, nurses, teachers, and administrators (Bohan 1986; Hales, 1977; Hales \& Fenner, 1975, 1973, 1972; Hales \& Hartman, 1978; Klampe, 1983; Ulrich, 1987; Waggoner, 1986). Other studies have investigated vocational interests (Holland, 1965; Roe, 1956; Strong-Campbell, 1974; Super, 1970). Kramer's (1986) study examined the effects of faculty practices on student acquisition of beliefs, values, and attributes associated with professional craftmanship. Gavin and Boyle (1985) followed values of nursing students over a ten year period. Studies of nursing students' personal values 
and their relationship to work values appear to need further investigaton.

The existence of values as being a part of an individual's personality was recognized by Holland (1973) as he studied personality types and the differentation of preferred activities, interests, competence, and values. As stated earlier, children begin to form values in early childhood as they choose and select options within the family environment. As children enters the educational system, the influence of teachers becomes evident. Role models are seen to affect children's values, as they take on and identify with a set of standards. Research does show that children continue to pick and choose from the options (Sarason \& Sarason, 1973).

"Every teacher is believed to be a value builder as they engage the learner in meeting their own needs - the roots of our values" (Tyson \& Carroll, 1970, p. 2). Teachers do, however, have clearly defined personal values. Some are more receptive and open to a variety of value systems. The rigid teacher is less open to facilitating experiences that promote independent decision making by the student and the development of individual personal values. Again, this raises questions as to what effect the fostering of the development of values has on the professional behavior of nursing students. Does one form of educational preparation tend to influence student's values more than another? Does the form of educational preparation tend to influence student nurses' 
interest in one particular area of specialization more than another?

The complexity of the above concerns raise questions about personal values and work values of nursing students. The influence that education has on further development of values raises questions about the effect that nursing faculty have on the values of students. Basic research on the relationship between personal values and work values of student nurses is an area for further study.

No research study was found to examine the relationship between personal values and work values of nursing students and the form of educational preparation. Few studies have examined student nurses' personal values and work values in relation to job interest and educational preparation. No study explicitly examined the relationship of previous employment with the personal values and work values of nursing students. Therefore, this study of personal values, work values, education, and job interests of nursing students was undertaken to determine some of the relationships between values, education, and job interests.

\section{PROBLEM STATEMENT}

Personal values and work values have received increased attention in the nursing curriculum and in the job market. Educational leaders acknowledge the importance of recognizing certain values for nurses. Surveys were taken to identify 
these values. Few studies described the incidence of these values. Few research studies reported on the relationship of personal and work values to educational preparation or job interest. Thus, there is a lack of substantive information concerning the personal values and work values of nursing students.

\section{Research Question}

Based on the attention nursing education has given to the personal values of students in higher education, this investigator chose to study the values of nursing students in the final year of their nursing program at the Associate, Baccalaureate, and Graduate Degree level. This study addressed the following research questions.

1. What is the educational background of nursing students in the last year of their nursing program?

2. What are the job interests of nursing students in the final year of their nursing program?

3. What are the personal values of nursing students in the final year of their nursing program?

4. What are the work values of nursing students in the final year of their nursing program?

5. Do the personal values of student nurses differ across levels of educational preparation?

6. Is there a difference in the work values of the students in the differing levels of educational 
preparation?

7. Do personal values differ with job interests?

8. Do work values differ with job interests?

9. Do personal values differ with age?

10. Do work values differ with age?

11. What is the relationship between personal values and work values in the student nurse population?

12. Are educational preparation and job interests independent?

\section{STATISTICAI HYPOTHESES}

Eight statistical hypotheses were generated for this study.

I. When examined by educational preparation, student nurses will not differ in their personal values.

II. When examined by educational preparation, student nurses will not differ in their work values.

III. Student nurses with different job interests will not differ in their personal values.

IV. Student nurses with different expressed job interests will not differ in their work values.

V. When examined by age, student nurses will not differ in their personal values.

VI. When examined by age, student nurses will not differ in their work values.

VII. There will be no correlation between the work values 
and the personal values of the students.

VIII. For student nurses in their final year, educational preparation and job interests will be independent.

\section{ASSUMPTIONS}

Although not the direct focus of this study, the following assumptions of this researcher may have influenced the design, execution, and outcomes of the study.

I. Basic personal values and work values begin to emerge at a young age.

II. Work values and life values are influenced by parents, peers, and teachers.

III. Students enter nursing with a fairly defined value system.

IV. The various educational curricula for nursing students do not differ to the extent that they influence student's personal values, work values, and area of job interest differently.

V. Curricula of various educational programs generally do not address values specifically with value modifications.

VI. The job interests of nurses are reflected in their career field choice. 


\section{DELIMITATIONS OF THE STUDY}

The delimitations of this study are: (1) the sample in the study will only be taken from the Schools of Nursing in Washington and Oregon, therefore, generalization to a larger sample may be inappropriate; (2) adults form work values and personal values at an earlier age, therefore, pre-existing work values and personal values influence the survey findings; (3) since most student nurses are female; males represent less than 3.3\% of the nurses (McKibbon, 1990); the sample would be less representative of the males; and (4) previous work experience may attribute to variations in personal values and work values.

\section{DEFINITIONS}

General, instrument specific, and personal qualities of the AACN report definitions of terms used in this particular study are presented in this section.

\section{General Definitions}

Attitude: A general set of valuing that an individual has and uses in his/her behavior (Krathwohl, Bloom, and Masia, 1964). Associate Degree nursing student: A student enrolled in a Community College nursing education program that qualifies the student to earn an Associate Degree in nursing and sit for the Registered Nurse licensure exams. 
Baccalaureate Degree nursing student: A student enrolled in a University nursing education program of four or more years that qualifies the student to earn a Bachelor of science in Nursing and sit for the Registered Nurse licensure exams. Graduate Degree nursing student: A student enrolled in a University nursing education program that grants a Master's or Doctorate in nursing upon completion of the program. Values: Pertain to the effective disposition of human behavior, are organized in a hierarchial order, have motivational worth, and are expressed as behaviors or verbalized standards of conduct (Omery, 1989, p. 500). Work values: An extensions of the value system to the world of work (Combs and Snygg, 1949).

\section{Work Values}

Definitions of the work values are those used for the Ohio Work Values Inventory by Hales and Fenner (1973). Altruism: "Importance given to the opportunity for involvement with other people in a helping, supportive or service role" (p. 9).

Control: "Importance of having an opportunity to take a leadership role or responsibility for other workers in the conduct of their work" (p. 9).

Ideas/data orientation: "Indicates the importance of having an opportunity to work with facts and ideas". Being creative; communicating ideas" (p. 10). 
Independence: "Signifies the importance of work which allows the person to determine his/ her own working conditions" (p. 9) .

Money: "Indicates the importance of work which enables the person to have a substantial income; more than enough to assure basic needs" (p. 9).

Prestige: " Concerns the desire for work which will bring personal recognition and acclaim; association with important people" (p. 10).

Security: "Concerns the desire for work which is steady and dependable" (p. 9).

Self Realization: "Expresses a preference toward work which permits an individual to utilize his/her skills, abilities, or talents" (p. 9).

Solitude: "Relates to the preference for work situations characterized by the absence of close relationship with other people" (p. 10).

Task satisfaction: "Concerns the importance associated with work that is generally interesting and enjoyable; work that an individual looks forward to doing" (p. 10).

Object Orientation: "Expresses the valuation of handling, tending, or manipulating physical objects such as utensils, materials, tools, or apparatus" (p. 9).

\section{Personal Values}

Personal values may be defined as internalized desirable 
features expressed by an individual. These definitions are used with the profile of life Values in this study.

Achievement: Concerns the desire to attain, accomplish, or succeed; desired results; perform successfully.

Artistic: Doing something tastefully - skillfully; the showing of good taste-fine arts.

Considerate: The act of giving careful thought or attention; sensitive to others.

Creative: Having or using imaginative or inventive ideas; resourceful in dealing with new or unusual experiences. Intellectual: The act of acquiring, using knowledge; the seeking of new information; determining how truths are known through inquiry or research.

Recognition: Reputation; identity; acknowledgement by others of status.

Integrity: The importance of being correct, sincere, honest; exact in accordance with the facts.

\section{Personal qualities: AACN REPORT}

The AACN Report of Edwards and panel (1986) listed the values, personal qualities and attitudes that are believed to be a part of the individual nursing student's values in higher education. These are listed below. The definitions of the values are those of the AACN Panel on Essentials of College and University Education for Professional Nursing. Altruism: "Concern for the welfare of others" (p. 6). 
Equality: "Having the same rights, privileges, or status" (p. 6).

Esthetics: "Qualities of objects, events, and person that provide satisfaction" (p. 6).

Freedom: "Capacity to exercise choice" (p. 6).

Human dignity: "Inherent worth and uniqueness of an individual" (p. 7) .

Justice: "Upholding moral and legal principles" (p. 7).

Truth: "Faithfulness to fact or reality" (p. 7).

None of the personal qualities and attitudes were specifically defined, therefore, the definitions for these are those of the investigator or the source as stated with the definition.

Acceptance: To agree or to consent to; to believe in. Accountability: Obligation to account for one's acts; responsible.

Appreciation: To recognize or hold in high regard; respect. Assertiveness: "The employment of expressive, goal directed, spontaneous, and self-enhancing behavior" (Johnson, 1986, p.683).

Authenticity: A quality of reliability; trustworthiness. Caring: "Cognitive and culturally learned actions, behavior processes, and patterns that enable others to improve their way of life" (Leninger, 1984, pp. 4, 46).

Commitment: "Agreement, obligation to do something" (Kozier \& Erb, 1987, p. 591). 
Compassion: Feeling or concern for others; desire to help. Confidence: The fact of feeling certain; belief in oneself. Courage: The courage to do what one thinks is right. Creativity: Having or showing imagination; using artistic or inventiveness skills.

Empathy: Sharing of emotions or feelings.

Fairness: Just, honest, impartial, unprejudiced.

Generosity: Willingness to give or share.

Honesty: The state or quality of being fair, sincere, truthful, trustworthy.

Humaneness: The quality of being kind, merciful, or sympathetic.

Imaginative: Resourcefulness in dealing with new and unusual experiences.

Independence: Free from influence, persuasion, or bias. Inquisitiveness: Given to seeking information. Kindness: The act of being friendly, gentle, cordial, or generous.

Morality: A moral quality or characteristic of standards of conduct; being in accord with the principles of right or wrong .

objectivity: The aiming or striving for something. Openness: Open to new ideas; open to differing views. Perseverence: Adherence to a purpose, action, or belief. Rationality: Use of an explanation or idea. Reflectiveness: To think seriously; to analyze. 
Respectful: Showing deference or dutiful regard for another. Self direction: The disciplining or controlling of one's desires, actions.

Self esteem: An opinion of oneself; respect and understanding of oneself.

Sensitivity: Being emotionally aware, perceptive.

Tolerance: Recognition of and respect for other's beliefs and practices.

Trustworthy: Acceptance and maintenance of confidence; honest, dependable.

Given these qualities and characteristics, only a modest relationship exists between the AACN values and these qualities. The AACN qualities, while not defined, do appear to be overlapping with each other and seem to form clusters. Therefore, the investigator chose to view these qualities as clusters that are somewhat related to the personal values that are used in this study, with the first grouping related to Intellectual, inquisitiveness, reflectiveness, openness; the second: Achievement, objectivity, confidence, self direction, accountability, perseverence; the third: Artistic, creative; the fourth: creative, rationality, independence; the fifth: Recognition, commitment, self esteem; the sixth: Considerate, caring, acceptance, empathy, compassion, appreciation, kindness, sensitiveness, humaneness, generosity, respectful, fairness, tolerance, assertiveness; the seventh: Integrity, courage, authenticity, morality, trustworthy, honesty, and 
hope. These values seemed to be values that are often associated with education and nursing practice.

\section{SIGNIFICANCE OF THIS STUDY}

While previous studies have examined work values among nurses in the late 1960's and early 1970's, few investigations have studied both the personal values and work values of nursing students. Few studies have examined the effect of nursing education on the values of student nurses. No study has examined the relationship between personal values and work values and the differing levels of educational preparation (Associate Degree, Baccalaureate Degree, and Graduate Degree). Few studies have examined the personal values and work values of nurses since the preceived professional nursing values changed from obedience and dependence to accountability, responsibility, and competence. Thus, this study of personal values and work values of student nurses in various nursing preparation programs provides an informational base pertaining to personal and work values of student nurses and how these are related to preparation and job interests. It should provide some basis for further review of nursing curricula and teaching practices in the colleges and universities with schools of nursing. 
OVERVIEW OF THE STUDY

Chapter one includes an introduction to the study with a summary of the background that stimulated the study, the problem statement, significance for the study, assumptions, hypotheses, limitations, and definitions.

Chapter II provides a review of the literature related to the study. Areas that will be covered are historical changes in nursing education and practice as related to personal values and work values, theoretical perspectives of these values, discussion of scales and measures of these values, a review of studies on work values, and a review of studies on personal values.

Chapter III focuses on methodology and research instruments used for or in gathering the data.

Chapter IV describes, analyzes, and reports the findings of the study.

Chapter $\mathrm{V}$ includes a summary of the study, the significance of the findings, and recommendations for future investigations. 
CHAPTER II

\section{REVIEW OF THE LITERATURE}

A review of the literature revealed that values have a philsophical foundation, that the definitions given for values vary, that culture has an effect on values, and that people engaged in professional disciplines differ in their values. Anthropologists have contributed to the study of human values by examining culture patterns and life styles. Sociologists have studied ideologies and mores of human values. Psychologist have subscribed to studying constructs for attitudes, motives, cathexis, and human values. Economists have explored material and personal values with an interest on monetary returns. Educators have ascribed to developing values with learning. Nurses have ascribed to certain professional values.

Much of the research in the literature has been on the values of students in elementary and secondary education. A growing body of research has examined the values of college students and groups of workers across cultures. Little research has been initiated to determine if student nurses have a set of professional values. Few studies have examined personal or work values of nursing students and nurses engaged in practice. 
To review the literature on values, the researcher chose to begin with the theoretical foundations used for this research of values; follow this discussion with a historical perspectives of values; present research on the development of values through education in primary, secondary, and postsecondary education; include research on values of the multicultural worker in the environment; present research findings on the values of nurses; and finally summarize the review of the literature. Each has contributed to the development of the study, the measurements, and the significance of values through education and work.

\section{THEORETICAL FOUNDATION FOR VALUES}

The literature offers many theoretical conceptualizations for values with grounding of values in behavioral responses. For this study, the investigator chose to discuss the formation of values from the following theories: personality-need theory by Maslow (1954), (2) self-theory by Combs and Snygg (1949), (3) social psychological theory of Horney (1945), and (4) occupational choice theory by Roe (1956). These are the theoretical concepts used in the investigation. They are also used with the formation of the Ohio Work Values Inventory and the Profile of Life Values. 
Personality-need Theory

Maslow's (1954) theory of motivation makes the assumption that human needs form a hierarchy. The motivation of a person is influenced by the relative importance of the need. Once the need is satisfied, it ceases to be motivational. The next higher order of need then becomes the important motivating factor. Maslow's lower order needs are primarily physiological and basic to survival. His higher order needs are psychological and social in nature. The highest level of motivation is self actualization. Maslow (1968) describes the self actualizing person as one who makes choices from among a variety of possibilities, those that really are valuable and pleasant. He states that values are" partly discovered by us within ourselves and partly chosen by the person themself. The inner structure of human nature can be trained and guided" (p. 176).

Maslow (1968) further describes a person as having "higher needs for meaningful work, for responsibility, for creativeness, for being just and fair, for doing something worthwhile, and for preferring to do it well" (p. 222). He conceptualizes the self actualizing people as:

being involved in something outside themself, as being devoted, working at something that is precious to them, which they love, and devote their lives to, a search for 'being' values - - which are intrinsic truth, beauty, efficiency, excellence, justice, perfection, order. (p. 222) 
Self-Theory

Combs and Snygg's (1949) theory is based on the assumption that the causes of behavior lie within the phenomenal field of the self. What one does and how one behaves is influenced by the concept one has of himself and his abilities. According to Combs and snygg:

The self is the most permanent part of an individual. It is the point of reference for their every behavior. Everyone has a basic need to preserve and enhance their self. The characteristics of the self govern individual needs. The governance from within the self is the mechanism which gives continuity and consistency to behavior. How the person sees themself has a tremendous effect on the behavior in differing situations. ( $p .78)$

They describe the self concept "as being the parts of the phenomenal field used by an individual for differentiating definite and fairly stable characteristics of himself" (p. 112)

According to Combs and Snygg's theory, an individual's values are reasonable and real to them. "Any and all behavior, without exception, is completely determined by and pertinent to the person's personal field, private world, and individual life span" (1949, p. 15). The strength of a value or goal is related to the degree of satisfaction achieved by the phenomenal self. The degree to which the person achieves a goal is associated with reactions to cultural effects and the behavioral will to be consistent with the culture (p. 102). The goals need to lead to a feeling of adequacy. If 
the goal is not met, the person seeks new interests through expression of new values and goals. The person needs to preserve their self concept.

\section{Social Psychological Theory}

Horney's (1945) theory of personality holds a basic premise that, in a given culture, a person meets culturally determined difficulties through childhood experiences. When a child encounters a great deal of difficulty in resolving personal problems, the problems are resolved at a great expense to the child's personality. Horney's theory is based on the concept of individual need, a need that comes from within the person for affection and approval, a partner, power, control of self and others, omnipotence of will, social recognition, personal admiration, personal achievement, independence, and a desire for perfection. These needs infer that individual desires are based upon the values they hold for themself. Self perceptions are reflected externally as needs for achievement.

\section{Occupational Choice Theory}

Roe's $(1956,1957)$ theory makes the assumption that early childhood experiences, interaction between the parents and child, interpersonal experiences within the family, the environment of the home, and a system of channeling are related to vocational choice. The differentiation in the interpersonal experiences has a potential influence on a child's orientation 
towards person-directed or non-person directed interests.

According to Hales and Fenner (1973), values are formed

and influenced by intrinsic and extrinsic factors. The theories support these assumptions.

\section{HISTORICAL PERSPECTIVES}

From a historical perspective, values have been recognized as an important part of the human behavior. The significance of valuing has been subject to interpretation, both scientifically and behaviorally.

The concept of the nature of values has been traced by Perry (1954, p. 9) and Maslow (1968, p. 158) to the philosophical ideas of Artistotle and Plato who believed that things that were valuable and pleasant were really valuable and pleasant to a good person. The concept of values based on the desiring for something because it has value originated with Ehrenfels according to Perry (1954, p. 9). The concept that values are based on affection originated from Meinong's ideas (Perry, p. 9). The idea that values originate from two perspectives, one as scientific fact, and the other as being significant to human concerns with grounding in a person's emotion originated with Lotze's doctrine of values in the $1800^{\prime} \mathrm{s}$ (Rescher, 1969; 1982).

Studies on the significance of values in the United States began with Munsterberg (1913) using Lotze's ideas. His work centered on identifying the man best fitted for 
managerial positions, the psychological conditions that caused man to achieve the greatest output, and the factors that influence the human mind and contribute to the interests of management.

The studies by Rokeach (1973) viewed values as deeply internalized standards for personal behavior. Other studies suggested that values become more stable over time because they are deeply internalized (Goodale, 1973; Jurgensen, 1978; Kluckhohn, 1951; Lusk and Oliver, 1974; Rokeach, 1973).

Studies by Rescher (1982) indicate that values are manifested in both verbal and behavioral responses. Rescher describes the process of valuing as initially involving thought or talk. The value is taken into account through personal deliberation. A decision is made which is followed by a behavioral response. Character traits, abilities and talents, features of the personality, habits and life patterns are formed through this process. Rescher describes values as:

being self oriented, (egocentric), where privacy, comfort, and success are the value focus; and other oriented, (in group oriented), where pride, reputation of one's profession, patriotism, social justice, aesthetic, and humanistic values are the focus. (p. 16)

$$
\text { According to Raths, Harmin, \& Simon's (1965, 1978) }
$$

research, values are formed by a process of choosing, prizing, and acting. In the process, values are valued by the individual, chosen from the alternatives, affirmed, prized and cherished, then acted upon, and repeated. This process then tends to give a pattern to a person's life (pp. 10, 47). 
Reseach on values by Thompson \& Thompson (1985) support Raths et al. criteria for a value. They add that, in the process, " values must actually be put into practice" (p. 78). The interpretation of the term values is diverse. A value, as defined by Kluckhohn (1951), is a conception, explicit or implicit, distinctive of an individual or characteristic of a group, of the desirable which influences the selection from available means and enters into action ( $p$. 2). Factors that influence values are culture, time, and control over the problem. Values, according to Raths et al. (1965), are experiences that enable a person to grow, to learn (p. 27). Perry (1954) defined value "as a thing - anything having value in the original sense when it is an object of interest - any interest" (p. 9). Values, from an economic point of view, are seen as an application of preference for societial resources. From the social point of view, values are viewed as being something useful or desirable (Omery, 1989 ; Rescher, 1982, p. 1). For educational purposes, values have been described as being a social product that has been internalized or accepted for use by an individual as a criterion of worth (Krathwohl, Bloom, and Masia, 1964).

The work of Krathwohl, Bloom, and Masia (1964) recognized the importance of values as an element that guides behavior. In viewing values from an educational perspective, they acknowledged that the conscience of an individual enables the person to develop behavioral controls (p. 180). They 
described values as developing through a process of acceptance, preference, commitment, conceptualization, and organization. More specifically, they stated:

Values are internalized, have a place in the individual's values hierarchy, are organized into some kind of internally consistent system, have controlled behavior for sometime, and the person has adapted to behaving in a certain way. (p. 184)

The work by Kohlberg (1981) describes moral values as developmental stages. According to Kohlberg, certain conditions provide the stimulus for moral development: the educational climate, the social climate, and the stage of individual intellectual development. Initially, children respond to culture rules of good or bad as they interpret these in terms of the physical consequences. After children pass through this stage, they enter a stage where they act to please others. In the final stage of moral development, children base their standards of behavior on the recognition of their own personal values and opinions. On reaching adulthood, moral values are usually fairly well established.

The interpretation of the work ethic of an individual has been described as a value or belief about the place of work in one's life. The research of Campbell (1966), Hales and Fenner (1972, 1973), Holland (1965), Strong \& Campbell (1974), and Super (1970) on selection of a career shows that people choose a career using a set of values. When given the choice, people use a group of values that are important to them in their work. 


\section{CLASSIFICATIONS OF VALUES}

Values have been classified in many ways. Just to mention a few, values have been classified as characteristics of the personality, work ethics, moral standards, economic values, social values, and spiritual values. Nursing, as a profession, has many speciality areas, therefore, types of men and classifications of values on scales are used as references with the development of the profile of Life values and biographic data for this study.

In the literature, Spranger (1928) contended that the personalities of men were revealed through their values or attitudes, that there were six types of men: theoretical, economic, aesthetic, social, political, and religious. Allport and Vernon's (1931) studies were initially designed to test Spranger's classification of types of men.

Rescher (1969) reviewed a variety of classifications of values and determined that values classifications can be approached from many directions. He described the most obvious classification as being that of subscribership to the value which includes groupings of personal values, professional values, work values, and national values. Calling these types of values, Rescher identified them as:

thing values with desirable inert features, environmental values with desirable features in the nonhuman arrangement, individual or personal values with desirable features of an individual, group values featuring relationships between individuals and groups, and 
societal values with desirable features related to the arrangements in society. (p. 15)

Rescher (1969) grouped values along the line of categories. He listed the categories as " material and physical, economic, moral, social, political, aesthetic, religious, intellectual, professional, and sentimental" (p. 17). An approach that Rescher used was to classify values using a relationship between self-orientation and other-orientation.

Kluckhohn (1951) classified values in terms of dimensions of modality and content, and generality and intensity with relationship to explicit and implicit characteristics of an individual or group. This classification of values has been used quite extensively in studies of personal values.

Hales and Fenner (1972) suggested that values tend to serve as judgement standards and criteria for behavior. They are a result of a dynamic process that involves both the needs of the individual and the culture. They tend to be more permanent and general in nature. The classification used by Hales and Fenner associated values with intrinsic and extrinsic characteristics. In applying the classifications to the Ohio Work Values Inventory, Hales and Fenner $(1973,1975)$ categorized Altruism, Object Orientation, Self Realization, Task Satisfaction, and Idea/Data Orientation as intrinsic values, and the rewards of work (Control, Money, Prestige, Security) and the situation (Independence, Solitude) as extrinsic work values. This instrument was used in the study. 
VALUES OF STUDENTS IN ELEMENTARY AND SECONDARY EDUCATION

Much of the research on values has focused on the values of students during their elementary and secondary education. Studies have focused on factors that influence students' values, both intrinsic and extrinsic. Some studies have examined values, particularly work values, of students at different levels of their education, looking for changes in values during these developmental years. Some studies have examined cultural influence on student values. The significance of students' values during the formative years should have some implications for studying student nurses' values during their nursing education. An understanding of or lack of understanding of different cultural values may also effect the way in which a student responds to other values.

In 1972, Hales and Fenner investigated the work values of fifth, eighth, and eleven grade students using the ohio Work Values Inventory. The eleventh grade students were found to value Altruistic work values and work that permitted Self Realization more than the students in the lower grades. A second study of six grade elementary students work values by Hales and Fenner (1973) used sex and social class as independent variables. An analysis of the findings showed the female students placed greater value on Altruism, and lesser value on object Orientation and solitude than the comparative male students. 
A third study of fifth grade student's work values, self concept, and sex by Hales and Yackee (1974) reported boys tended to place more importance on opportunities to work with physical objects, to control, to work with ideas, and to gain recognition than girls. The children with a more positive self concept tended to place more value on being allowed to develop their talents, to engage in enjoyable activities, and to function in a human service capacity.

Using the Work Aspect Preference Scale, Schulenburg and Vondracek (1987) studied seventh through twelfth grade students for differientation in their work values over a two year period. In the analysis of their date, they reported finding a greater differientation in work values among the students in the higher grades. They also reported finding a greater differientation in the work values of the female sample than in the male sample. The Work Aspect Preference Scale includes values such as life style, detachment, independence, physical activity, surroundings, coworkers, self development, altruism, prestige, management, money, security, and creativity with a relationship to work. The non-work values that were studied included human personal concerns, power and control, and material orientation.

In the study of work values of boys and girls by Gribbons and Lohnes (1965), their findings indicated that boys valued prestige and salary more than girls. The girls viewed personal contact and social services as being more important. 
In Rodriquiz's (1980) study of values in ethnic groups, they reported in their findings that black students aspired to higher levels of education and occupational opportunities than white students. Crowley and Shapiro's (1982) findings were supported by Rodriquiz study.

In 1981, Mills studied sex roles, personalities, and intellectual abilities of seventh and eighth grade students enrolled in public schools and private schools, including a group of mathematically precocious youths. The instruments he used included the Bem Sex Inventory, The Femininity Scale from the California Psychological Inventory, and Allport, Vernon, and Lindzey's Study of Values Scale. The findings in the study suggested there was some evidence of a positive relationship occurring between masculine traits, values, and math ability. Some of the evidence also showed a positive relationship occurred between feminine traits, values, and verbal skills. Differing relations were found between the values of Intellectual and self concept in the male and female sample. Females with higher intellectual abilities perceived themself more positively; males with higher intellectual abilities perceived themself more negatively.

A survey of American and Japanese elementary students values (Ishii, S., and Klopf, D. W., 1987), as to what is good or bad, right or wrong, or important or unimportant, reported that the American students primary values were independence, 
individuality, human dignity, democracy, and loyality. The Japanese students primary value was peace. Independence, individuality, democracy, and hospitality were considered as secondary values among the Japanese students. Secondary values of the sample of American students were money, aggressiveness, hospitality, and firstness. This study used a scale patterned after that of Rokeach (1973) and Sitaram and Cogdell (1976).

A study of work importance determinants (Sverko, 1989) on a high school sample in Yugoslavia found that the perceived importance or salience of work was mostly dependent on the personal perception of the individual. Individuals with a high regard for autonomy, variety, and life style seemed to be less work oriented. Work values considered in the study included utilization of ability, achievement, personal development, participation in decisions, aesthetics, creativity, autonomy, life style, variety, altruism, social interaction, social relations, working conditions, economics, advancement, prestige, authority, cultural identity, risk, and physical activity. These values are found on Super's values instrument.

A study of adolescent work values and achievement by Donohue (1984) found that adolescent vocational education workers seemed to be more motivated by intrinsic work values when compared with adolescents who obtained jobs through their own efforts. The adolescent worker who obtained 
their own job were similar to non-worker adolescents on psychosocial skills and academic performance. The unemployed adolescent student seeking jobs scored lower on the self concept and decision-making scales. Vocational education workers scored higher on decision making while the nonworker had higher intelligence scores.

A large investigation of value choices (Harrington and Harrington, 1989) among students in grades seven through twelve and employed adults across different cultures reported that the participants values were more similar than different. Regardless of the gender or culture, values related to salary and job security were most often selected as being the most important. The students did, however, place greater value on working with their minds and on leadership, while the employed workers placed higher values on achievement and variety diversion.

Isralowitz and Singer's (1986) study on the impact of family unemployment versus employment on work values of youths found little differences in the work values' orientation between the two groups. Using Super's Work Values Inventory, their most significant finding was that esthetics was valued more by youths from unemployed families. When making comparisons between the sexes, they found esthetic values and altruism were more important to the females from unemployed families. 
An earlier study by Goodwin (1972) reported finding male youths work values from homes with no working parent did not differ from the work values of youths from homes with working parents in importance. Rosenberg's (1965) study did find that youths coming from a home environment of parental unemployment had a lower self concept. Studies by Ginsberg, Ginsberg, Axelrod, \& Herma (1963), Havighurst (1964), Super (1957), and Super, Stanshevsky, Matlin, \& Jordan (1963) reported finding significant relationships between adolescent experiences and their work values.

An investigation of the relationship between female delinquent behavior and work values, occupational choice, and work experience by Just and Wircenski (1984) reported finding no relationship between delinquency, work values, and occupational aspirations in their sample. Their study did show that work values remained unchanged in their sample of 4,000 participants, even when delinquency increased. Black females were more willing to seek further education to gain employment than the non-black sample. Females suspended from school were less likely to believe they could achieve their occupational aspirations. The residence of a person did not influence the work values or employment aspirations of the sample. 


\section{VALUES AND OCCUPATIONAL CHOICE}

The concept that people tend to select occupations that are compatable with their values has been supported in theory and in research on occupational choice (Blau, Gustard, Jessor, Parnes, and Wilcox, 1956; Holland, 1959, 1973; Katz 1963; Maslow, 1968; Perrone, 1965, 1967, 1973); Roe, 1957; Strong, 1943; Super, 1957). The choice of a person to remain in a particular academic field has been reported to be related to whether the person has attributes similar to the other students in that particular area (Holland and Nichols, 1964). Studies of vocational preference by Campbell (1966, 1969), Holland (1959, 1965), Holland \& Nichols (1964), Strong (1943, 1955), and Strong \& Campbell (1974) are among the often cited research on personalities and occupational interest. Holland's (1959) premise was that, each person may be described as having similarities to one or more of six occupational interest personality types, that personality types are closely associated with a job requirement, and that the personality type contribute to the tenor of a particular occupation. Six themes surface from the interest inventory: realistic, conventional, enterprising, investigative, artistic, and social. Two instruments often used to assess occupational interests of students and young adults are Holland's Vocational Preference Inventory (1977) and Campbell's Vocational Interest Inventory (1974). 
Enoch's (1988) study of values, as they relate to successful and unsuccessful entry into the same school of social work, found that the student applicants had similar work values and attitudes. A further comparison of this sample of students with students entering general social science programs showed that the two different samples held differing values. The social work students ascribed to helping people, improving the situation in the country, and doing work that had social importance more often than the students enrolled in the general social science program.

Parson's (1988) research on the values of entering students majoring in communications reported that students in advertising were more motivated by the desire for material success. Print journalist students valued writing (creative work), while public relation students expressed considerable discomfort with creativity. Students enrolled in telecommunication expressed more interest in having a secure future, and those interested in broadcast journalism seemed more conservative in their responses to questions with moral and ethical considerations.

A study of self selection for specialization in industrial and electrical engineering (Izraeli, Krausz, and Garbor, 1979) examined the values and interests of first year college students. Their questionnaire explored responses to preferences of working with people, working with things, the relative importance of the various occupations to the student, 
and the image the student had of their chosen field with regard to autonomy, authority, influence, salary, practicality, importance, prestige, creativity, diversity, opportunities for advancement, self expression, and social contributions. Students enrolled in industrial engineering were found to have a higher preference for working with people than working with things. They viewed their specialization as providing more influence and authority. Electrical engineering students were more interested in working with things. Both groups viewed their fields as having opportunities for autonomy.

\section{VALUES AMONG COLLEGE STUDENTS}

Traditionally, education, particularly higher education in the United States, was very committed to shaping the particular values of a very homogenous student population. The students of the 1980's and 1990's have become more diverse, comes from a range of social groups with varied ethnicity, varied educational preparation, and mixed educational purposes (Levine, 1980; Thomas, Murrel1, and Chickering, 1982). Research over time reflects some potential changes in the values of college students.

Allport, Vernon, \& Lindzey's (1931) initial studies arose in response to the question of measuring the types of men as described by spranger. Raising the question, does a person subscribe to values inherent with the six types of men 
with varying degrees, Allport et al. used a multidimensional scale to obtain his data. Significant findings from their studies were that teachers and students enrolied in education selected theoretical values more often than graduate students enrolled in business administration. Young graduate students majoring in business administration selected economic values more frequently than others. Esthetic values were selected more often by people with a liberal arts background. Social values were scaled lower among students in business adminstration, while political (power) scales were scaled higher. Graduate nursing students selected religious values more often than other students.

In Allport, Vernon, and Lindzey's (1931, 1960) studies, they found that theoretic and esthetic values tended to covary, economic and political values tended to covary, and social and religious values covaried when rank order sets of variables were used.

A longitudinal study of west Point military academy cadets' values and moral judgement (Bridges and Priest, 1983) used three different values instruments, Rokeach's, Values Survey Scale, Scott's Value Test and an Importance Inventory developed by the investigators. In the results of their study, they reported that the cadets did not change the values they had on entry. Integrity, duty, and success in their career were important throughout their education. Being honest, dependable, and responsible were important values. 
The cadet's also placed high importance on social values friendship, communication, and family security.

Ravlin, Meglino, and Adkins (1988) research on the stability of work values and decision-making among undergraduate business majors suggested that most of the participants values remained relatively stable over the time of the study, even when a change was initiated. Decisions made by the sample with more stable values showed they continued to use their own values even though the change emphasized concern for others.

Pratt and McLaughlin's (1988) research examined the self perceptions of ethical beliefs and behavior of students majoring in public relations. Associating the responses with behavioral dimensions (traditional behavior - unethical behavior among students; normative behavior - influenced by social pressures; collegial support behavior - opportunistic support for unethical behavior; and substitution behavior - do something unethical for someone else), Pratt and McLaughlin reported the following:

Students ethical beliefs were moderate to high indicating high ethical inclinations. The student's self reported ethical behaviors were significantly related to their ethical beliefs. Those beliefs that were believed to be more ethical were practiced more frequently. Student's self perception of their ethical beliefs and behaviors were higher than the perception they had of other college students. Student's rating of their beliefs were lower than those they preceived held by their professors. (p. 24) 
An earlier study of business students by Newstrom and Ruch (1976) indicated that their sample believed that their ethical standards were superior to those of their peers and less stringent than their professors.

A study of the effects of graduate education on student's personality, values, and interpersonal skills was completed by Wodarski, Pippin, and Daniels in 1988. Using pre-measures and post-measures in a sample of on-campus students and a sample of off-campus students in an extended program, they reported that the students in the extended program became more extroverted and more open to disclosure between the testing times. Both groups' interpersonal helping skills declined, even though they appeared to have more empathy. A positive change occurred in the samples social values and concern for a person's welfare. The findings in this study support the research by previous investigators on value changes with education (Hayes and Varley, 1965; Judah, 1976; Swanson and Wodarski (1982); Varley, 1968).

In Hardcastle's (1984) comparative study of two occupational interest groups' work values and personality types, he found that the personality types of the graduate students in industrial psychology did not differ from the personality types of graduate students in business administration as much as was found in previous studies by Holland. Hardcastle's sample of graduate students did not identify with the conventional personality type with high 
extrinsic values. This finding also differed from other previous studies that used Holland's Vocational Preference Inventory or Super's Values Inventory. The psychology group did, however, consist of social types. This finding was consistent with findings in previous studies. Intrinsic and extrinsic work values did not differ significantly between the samples in the study. The psychology students did score altruism higher than the business students. The composition of the graduate business student sample may have contributed to the differences in the business administration personality types as this group of students had undergraduate degrees in the social sciences, not in business administration.

St. John, Blumenfield, Angelidis, and Young's (1989) research focused on determining whether work values could be used to discriminate between doctoral students who planned to pursue academic careers and those who chose to pursue other careers. Using Super's Work Values Inventory, they concluded that the work values instrument was not an effective means for tracking this discrimination. A study by Neuman and Neuman (1982) did report finding Super's work values instrument a determinant for differientiating the values of students in engineering and in liberal arts academic programs.

Vodanovich and Kramer's (1989) study examined the work values of college students and each of their parents using Eyde's (1961) Work Values Scale, a scale that looked at six work value factor: dominance - recognition, economic, 
independence, interesting activty, mastery - achievement, and social. In their analysis of the results, they reported that sons values differed from both parents. Sons scored significantly higher on four of the six scales, scoring lower than their father on independence and interesting activity. Daughters work values differed from their mothers in that they scored higher on all six dimensions. Daughters did score dominance - recognition and independence on the lower end of the scale. No significant differences were found between the male and female college students work values.

A previous study by Winters (1981) showed similarities between student and parents work values, while a study by Glee (1975) reported differences in college students and parents work values. A study by Perrucci (1968) suggested that educational level may have more influence on work values than the gender of the person. A prior study by Galler (1951) found that upper class children tended to choose their occupations on the basis of their father's occupation. Children of the lower class were less prone to select their occupation in this way. Super (1957), in his studies, concluded that a person's occupational choice was related to the determination of the social class.

Kirchner and Hogan (1968) studied the value patterns of students enrolled in college preparing to teach elementary, secondary, and special education. Using the Allport, Vernon, and Lindzey Values Scale, they found the 
values among the sample were consistent for over a six month period. They did find significant differences in gender values. Males tended to score higher on the theoretical, economic, and political scale than females. Males scored lower on the religious and aesthetic scales in comparison to the females. Males in secondary education did, however, show that they were more inclined to emphasize social values, when compared with students enrolled in industrial administration and engineering master's degree programs.

$$
\text { Kirchner and Hogan's (1972) four to five year followup }
$$
study of the above teachers after graduation found that the values in their sample remained quite constant, even though some of their sample had left teaching for another service related profession or chose to become housewives. Religious values of the sample did decline to some degree. Former senior coed who had had lower religious values in college were described as more apt to have pursued graduate education.

\section{VALUES OF EMPLOYED ADULTS}

The Iiterature speaks of changing values in the adult worker. Reasons given for these changes have included job availability, changes in the male - female worker balance, changes in views on intelligence, increased emphasis on self fulfillment, changes in levels of decision making, changes in level of trust, decreases in work incentives, and increased expectations. Two ideas have been expressed by researcher in 
the area of personal and work values. Huntley (1984) described the worker of today as one who works up to 60 hours a week and one who uses leisure for the purpose of advancement. Toffler (1980) described the worker of today as a person who has a strong work ethic who chooses not to blend leisure with work.

Bloom (1964) described values and the role they play in the world of work as having a more permanent influence on a person than interests and attitudes. Hales and Fenner (1972) and Gribbons and Lohnes (1965) described the formation of values related to work as beginning in early childhood, entering into pre-adolescent behavior, and exerting an influence throughout the adult life.

Values and their relationship to work and the person have received attention from the disciplines of philosophy (Morris, 1948; Rosenberg, 1957), economics (Ginsberg et al., 1951), and psychology (Darley and Hagenah, 1955; Hales and Fenner, 1972, 1973, 1975; Rokeach, 1968; Super, 1957; Vroom, 1964).

Ginsberg's et al. (1951) research has been closely associated with the rewards of work, the intrinsic and extrinsic values. Darley and Hagenah's (1955) work focused on the intrinsic value of work in association with people. Havighurst (1964) examined work in relation to self actualization. Much of the research by Super (1957) and Super, Stanshevsky, MatIin, \& Jordan (1963) has been on work values and the self concept. Rokeach's (1968) studies investigate values in relation to 
importance and freedom. Hales and Fenner (1972, 1973, $1975)$ studied values as they relate to the world of work. More recent research has also examined cultures in relationship to values.

Loscocco and Kalleberg (1988), in their study of age differences in work values and work commitment of employed United States and Japanese men and women, reported that older men in both countries were more committed to work than younger men. Older women in the United States were more committed to work than younger women. No age differences were found in the commitment to work among the sample of Japanese women. Japanese men with tenure had a greater commitment to work than their American counterpart. American employees placed higher value on economic returns, while younger Japanese employees emphasized good pay more often than the older Japanese employees. Good relations with coworkers was positively correlated with age in the American sample. Older men and women in Japan placed less value on relations with coworkers than the younger men and women.

Howard, Shudo, and Umeshima's (1983) investigation of motivation and values differences in Japanese and American managers found that Japanese managers placed more importance on socially beneficial values and accomplishments than American managers. Japanese managers were more interested in advancement, money, and moving forward. American managers valued individuality and being straight forward more often 
than their Japanese counterpart. They used the Rokeach Values Inventory and Sasnoff's Attitude Toward Life Survey instrument in their study.

An examination of the relationship between managerial values and managerial success in four countries, the United States, Japan, India, and Australia, reported their sample as having similar values (England and Lee, 1974). The successful managers, in the study, valued achievement and expressed a preference for having an active role in interactions with other people the most. Successful managers believed in being pragmatic, dynamic, and productive. The less successful managers valued conformity, security, conservatism, and a more protected environment the most.

A 1970 study of the personal values of Japanese managers found that their sample of subjects was more pragmatic (England and Koike). Their primary values were ability and skill; their secondary values were oriented toward moral and ethical concerns of honor, tolerance, and conformity.

An earlier study by England (1967) investigated the personal values systems of American managers. Using four modes of valuation (important-unimportant, a success scale, a moral scale, and a pleasant scale), he found the primary orientation among the managers' was to be successful. The secondary orientation was toward being moral and ethical. Ability, ambition, and skill were viewed as the values which most influenced a manager's behavior. The idea behind the 
scale was that personal values influence perceptions of situations, decisions and solutions to problems, the way a person looks at others, success or achievement, limits as to what is ethical behavior, and the extent to which a person will accept or resist risk.

Using samples from three large American and three foreign populations, Gruen (1966) examined four major categories of values: status change, preference for external things rather than personality attributes and social relationships, standardized behavior, and impulse restriction or control. The results of his study indicated that the traditional core culture values of the employed unskilled worker were ingrained in their value system. White collar worker were more diverse in their values orientation. Students and the middle class sample were more homogenous in their value patterns. Teachers over the age of 50 tended to choose core culture values more frequently than teachers age 20 to 30 . The age induced sets of values were characteristic of the total population.

Harris and Earle's (1986) study of gender and work values on what unskilled and semiskilled employees wanted in small business settings found that the men and women in their sample differed very little with respect to the level of importance they attached to intrinsic and extrinsic values. Both men and women selected intrinsic work values that offered them a chance to learn new skills and a chance to use these skills. Extrinsic work values on working with people and the quality 
of the place of employment were more often selected by the women. The work values selected the least often by the sample was freedom to plan the work.

Kenkel and Gage's (1983) study of low income women's work values found similar emphasis on intrinsic work values. The opportunity to do exciting and interesting work was valued the most. When questioned regarding occupational choice, this sample chose the sterotyped feminine occupations.

Iindsay and Knox (1984) also found that women were more likely to value intrinsic rewards. Their study reported finding a strong relationship between educational level and attainment of intrinsic and extrinsic rewards.

Pearson and Kahn's (1989) study of women clerical workers sex - role socialization characteristics and their work values found that younger women were more accepting of the worker role. They expected to combine employment and the family role. The total sample had very similar work values. Achievement and social values were rated highest by the clerical workers.

Brenner, Blazini, and Greenhaus (1988) investigated race and sex differences in work values of middle managers. In the analysis of their study, they found white females placed greater importance on extrinsic values than black females. Black males placed higher value on independence. The women did place more emphasis on intrinsic job characteristics than the men. Earlier studies have found that males value long- 
range career objectives, high income, risk taking, and supervising others (Bartol and Manhardt, 1979; Brenner and Tomkiewicz, 1979, 1982; Manhardt, 1972). Other studies have found that women's values are more intrinsic. Job characteristics, utilization of skills, security, intelligence, self actualization, and interpersonal relations were the more or most important values of women (Bartol and Manhardt, 1979; Brenner and Tomkiewicz, 1979, 1982; Jurgensen, 1978; Morgan, Brenser, and Chou, 1980; Walker, Tausky, and Oliver, 1982).

Waggoner's (1986) research on the work values of metropolitan school administrators found differences between male and female values. Female administrator assigned more importance to the work value of Self Realization and Idea/Data Orientation. Central office managers differed significantly from elementary school administrator on three work values. More importance was assigned to the work values of Independence and Prestige by the central office administrators. Elementary school administrators placed more importance on the work value of Altruism. Waggoner used the Ohio Work Values Inventory to collect data.

Klampe (1983) used the Ohio Work Values Inventory to collect data for her study of secondary school teachers work values. The study chose to determine differences in teacher values by subject area taught. All teachers in the sample placed high values on Self Realization and Task Satisfaction. Business teachers placed more value on Self Realization than 
math/computer science teachers. Secondary male teachers in the sample placed more value on object orientation, solitude, and Prestige than female teachers. Female teachers placed greater value on Self Realization than male teachers.

\section{STUDIES OF NURSES' VALUES}

At the turn of the century, Robb (1900) wrote of the nurse valuing obedience, submission to the rules, and loyalty to the physician. These values were written into the code of ethics for the profession and were not changed until the 1970's when values were changed to reflect responsibility, accountabilty, and competence (Vien, 1989).

Edwards and panel on Essentials of College and University Education for Professional Nursing (1986) reported that seven specific values were essential to the education of professional nursing students. These included altruism, equality, esthetics, freedom, human dignity, justice, and truth. In addition to these values, they listed personal qualities and attitudes (36) as contributors to these values. These were caring, commitment, compassion, generosity, perseverence, acceptance, assertiveness, fairness, selfesteem, tolerance, appreciation, creativity, imagination, sensitivity, confidence, hope, independence, openness, selfdirection, self-discipline, consideration, empathy, humaneness, kindness, respectfulness, trust, courage, integrity, morality, objectivity, accountability, authentic- 
ity, honesty, inquistiveness, rationality, and reflectiveness (pp. 6-7). No study was undertaken to examine the relationships between the listed values and the examples of personal qualities or attitudes, however, previous nursing research has investigated some of these characteristics and values. O'NeiI's (1973) study of a group of nursing students and a group of general female college students used the Allport, Vernon, and Lindzey Instrument and Gordon's (1960) Survey of Interpersonal Values to study values. She reported finding significant differences in social values in the sample. Nursing students placed greater importance on altruistic services; the general female student sample placed greater importance on personal power, influence, and domination of others. The nursing students also placed more importance on independence, less on achievement and recognition.

A study by Hales (1977) compared the work values of nursing students in training and practicing nurses. Using the Ohio Work Value Inventory, she found that the practicing nurses placed more value on Task Satisfaction, SelfRealization, and Altruism and relatively lesser value on Prestige, Object Orientation, and Solitude. A further finding was, nursing students' work values did not differ significantIy from the practicing nurses' values.

Bloomquist, Cruise, and Cruise's (1980) study of how baccalaureate nursing students values changed during their academic nursing experience found a significant change on the 
Rokeach Values Survey. The value of being helpful decreased in importance during the educational experience. Students in secular programs valued freedom, self respect, ambition, and being intellectual more than those in the religious group. These findings differed from Kane's (1961) earlier work where no differences were found between students in religious and secular institutions.

Sheahan's (1983) study of occupational values of 170 nursing students reported that the predominant values of the sample were a preference for working with people rather than things, and an opportunity to use special abilities. The exercise of leadership and prestige were given low priorities on the Rosenberg's (1957) Survey of Occupational Values.

A comparison of values of entering nursing students for two periods, ten years apart, by Garvin and Boyle (1985) reported finding higher scores placed on economic values by the 1982 entering class in comparison to the 1972 entering class. Both groups completed the Allport, Vernon, and Iindzey instrument. The groups did not differ significantly in values; social values and religious values were scored high by both.

Schank and Weis's (1989) study of values of baccalaureate nursing students and graduate nurses from secular and nonsecular programs found that their sample identified values that dealt with patient care issues more often than values associated with social issues. No differences were found 
between the samples. Data for this study was obtained through the use of open ended questions.

Thurston, Flood, Shupe, and Gerald (1989) investigated the values of nursing faculty and entering nursing students in a university setting, using the $\mathrm{AACN}$ Report values and the Rokeach Survey Instrument. Fifty faculty and 367 generic students participated in the study by ranking their top three choices on each instrument. On the Rokeach Survey Instrument (Mode of Conduct), faculty ranked being responsible while students ranked loving more often as their top choice. The responses on the Rokeach Terminal Instrument (Iife goals) ranked inner harmony as the top selection by the faculty and the sense of accomplishment as the more often selected option by students. Faculty members commitment to recognition of human dignity and altruism were significant as shown by their responses to the values listed on the AACN Report. The ranking of the seven $A A C N$ essential values by faculty did show integrity, honesty, and caring as the most frequent selected options.

Ulrich (1987) examined the differences in work values of practicing nurse executives and graduate educators teaching aspiring nurse executives using the ohio work Values Inventory. From a sample of 124 participants, 79 nurse executives and 45 educators, the investigator found nurse executives valued Control more than the educators. Educators valued solitude more than the nurse executives. Task 
Satisfaction was valued more by the sample under 45 years of age. The sample with graduate degrees placed more value on Prestige. The under 45 years of age graduate degree sample valued security and Control more. People that had past senior administrative experience valued Control more than those who had no senior administrative experience.

\section{SUIMMARY}

Values of a personal nature begin to develop at a very early age through the process of integration and internalization forming a value system (Combs \& Snygg, 1949; Rokeach, 1973). The immediate family and local community are the primary sources of influence for forming the values of the preschool child (Yankelovich, Skelly, \& White, 1977). The family structure, alternative family support systems, and peers contribute to the variation in a child's personal values. The media, television in particular, influences a child's values (Levine, 1980). During the school age years, teachers are viewed as value builders (Sarason \& Sarason, 1973; Tyson \& Carro11, 1970). Teachers affect students' achievement and classroom behavior. Formation of work values at an early age become part of a child's early value system (Hales \& Fenner, 1972). Sex differences (Bohan, 1986: Hales \& Fenner, 1973; Hales \& Hartmann, 1978; Waggoner, 1986) and grade level influence these values (Hales \& Fenner, 1972). 
Internalized values and external influences provide a rationale for career choice and life work.

In education, values have been described as being a social product that has been internalized or accepted by an individual as a criterion of worth (Krathwohl, Bloom, \& Masia, 1964) and are viewed as a way of judging something as being desirable or useful (Omery, 1989; Rescher, 1982). The American Association of Colleges of Nursing (AACN) Report: Essentials of College and University Education for Professional Nursing (Edwards \& panel, 1986) fosters emphasis on certain values as a part of a nurse's education and development. Just how much effect nursing education has on a student's values is an area for further research.

Studies on the values of nursing students by nurse educators seems to be in the early stages of investigation. With the changes in educational curriculum, technology, and increased demand for nurses with differing interests, the probability of a change in the personal values and work values among persons interested in nursing may be of significance. 
CHAPTER III

\section{METHODOLOGY}

The investigator chose to study the personal values and work values of nursing students in the final year of their nursing program at Associate, Baccalaureate, and Graduate Degree levels. Using an instrument for work values, personal values and biographic information, the following questions were investigated. (1) What is the educational background of nursing students at the different program levels? (2) What are the job interests of student nurses in the final year of their educational program? (3) What are the personal values of nursing students in the final year of their nursing preparation at the Associate, Baccalaureate, and Graduate Degree levels? (4) What are the work values of nursing students in the final year of their nursing preparation at the Associate, Baccalaureate, and Graduate Degree level? (5) Do personal values of student nurses differ across levels of educational preparation? (6) Is there a difference in the work values of students in the differing levels of educational preparation? (7) Do personal values differ with job interests? (8) Do work values differ with job interests? (9) Do personal values differ with age? (10) Do work values differ with age? What is the relationship between personal values and work 
values in the sample of student nurses? (12) Are educational preparation and job interests independent?

\section{SUBJECTS}

The subjects were drawn from the accessible population of nursing students in the last year of their educational program in the states of oregon and Washington. Students included in the sample were from Associate Degree, Baccalaureate Degree, and Graduate Nursing Degree programs. Participation was contingent upon approval of the College or University and student willingness to complete a survey questionnaire.

\section{INSTRUMENTATION}

Survey questionnaires were used to obtain the data from the sample of student nurses. The questionnaire contained three parts, a demographic information form with relevant future job interests, the ohio Work values Inventory (a profile of work values), and a profile of life values (designed to reflect some of the values and characteristics which have been associated in the literature with desired professional nurse behavior).

\section{Demographic instrument}

The demographic instrument (Appendix A) was designed to elicit participant biographical information as to sex, date of 
birth, present nursing education program, previous education, previous and present employment data, identification of job interests, and place of preference for employment upon graduation.

Biographic information served as a foundation for interpretation of the data. Identification of the participants' educational program (research questions $3 \& 4$ ), job area interests (research questions $7 \& 8$ ), and age (research questions $9 \& 10)$ served as variables in the study.

\section{Ohio Work Values Inventory}

The Ohio Work Values Inventory (Hales and Fenner, 1975) consisted of 77 questions with no right or wrong answers to the questions (Appendix B). Each question pertained to a work value. Each question had five response options. The scoring related to eleven characteristics: Altruism, Object Orientation, Security, Control, Self Realization, Independence, Money, Task Satisfaction, Solitude, Ideas/Data Orientation, and Prestige. Scoring was based on a point system of one to five with one being not much and five being very much.

The theoretical foundations for the ohio work Values Inventory were traced to five sources by Hales and Fenner (1975). These sources were: the personality theory of Horney (1945), the personality-need theory formulated by Maslow (1954), the theory of occupational choice adapted from the 
personality-need theory by Roe (1956), self theory formulated by Combs and Snygg (1949), and the United States Department of Labor's descriptors of worker functions (1965).

Various studies provided evidence of the reliability and validity of the Ohio Work Values Inventory including studies of students in elementary schools and technical colleges (Coefficient Alphas above .79 and .85, respectively, and testretest coefficients above .80 for elementary students. This instrument was also used in studies on work values of administrators in education (Waggoner, 1986), teachers (Klampe, 1983), and nurses (Hales, 1977), with Coefficient Alphas between .75 and .94 for the later sample.

\section{Profile of Life Values}

A personal values inventory, (Profile of Life Values) was developed to elicit information on the nature of personal qualities of individuals in nursing (Appendix C). This inventory consisted of statements with no right or wrong answers, expressed on a Likert scale from strongly agree to strongly disagree. A point system of scoring was used to assess personal values of student nurses. Statements were designed to focus on personal values that could have a relationship to some of the personal qualities and attitudes Iisted in the American Association of Colleges of Nursing Report: Essential of College and University Education for Professional Nursing (Jennings and panel, 1986). 
To develop this inventory, a number of instruments designed by investigators for use in studies of personal values, attitudes, and personalities were reviewed. Among these were: Allport's et al. (1960) study of values and the relative importance of six basic interests (truth, usefulness, esthetic, altruistic, influence, and unity); Blair's (cited in ward and Fetler, 1979) nurses values questionnaire on opinions regarding importance of certain values in nursing; Duttweiler's (1984) measures of locus of control; Ferrill's (cited in ward and Fetler, 1979) autonomous learning index on attitudes toward learning and self direction; Garlington and Shimoto's (cited in ward and Fetler, 1979) index on change seeking needs or perceived desire for activity, novelty or excitement; Gordon's (1960) survey of interpersonal values of what is important or not important to an individual; Kibrick's (cited in Ward and Fetler, 1979) nursing student's behavior instrument on perceptions of obligations toward faculty members and supervisors; Rokeach (1968) rank order scale for beliefs, attitudes, and values; Shorr's (1953) test to measure intensity of values with questions of occupational choice; and Wax's (1982) instrument for measuring administrator burnout.

The theoretical support for the profile of Life values was derived from Brentano's basis of evaluation being grounded in man's emotions, Combs and Snygg's (1949) self theory of enhancement and preservation of the self concept, Maslow's 
(1954) personality needs theory, and Horney's (1945) personality theory.

Following the review of the above, the Profile of Life Values was developed with a focus on the values to be considered in nursing education. The values selected for use in the instrument were identified as Intellectual, Considerate, Creative, Artistic, Recognition, Achievement, Control, and Integrity. Items were written for each value. Each value was evaluated in terms of singleness of interpretation, face validity, educational orientation, clarity, and generality, and field tested on a volunteer sample of graduate students. Following the initial testing, the items were submitted to the same evaluation techniques as were used on the OWVI. Three measures were used: correlations of each item with its own scale (after its contribution to that scale were removed), correlation of each item with each of the other scales, and a correlation of each item with total scores. Coefficient Alphas for the scales were examined. Some items were revised and others were deleted prior to the second testing; some new items were written. After making revisions, the instrument was again tested on a second volunteer sample of graduate students. Again, the data was subjected to the same analysis as used during the first testing. The items used in the second testing of the instrument exhibited higher correlations with their assigned scales, and low to moderate correlation with the total scale. 
This information was utilized to construct the instrument used in this study. An estimate of Coefficient Alpha for the revised instrument was made using the data obtained from the second field testing. The Coefficients Alphas are presented in Table $I$.

\section{TABLE I}

COEFFICIENT ALPHAS FOR PROFILE OF LIFE VALUES SUBSCALES

scale

$$
\text { Coefficient Alpha }
$$

Intellectual

.854

Achievement

.828

Creative

.906

Artistic

.889

Recognition

.879

Control, Internal

.767

Control, External

.439

Control, Desire for

.836

Integrity

.885

Considerate

.892

Several of the items under control exhibited high correlation with the scales of Recognition and Achievement. Other Control items exhibited unacceptable correlations with other scales. Correlations among the Control scales were 
high, but not sufficient to permit constructing a single scale. Based on these findings, the scales for Control were were not used for data analysis in this study of nursing students values.

\section{DATA GATHERING PROCEDURE}

Following the approval of Portland State University Human Rights Committee to conduct this study, written consent to initiate data collection within the schools of Nursing in Oregon and Washington was requested. A letter (Appendix D) explaining the research project was sent to the Presidents of the Colleges and Universities, the Dean of the Schools of Nursing and/or appropriate department head; a written consent form allowing for approval of the study was attached with a stamped self addressed envelope for return of the consent form.

Upon approval to conduct the study, arrangements were made with the school of nursing for the investigator or a representative designed by the school to collect the data. Anonymity of the participants was insured. Participants name did not appear on the instruments. Completion of the instruments was considered as consent to participate in the study.

A packet containing a letter of introduction, biographical data form, the Profile of Life Values, and the Ohio Work Values Inventory was presented to each participant. The three instruments are presented in Appendix $A, B$, and $C$. 
The letters of introduction to student nurses in Associate Degree, Baccalaureate Degree, and Graduate Degree programs are found in Appendix E. The longer letters went to graduate students.

Each participant was asked to fully complete the survey questionnaire in the following order: First, fill in the demographic information, then complete the profile of Life Values, and finally respond to the ohio Work Values Inventory. Upon completing the survey questionnaire, each participant was asked to place the questionnaire into an envelope, seal the envelope, and return the survey to the investigator.

\section{STATISTICAL ANALYSIS}

\section{Descriptive statistics}

Descriptive statistics of the characteristics of the sample are discussed and analyzed statistically in chapter IV. For age, length of employment, and values, means and standard deviations were calculated. For gender, present educational program, type of educational institution, previous educational level, and employment setting and job interests, frequencies and percents in each response category were calculated. Table II lists the measures that were used. 
TABLE II

MEASURES USED TO ANALYZE DATA

Variables

Frequency

Mean

SD Median \%

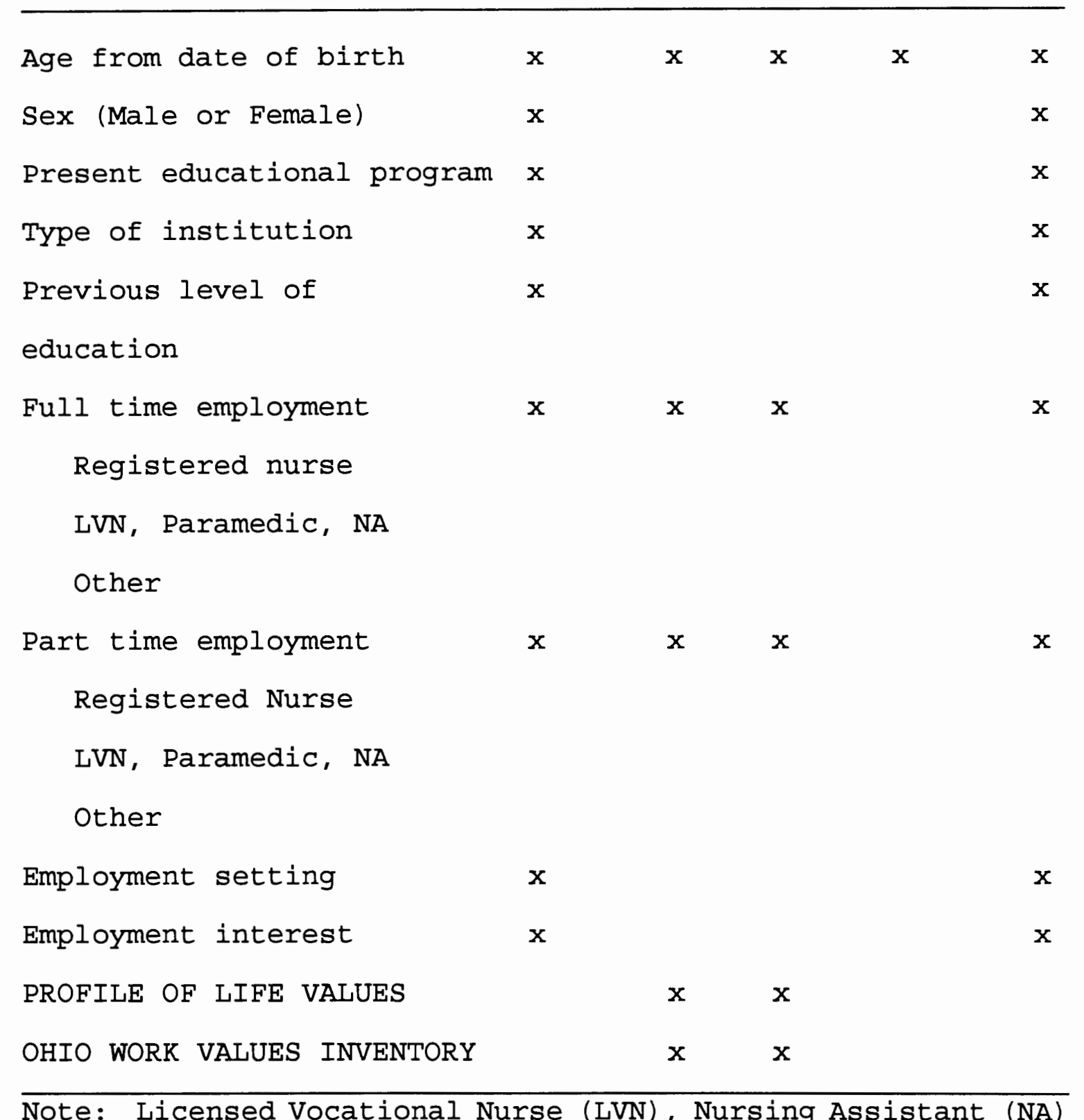


Inferential Statistics

The following statistical hypotheses were analyzed, using statistical techniques from the Statistical Package for the Social Sciences (1991). Each MANOVA and ANOVA was tested at the .05 level of significance. As recommended by Scheffe, the .10 level was used in the test of significance for the pairwise mean comparisons.

Hypothesis I. When examined by educational preparation, student nurses will not differ in their personal values. This hypothesis was analyzed using MANOVA, followed by ANOVAs and Scheffe pairwise mean comparisons, as appropriate.

Dependent variables: Personal values

Independent variable: Educational preparation

Hypothesis II. When examined by educational preparation, student nurses will not differ in their work values. This hypothesis was examined by MANOVA, followed by ANOVAs and and Scheffe pairwise mean comparisons, as appropriate.

Dependent variables: Work values

Independent variable: Educational preparation

Hypothesis III. Student nurses with different expressed job interests will not differ in their personal values. Differences in personal values of nursing students with different job interests were examined by MANOVA, followed by ANOVAs and Scheffe pairwise comparisons, as appropriate.

Dependent variables: Personal values

Independent variable: Job interests 
Hypothesis IV. Student nurses with different expressed job interests will not differ in their work values. Differences in work values of nursing students with different job interests were examined by MANOVA, followed by ANOVAs and Scheffe pairwise mean comparisons, as appropriate.

Dependent variables: Work values Independent variable: Job interests

Hypothesis V. When examined by age, student nurses will not differ in their personal values. The hypothesis was examined using MANOVA, followed by ANOVAs and Scheffe pairwise mean comparisons, as appropriate.

Dependent variables: Personal values Independent variable: Age

Hypothesis VI. When examined by age, student nurses will not differ in their work values. This hypothesis was examined using MANOVA, followed by ANOVAs and Scheffe pairwise mean comparisons, as appropriate.

Dependent variables: Work values

Independent variable: Age

Hypothesis VII. There will be no correlation between work values and personal values among the nursing students. A two-tailed test of significance was used, with the level of significance set at .05 for each coefficient of correlation.

Hypothesis VIII For nursing students in their final year, educational preparation and job interests are 
independent. Chi-square was used to investigate the relationship, using .05 as the level of significance. 
CHAPTER IV

PRESENTATION OF THE FINDINGS

Presented in this chapter are the results of the survey of nursing students values in the last year of their education program. Work values were measured by the ohio Work Values Inventory and personal values were measured by the profile of Life values. The biographic characteristics of the sample are presented. The research questions and statistical hypotheses are discussed, using descriptive and inferential statistics.

\section{CHARACTERISTICS OF SAMPLE}

Biographic data is described in terms of sample size, sex, age, present nursing education program, previous formal education, work experience, future site of employment preferance, and specific job interests.

\section{Sample Size}

Listings of the Schools of Nursing were obtained from the State Boards of Nursing in Oregon and Washington. The listings mailed to the investigator included all the schools of nursing in Oregon (19), and a part of the schools of nursing in Washington (14). The number of Schools of Nursing in Oregon granting consent for the study totaled 18. The number of Schools of Nursing in Washinton granting consent 
totaled 11. Data was collected from student nurses during the final two to six weeks of their educational program. In Oregon, 496 students were contacted; $62.9 \%$ (312) of the students completed the surveys. In Washington, 464 students were contacted; $31.9 \%(148)$ of the students completed the surveys. A total of 460 students participated in the survey. Of these, 452 responses were complete and used in the data analysis.

The timing for collection of the data presented some difficulty. In the larger Schools of Nursing, it took longer to complete the administrative processes. While, most schools of Nursing did indicate a willingness to allow the researcher to collect data at the end of the school year or during the beginning quarter/semester for fall, the percent of the students participating in the study from larger institutions is smaller and less representative of students enrolled in larger institutions. If part of the data had been collected at the beginning (fall) of the last year of the students educational preparation, an unanticipated variable may have had an effect on the results of the study. As it is, the data is based on values of student nurses as they finish their nursing education program.

Several Schools of Nursing were on semesters and finished the school year the end of April, much earlier than those on the quarter system. Still, a representative sample from nursing programs with semesters did participate in the survey. 
The investigator was more familiar with the educational programs and research protocal in oregon than in washington, thus, the researcher was able to collect more data in Oregon. One difficulty the researcher encountered was, the listing that the researcher received from the state Board of Nursing in washington did not list all Schools of Nursing in the state. When the researcher learned this, it was too late in the quarter/semester to initiate and complete the administrative protocal and collect data from the other schools of Nursing before the end of the school year.

\section{Gender}

While nursing is perceived to be predominantly a female profession, the data from this survey shows a trend toward more male involvement in the profession. Table III presents the distribution by gender.

TABLE III

GENDER OF NURSING STUDENTS

\begin{tabular}{lcr} 
Gender & Number & Percent \\
\hline Male & 51 & 11.3 \\
Female & 401 & 88.7
\end{tabular}


Male respondents totaled 51, while female respondents totaled 401. This shows a higher representation of male than the national average of approximately 3.3 percent (Mckibbin, 1990)

Age

Respondents were asked to give their date of birth. Based on the date of birth, age was calculated to the nearest year. Ages ranged from 20 to 54 years with a mean age of 33.5, a median age of 34.1 , and a mode of 23 ; the standard deviation was 8.8. Table IV presents the distribution of the sample by age. As can be seen, between ages 22 and 41 , the distribution plateaus and peaks, with minor peaking at several ages $(23,32,36$, and 41$)$.

\section{Educational Background}

Research question one was "What is the educational background of the nursing students?" Three types of data were collected to answer the question: type of present educational preparation, type of educational institution, and prior education. Students were asked to state whether their present educational preparation offered an Associate Degree, Baccalaureate Degree, or a Graduate Degree. The subjects in the study included 266 students in Associate Degree, 143 students in Baccalaureate, 39 students in Master's, and 4 students in Doctorate degree programs. See Table V. 
TABLE IV

AGES OF NURSING STUDENTS

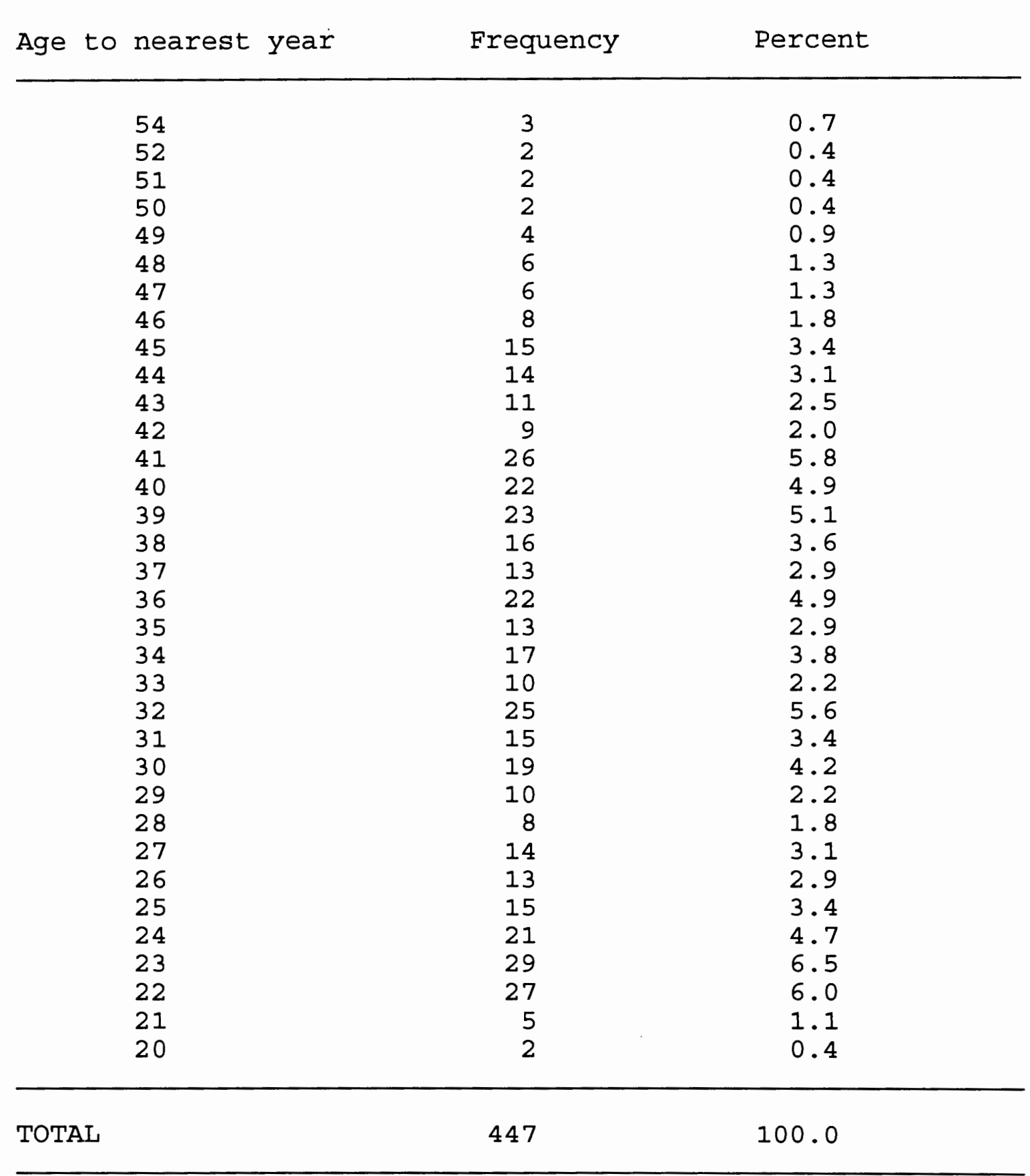


TABLE V

PRESENT EDUCATIONAL PROGRAM

Educational Program Frequency Percent

\begin{tabular}{lrc} 
Graduate Degree* & 43 & 9.5 \\
Baccalaureate Degree & 143 & 31.6 \\
Associate Degree & 266 & 58.9 \\
\hline Total & 452 & 100.0
\end{tabular}

Note: «Master's and Doctorate Degree

Type of Educational Institution

In this sample, 379 students were enrolled in a public education system, while 72 students were attending a private educational system. One student did not state whether she/he attended a public or private educational system. Table VI presents the distribution of subjects by type of institution.

\section{TABLE VI}

TYPE OF EDUCATIONAL INSTITUTION

Educational Institution Frequency Percent

\begin{tabular}{lcc} 
Public & 379 & 84.0 \\
Private & 72 & 16.0 \\
\hline Total & 451 & 100.0 \\
\hline
\end{tabular}




\section{Prior Educational Level}

Participants were asked to indicate the highest level of education they had achieved prior to entering their present education program. The largest percentage of the sample had preceeded their present education with a High School Diploma or the equilivant of a High School Diploma (276). Nine students had a Master's Degree, 80 students had a Baccalaureate Degree, 11 had a Diploma in Nursing, and 76 students entered their present education program with an Associate Degree. The distribution of this sample is summarized in Table VII.

TABLE VII

LEVEL OF PRIOR EDUCATIONAL PREPARATION

Prior educational preparation Frequency

Percent

Master degree 9 2.0

Bachelor of Science 80 17.7

Diploma (nursing) 11 2.4

Associate degree 76 16.8

High school diploma 276 61.1

Students in Master's Degree programs listed their previous education as having earned a Bachelor of Science in 
Nursing (38), an Associate Degree in Nursing (5), a Master's Degree in Education (1), a Bachelor of Arts or Science (9) in Biology, Zoology, General Science, Social Work, Language, Administration, Psychology, or Health Education. Eight of the students in Master's Degree programs listed having more than one earned Baccalaureate Degree.

Students in Baccalaureate degree programs listed their prior degrees as an Associate Degree in Nursing (17), a Diploma in Nursing (8), Baccalaureate Degrees in other fields (15) such as Science (4), Social Science, Anthopology, or Psychology (3), Home Economics or Nutrition (3), Occupational Health (1), Community Health Education (1), and Music (1). Twenty-five students had an Associate Degree in other fields: Science (7), Arts or Arts and Science (7), General studies (3), Health related fields (3), Business (1), Education (1), Social Studies (1), Bible Studies (1), and Horticulture (1). Five students listed having a Master's Degree in the field of Education.

For students in Associate Degree nursing programs, two listed having a Master's Degrees in Science. Twenty-seven listed having a Baccalaureate Degree in other fields such as Psychology (4), Science (4), English or Literature (3), Liberal Arts (1), Education (4), Accounting or Marketing (3), Language (1), History or Political Science (2), and Theology (1). Twenty-nine students listed having an Associate Degree in other fields for Science (5), Arts (4), General studies 
(3), Liberal Arts (3), Arts \& Letters (1), Business or Accounting (5), Religion (1), Human Services (2), Veterinary Technology (1), Engineering (1), and Math (1).

Prior degrees were weakly related to educational preparation of the program (Master's, Baccalaureate, or Associate Degree in Nursing). Students enrolled in the different nursing education programs indicated that their education prior to entry into their present education program in nursing was diverse.

\section{Years of Work Experience}

Subjects were asked to state the accumulative number of years they had worked full-time as a Registered Nurse, as a a Licensed Vocational Nurse or Paramedic or Nursing Assistant, or in another field. In addition, they were asked to state the number of years they had worked in a part-time position. Sixty-five respondents had been employed full-time as a Registered Nurse; 108 had been employed full-time as a Licensed Vocational Nurse or Paramedic or Nursing Assistant; and 187 had been employed full-time in another field. Thirtythree subjects had been or were employed part-time as a Registered Nurse, while 98 of the subjects stated they had been or were employed part-time as a Licensed Vocational Nurse, Paramedic, or Nursing Assistant. Also, 155 respondents stated they had been or were employed part-time in other fields. A number of respondents had been employed full- 
time or part-time in more than one of the positions. Table VIII presents the distribution of years of full-time $(n=65)$ and part-time $(\mathrm{n}=33$ ) employment as a Registered Nurse.

TABLE VIII

YEARS OF EMPLOYMENT AS A REGISTERED NURSE

\begin{tabular}{|c|c|c|c|c|}
\hline \multirow[b]{2}{*}{ Years } & \multicolumn{2}{|c|}{ Full Time } & \multicolumn{2}{|c|}{ Part Time } \\
\hline & Frequency & Percent & Frequency & Percent \\
\hline 25 & 1 & 1.5 & 0 & 0.0 \\
\hline 24 & 2 & 3.1 & 0 & 0.0 \\
\hline 23 & 0 & 0.0 & 1 & 3.0 \\
\hline 22 & 1 & 1.5 & $\overline{0}$ & 0.0 \\
\hline 21 & 1 & 1.5 & 0 & 0.0 \\
\hline 20 & 4 & 6.2 & 0 & 0.0 \\
\hline 19 & 0 & 0.0 & 0 & 0.0 \\
\hline 18 & 0 & 0.0 & 1 & 3.0 \\
\hline 17 & 1 & 1.5 & $\overline{1}$ & 3.0 \\
\hline 16 & $\overline{2}$ & 3.1 & $\overline{1}$ & 3.0 \\
\hline 15 & 3 & 4.6 & 0 & 0.0 \\
\hline 14 & 4 & 6.2 & 1 & 3.0 \\
\hline 13 & 0 & 0.0 & 1 & 3.0 \\
\hline 12 & 1 & 1.5 & 0 & 0.0 \\
\hline 11 & $\overline{0}$ & 0.0 & 0 & 0.0 \\
\hline 10 & 3 & 4.6 & 3 & 9.1 \\
\hline 9 & 1 & 1.5 & 0 & 0.0 \\
\hline 8 & 8 & 12.3 & 1 & 3.0 \\
\hline 7 & 4 & 6.2 & 0 & 0.0 \\
\hline 6 & 4 & 6.2 & 1 & 3.0 \\
\hline 5 & 6 & 9.3 & 4 & 12.2 \\
\hline 4 & 7 & 10.8 & 2 & 6.1 \\
\hline 3 & 8 & 12.3 & 4 & 12.2 \\
\hline 2 & 3 & 4.6 & 10 & 30.3 \\
\hline 1 & 1 & 1.5 & 2 & 6.1 \\
\hline Total & 65 & & 33 & \\
\hline
\end{tabular}


The students who stated they had worked full-time ( $\mathrm{n}=$ 108) and part-time $(n=98)$ as a Licensed Vocational Nurse, Paramedic, or Nursing Assistant showed similar length of employment. This data is presented in Table IX.

TABLE IX

YEARS OF EMPLOYMENT AS A LICENSED VOCATIONAL NURSE, PARAMEDIC, OR NURSING ASSISTANT

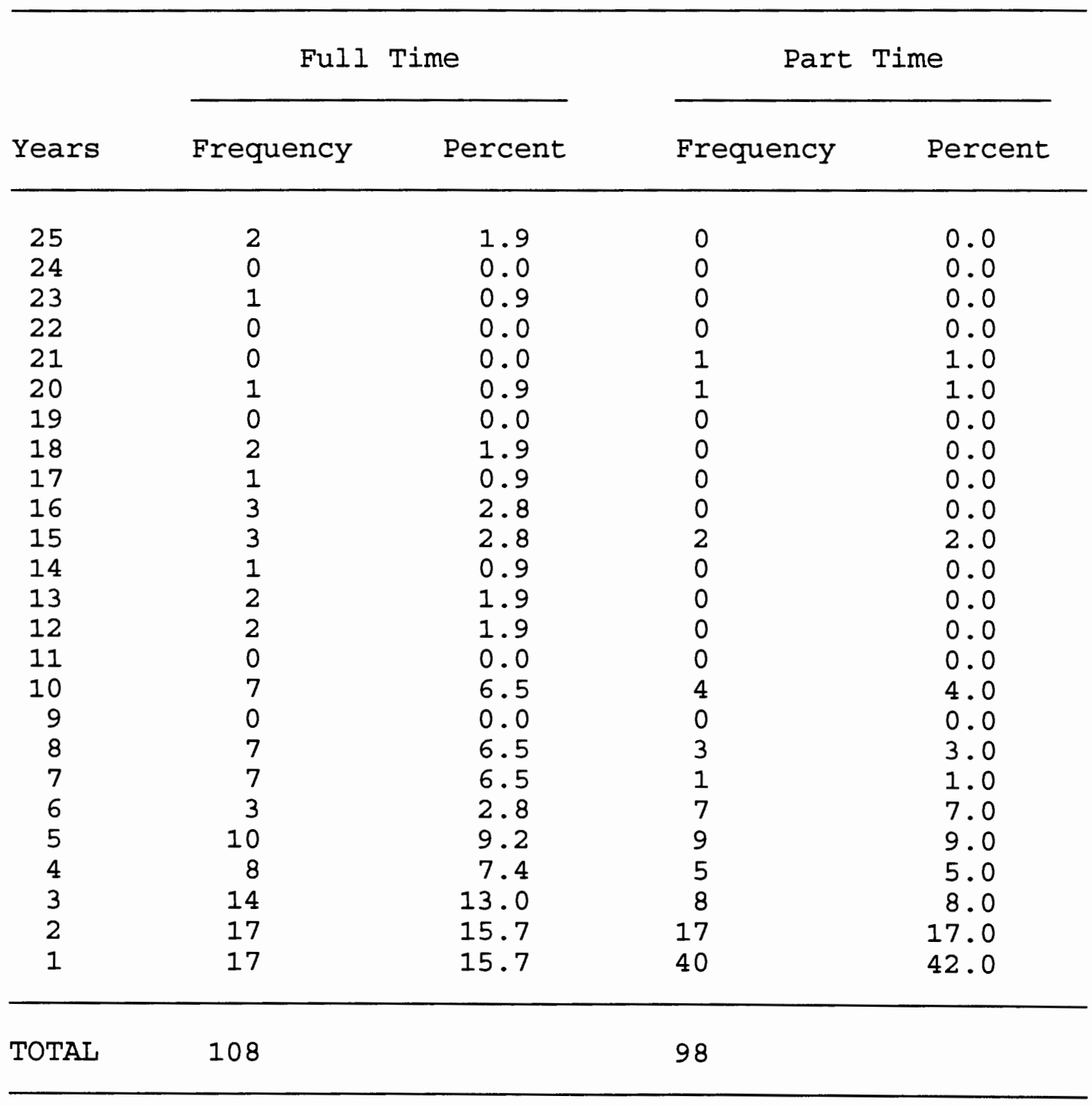


More than one-third of the students (187) stated they had worked full-time in another field; a smaller number (155) had worked part-time in another field. (See Table X.)

\section{TABLE X}

YEARS OF EMPLOYMENT IN OTHER FIELDS

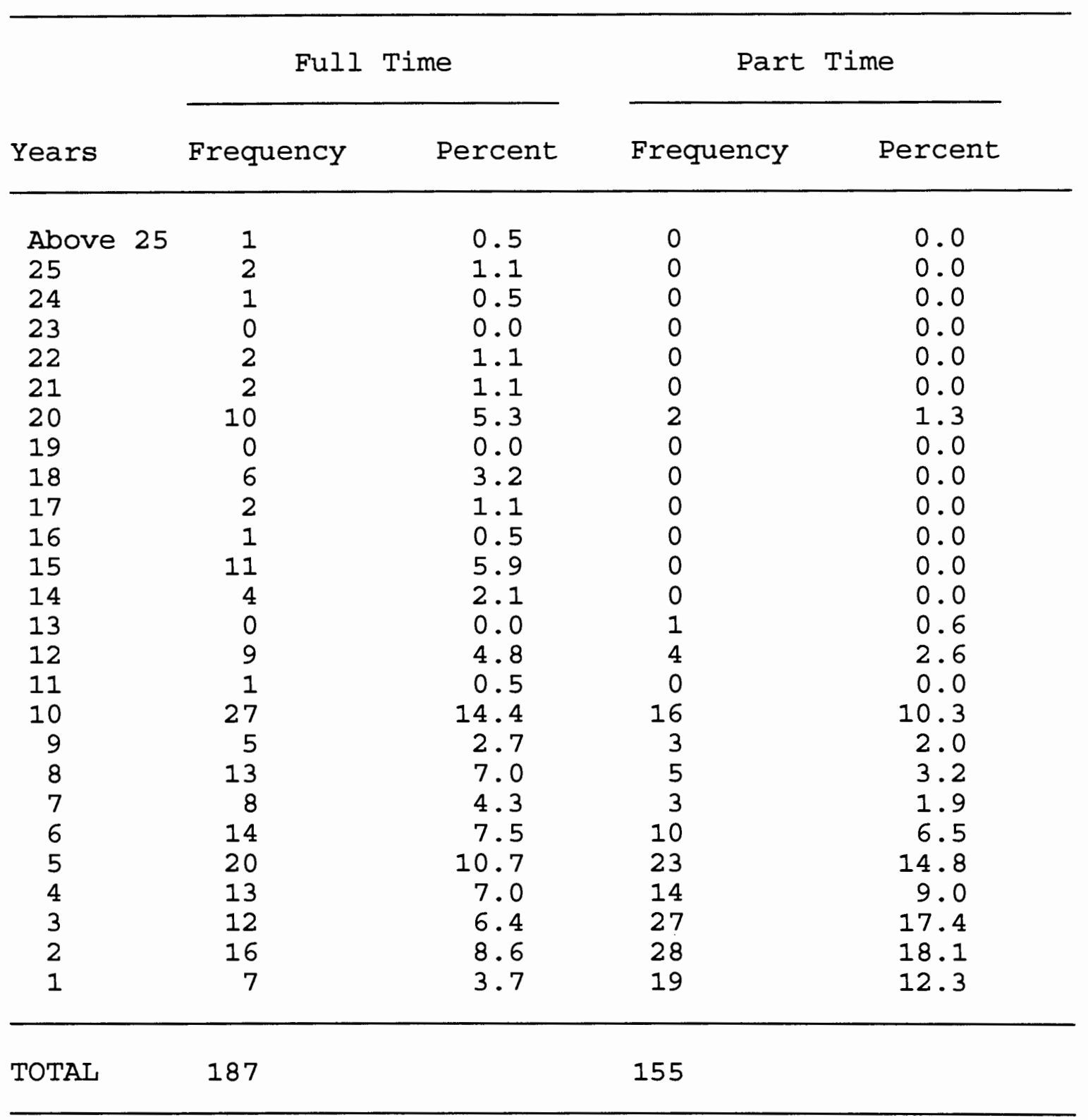


A total of 137 students had been employed only in fulltime positions; 210 of the students had worked both full-time and part-time. A total of 87 students had been employed in part-time positions only, while 18 students had not been employed in any position. The frequency distribution for part-time and full-time employment for the total sample is presented in Table XI.

TABLE XI

FULL-TIME AND PART-TIME EMPLOYMENT

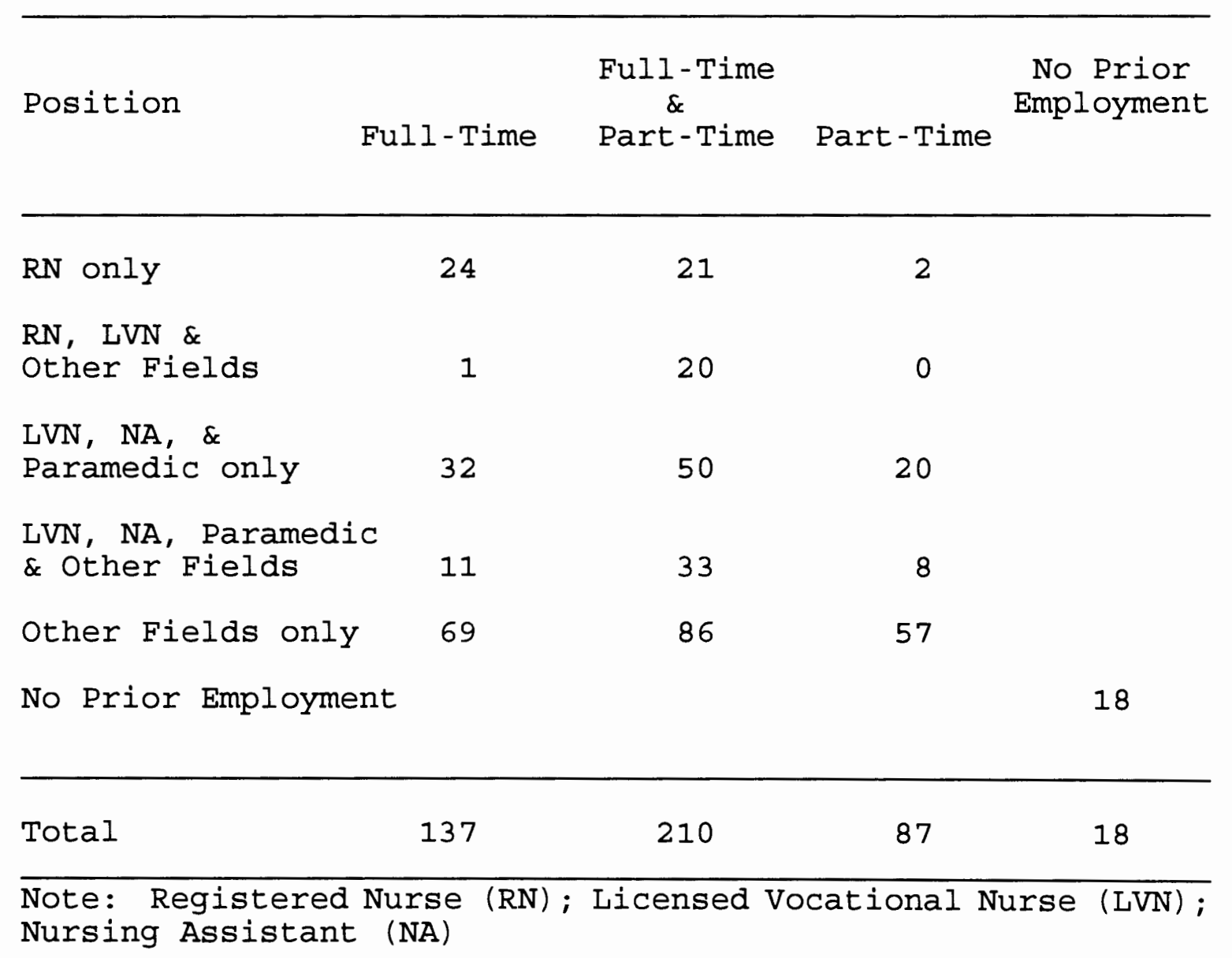


When comparing Tables VIII, IX, and $\mathrm{X}$, it was determined that more students had been employed for some period of time in other fields before entering nursing. Many had been employed in medical or nursing related positions. However, a greater number had been employed in other fields for as long as 25 and 33 years.

Further analysis of the data showed years of employment for the total sample ranged from zero to 33 years, with a mean, median, and standard deviation for length of employment as shown in Table XII for full-time and part-time employment. Overall, most of the students had some previous work experience.

TABLE XII

STATISTICAL SUMMARY OF PRIOR EMPLOYMENT

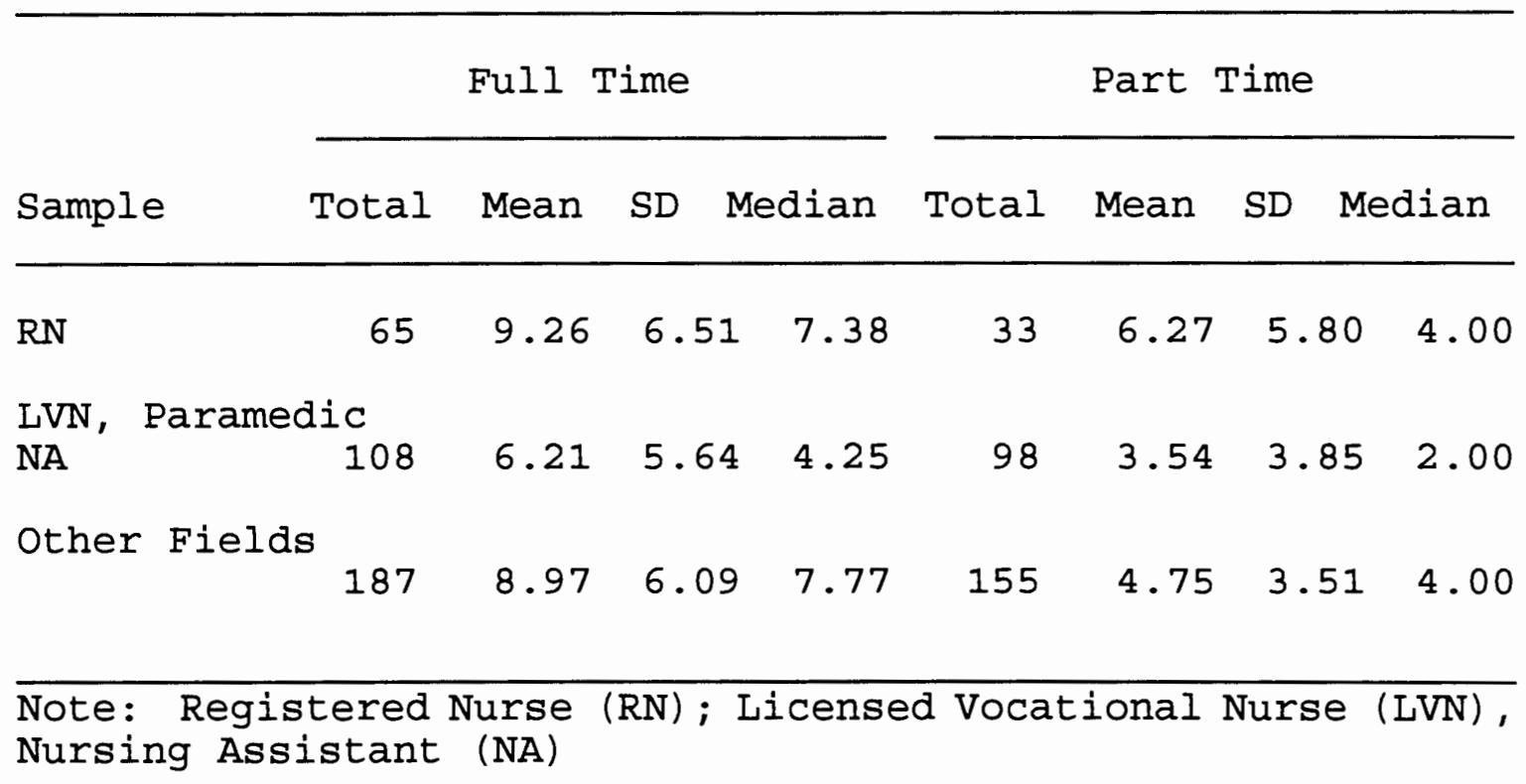


PROFESSIONAL INTEREST AREAS

Research question two was: "What are the job interests of nursing students in the final year of their nursing program?" This was addressed by examining the interest in work setting, practice interest, and specific interest in some areas of practice.

\section{Intended work setting}

The intended work setting for the respondents was predominantly in the hospital (78.6\%) with fewer numbers showing an interest in seeking employment in other settings. This data is summarized in Table XIII. National figures show that $67.9 \%$ of the Registered Nurses are employed in hospital setting (McKibbin, 1990). The percentages in this study is more than that reported nationally.

\section{Area of Practice}

An examination of the practice area of interest (Table XIV) showed that a greater number of the graduating nurses (161) were interested in medical/surgical nursing care of the adult. A smaller number, yet a significant number of the respondents showed an interest in critical care (57), obstetrics (57), and special areas of practice such as the emergency room and operating room (54). Fewer graduating students were interested in geriatric nursing (31), pediatrics 
TABLE XIII

INTENDED WORK SETTING

\begin{tabular}{lcc}
\hline Worksetting & Frequency & Percent \\
\hline Hospital & 355 & 78.6 \\
Home Health & 11 & 2.4 \\
Community Health & 13 & 2.9 \\
Industrial Health & 1 & 0.2 \\
Public Health & 3 & 0.7 \\
Doctor's Office & 15 & 3.3 \\
Nursing Home & 24 & 5.3 \\
Private Practice & 11 & 2.4 \\
Hospice & 1 & 0.2 \\
College & 7 & 1.5 \\
School Nursing & 3 & 0.7 \\
Other & 852 & 100.0 \\
\hline TOTAL & 3 & 13 \\
\hline
\end{tabular}

(25), mental health (20), administration (5), education (7), nurse practitioner (25), and clinical specialist role (10).

\section{Critical Care Interests}

of the respondents, 57 stated they were interested in critical care nursing. Most of these student nurses (48) 
TABLE XIV

PRACTICE INTEREST FOR EMPLOYMENT

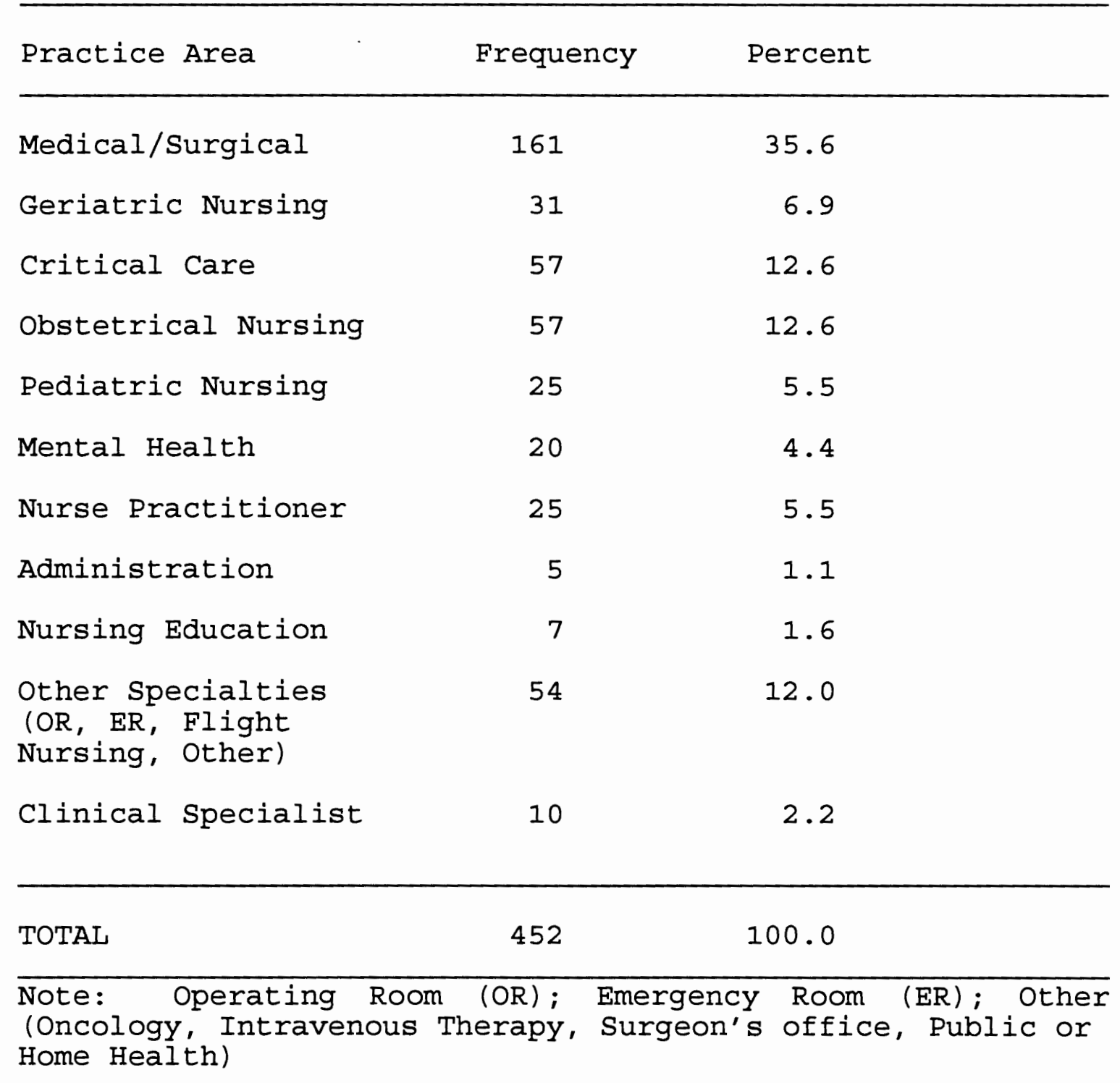

chose to work with adults (86\%). Eight chose to work with neonates and children. Table XV presents this distribution. 
TABLE XV

CRITICAL CARE NURSING INTEREST

\begin{tabular}{lcc} 
Area & Frequency & Percent \\
\hline Critical Care of Adult & 48 & 85.7 \\
Critical Care of Children & 3 & 5.4 \\
Critical Care of Neonates & 5 & 8.9 \\
Not specified & $(1)$ & \\
\hline TOTAL & 56 & 100.0 \\
\hline
\end{tabular}

\section{Mental Health}

Only one nursing student among the respondents identified an interest in working in mental health with children; four did not specify a choice. Fifteen student nurses interested in mental health chose to work with adults. This data is presented in Table XVI.

TABLE XVI

MENTAL HEALTH INTERESTS

\begin{tabular}{lcc} 
Area & Frequency & Percent \\
\hline Adults & 15 & 93.7 \\
Children & 1 & 6.3 \\
\hline Total & 16 & 100.0
\end{tabular}


Nurse Practitioner

Of the 25 nurses interested in working as a nurse practitioner, 13 were interested in family practice, four midwifery, and six in adult care. Two respondents did not identify an area for their particular practice. Table XVII presents this data.

TABLE XVII

NURSE PRACTITIONER INTERESTS

Area Frequency

Percent

Family Practition

13

56.5

Midwifery

4

17.4

Adult Care

6

26.1

Total

23

100.0

\section{Special Areas}

Fifty four nursing students were interested in working in these areas. More of these students were interested in working in the emergency room (46\%) than in the operating room (26\%), or as a flight nurse $(4 \%)$. Table XVIII presents this data. Respondents listed other specialty interest as oncology/hospice, intravenous therapy, surgeon's office, public or home health, and school health. 
TABLE XVIII

INTERESTS IN OTHER SPECIALITIES

\begin{tabular}{lcc}
\hline Interest & Frequency & Percent \\
\hline Emergency Room & 25 & 46.3 \\
Operating Room & 14 & 25.9 \\
Flight Nursing & 2 & 3.7 \\
Intravenous Therapy & 1 & 1.8 \\
Surgeon's Office & 3 & 5.6 \\
Oncology/Hospice & 4 & 7.4 \\
Community/School/Home Health & 5 & 9.3 \\
\hline TOTAL & 54 & 100.0 \\
\hline
\end{tabular}

ANALYSIS OF THE PROFILE OF LIFE VALUES

Research question number three was: "What are the personal values of nursing students in the final year of their nursing program?" The responses to the Profile of Life Values were used for analysis of this data.

The profile of Live Values (PLV) consisted of 56 items, divided among seven internalized value scales: Intellectual, Considerate, Creative, Recognition, Artistic, Achievement, and Integrity. The assignment of the PVI items to each of the scales is shown in Table XIX. 
TABLE XIX

SCALES FOR PROFILE OF LIEE VALUES

\begin{tabular}{lccccccccc}
\hline \multicolumn{1}{c}{ Scale } & \multicolumn{1}{c}{ Items } \\
\hline Intellectual & 1 & 8 & 15 & 22 & 29 & 36 & 43 & 50 \\
Considerate & 2 & 9 & 16 & 23 & 30 & 37 & 44 & 51 \\
Creative & 3 & 10 & 17 & 24 & 31 & 38 & 45 & 52 \\
Recognition & 4 & 11 & 18 & 25 & 32 & 39 & 46 & 53 \\
Artistic & 5 & 12 & 19 & 26 & 33 & 40 & 47 & 54 \\
Achievement & 6 & 13 & 20 & 27 & 34 & 41 & 48 & 55 \\
Integrity & 7 & 14 & $21 *$ & $28 *$ & $35 *$ & $42 *$ & $49 *$ & $56 *$ \\
\hline Note: *Reverse & & & & & & & & \\
\hline
\end{tabular}

Note: *Reverse scoring used

The subjects were asked to read each statement in the Profile of Iife Values, decide how they felt about the statement, and mark an " $x$ " in the brackets that corresponded with their decision. For each statement, one of the five responses could be selected: strongly disagree, disagree, neutral, agree, strongly agree. Items were scored from one to five, with the highest score, five, representing strongly agree and the lowest score, one, representing strongly disagree. The maximum possible score on each scale was 40 ; the lowest possible score on each scale, eight. Higher scores corresponded to higher personal values. 
Total Sample Responses on Personal Values

The responses to the personal values from 452 student nurses were scored. The mean, standard deviation, and Coefficient Alpha for each personal value are presented in Table Xx.

TABLE XX

MEANS, STANDARD DEVIATIONS, AND COEFFICIENT ALPHAS FOR PERSONAL VALUES

\begin{tabular}{llcc}
\hline \multicolumn{1}{c}{ Scale } & Mean & $\begin{array}{c}\text { Standard } \\
\text { Deviation }\end{array}$ & $\begin{array}{c}\text { Coefficient } \\
\text { Alpha }\end{array}$ \\
\hline Intellectual & 32.13 & 3.60 & .783 \\
Considerate & 34.66 & 3.10 & .816 \\
Creative & 30.71 & 4.07 & .880 \\
Recognition & 31.35 & 4.29 & .866 \\
Artistic & 29.62 & 5.33 & .872 \\
Achievement & 32.09 & 3.45 & .814 \\
Integrity & 29.20 & 5.43 & .869 \\
\hline
\end{tabular}

The means for each personal value ranged from 29.2 on the scale for Integrity to 34.7 on the Considerate scale. The standard deviations ranged from 3.1 for Considerate to 5.4 for Integrity. Coefficient Alphas ranged from .78 for Intellectual to .88 on Creative.

Intellectual. The value of Intellectual expresses interest in learning more about a greater variety of subjects 
through a variety of processes. A higher score on this scale indicates that individuals seek new learning experiences, are inquisitive, and are interested in broadening their knowledge base. The mean score of 32.1 indicates that the subjects in the study considered this value as being important to them. The standard deviation was 3.6 .

Considerate. The mean score for the Considerate scale was 34.7, higher than any of the other personal value scales. The standard deviation for this scale was 3.1 , less than the other scales on the profile of Life Values, indicating less variation in the respondents' perceptions of importance placed on being sensitive to others.

Creative. The value, Creative, signifies the importance of using ideas or working with new or unusual things in the role. The mean score for being Creative was 30.7 , showing that the participants agreed that being Creative was important to them. The standard deviation was 4.1. However, being Creative was perceived as being of less importance than four of the other personal value scales.

Recognition. The value of Recognition signifies acknowledgement of a person through their accomplishments and reputation. The mean score for this scale was 31.4, showing that the participants agreed that Recognition was important to them. The standard deviation was 4.3 .

Artistic. Interest in participating or doing something tastefully associated with the fine arts or being Artistic was 
perceived by this sample as having less personal importance to the individual. The mean score was 29.6 , while the standard deviation was 5.3 , showing more variation in the individual's perception of this value. Overall, the sample did perceive this value as being somewhat important.

Achievement. The Achievement value indicates a desire to accomplish or perform successfully. This value is closely associated with motivation. The mean score for Achievement was 32.1 , showing that the subjects perceived this value as being important. The standard deviation was 3.5 .

Integrity. The value, Integrity, implies morality, honesty, straightforwardness, and ethical consideration. The mean score for this scale was 29.2, showing acceptance of ethical considerations, yet a willingness to allow some flexibility in keeping with the circumstances. The standard deviation was 5.4 , showing the greatest variation on the personal value scales.

\section{Summary of Personal Values for the Total Sample}

The value of Considerate had the highest mean and least standard deviation for the sample, indicating that the participants perceived being thoughtful and sensitive to others as being most important to them. The value of Integrity had the lowest mean value with the greatest variation. While the respondents agreed that this value was important to them, they perceived that the other values were more important to them 
during this phase of their education. Ordered by importance, from highest to lowest, the values were Considerate (34.7), Intellectual (32.1), Achievement (32.1), Recognition (31.4), Creative (30.7), Artistic (29.6), and Integrity (29.2).

The greatest variation in the perceptions of personal values occurred in the value of Integrity, while the least variation related to the value of being Considerate. Standard deviations from the least to most occurred in this order: Considerate (3.1), Achievement (3.5), Intellectual (3.6), Imaginative (4.1), Recognition (4.3), Artistic (5.3), and Integrity (5.4).

ANALYSIS OF THE OHIO WORK VALUES INVENTORY

A fourth research question was: "What are the work values of nursing students in the final year of their nursing program?" A discussion of each work value follows with an analysis of the data.

The Ohio Work Values Inventory contains 77 items divided equally among 11 scales. Work value's scales were: Altruism, Object Orientation, Security, Control, Self Realization, Independence, Money, Task Satisfaction, Solitude, Ideas/Data Orientation, and Prestige. Question numbers related to each work value are presented in Table XXI.

Participants in the study were asked to place an " $x$ " in the brackets that corresponded with the answer they selected for a question. The answers ranged from not much, a little, 
TABLE XXI

ASSIGNMENT OF OHIO WORK VALUES INVENTORY QUESTIONS TO SCALE scale Question

Altruism

$\begin{array}{lllllll}1 & 12 & 23 & 34 & 45 & 56 & 67\end{array}$

object Orientation

$\begin{array}{lllllll}2 & 13 & 24 & 35 & 46 & 57 & 68\end{array}$

security

$\begin{array}{lllllll}3 & 14 & 25 & 36 & 47 & 58 & 69\end{array}$

Control

$\begin{array}{lllllll}4 & 15 & 26 & 37 & 48 & 59 & 70\end{array}$

Self-Realization

$\begin{array}{lllllll}5 & 16 & 27 & 38 & 49 & 60 & 71\end{array}$

Independence

$\begin{array}{lllllll}6 & 17 & 28 & 39 & 50 & 61 & 72\end{array}$

Money

$\begin{array}{lllllll}7 & 18 & 29 & 40 & 51 & 62 & 73\end{array}$

Task Satisfaction

$\begin{array}{lllllll}8 & 19 & 30 & 41 & 52 & 63 & 74\end{array}$

Solitude

$\begin{array}{lllllll}9 & 20 & 31 & 42 & 53 & 64 & 75\end{array}$

Ideas/Data Orientation

$\begin{array}{lllllll}10 & 21 & 32 & 43 & 54 & 65 & 76\end{array}$

Prestige

$\begin{array}{lllllll}11 & 22 & 33 & 44 & 55 & 66 & 77\end{array}$

fairly much, a lot, to very much. Each question was scored from one to five, with one being the lower end of the range (not much) and five being the upper end of the range (very much). A scale was formed by seven questions falling under a like concept. A total possible score for each scale was 35 , with the lowest possible score being seven. Higher scores corresponded to higher values. 
Total Sample Responses to Ohio Work Values Inventory

The means for this sample's work values ranged from a low of 17.9 for Solitude to a high of 33.3 for Task Satisfaction. The standard deviations for the work values scales ranged from 2.6 for Task Satisfaction to 6.9 for Prestige. Coefficient Alphas ranged from .84 for Task Satisfaction to .94 for Money. Table XxII presents this data.

TABLE XXII

MEANS, STANDARD DEVIATIONS, AND COEFFICIENT ALPHAS FOR OHIO WORK VALUES INVENTORY SCALES

\begin{tabular}{|c|c|c|c|}
\hline scale & Mean & $\begin{array}{l}\text { Standard } \\
\text { Deviation }\end{array}$ & $\begin{array}{c}\text { Coefficient } \\
\text { Alpha }\end{array}$ \\
\hline Altruism & 31.07 & 4.30 & .909 \\
\hline Object Orientation & 20.22 & 6.56 & .884 \\
\hline security & 27.75 & 6.34 & .928 \\
\hline Control & 19.80 & 6.74 & .928 \\
\hline Self Realization & 32.24 & 3.22 & .867 \\
\hline Independence & 26.43 & 5.38 & .870 \\
\hline Money & 27.59 & 6.84 & .939 \\
\hline Task Satisfaction & 33.32 & 2.63 & .835 \\
\hline Solitude & 17.90 & 6.00 & .863 \\
\hline Ideas/Data Orientation & 25.71 & 5.13 & .849 \\
\hline Prestige & 18.85 & 6.87 & .904 \\
\hline
\end{tabular}


Altruism. The importance of being involved with other people in a helping, supportive role was among the top three work values for this sample. A mean score of 31.1 indicated that this sample felt that Altruism was a significantly important work value. The standard deviation of 4.3 for this value was relatively small.

Object Orientation. Object Orientation is an expression of work values involving making, fixing, handling, operating, and changing the appearance of things such as utensils, materials, tools, machines, and instruments. The effects of performing tasks with material objects provided the individual with physical and measurable outcome. The mean score for this sample was 20.2 , placing this work values eighth from the top mean score. The standard deviation was 6.6 , indicating relatively higher variation among the respondents on this scale.

Security. Security implies a concern for work that is steady and dependable. This value is believed to be related to other values that render a reward of some form, i. e., money or prestige. The mean score for Security was 27.8, indicating that the respondents placed moderate importance on this value. The standard deviation was 6.3 , showing moderately high variation among these respondents.

Control. The mean for Control was 19.8, indicating that many subjects in this sample attached lesser importance to this value. However, the standard deviation for this scale 
was 6.7 , suggesting moderately high variation among the sample in this study. The Control scale relates to the valuing of of a leadership role and the responsibility for other workers. The value also suggests that a job can in itself give a person an influencing or decision making role in planning, working with, and evaluating their influence on others.

Self Realization. This value, Self Realization, allows for an expression of preference for work that give the person an opportunity to use their skills, abilities, or talents. Work values of this nature provide a basis for continued personal growth and further development of a person's potential. The mean score for this scale was 32.2 , an indication that Self Realization was very important. This was the second highest mean score work value for this sample. The standard deviation was 3.2 , indicating there was less variation in the responses.

Independence. The mean for Independence was 26.4, indicating the sample chose to assign a moderate degree of importance to this value. The standard deviation was 5.3. This value identifies with the importance of working in an environment where people are allowed to determine some of their own working conditions. Higher scores indicate that the respondents chose to have less supervision and more freedom in the selection of their work hours and the way they perform their job. 
Money. For this sample, Money was moderately important. The mean score was 27.6 , while the standard deviation was 6.8. The standard deviation for this value was second to the highest, suggesting there was a wider difference in money values among the respondents. Work values for this scale indicate the level of importance given to making a lot of money, a desirable income wherein the recipent may procure material satisfaction and psychological gratification from the income level. The mean score (27.6) for this value, Money, was similar to the mean score for security $(27.8)$

Task Satisfaction. The scale for Task Satisfaction is related to the importance of doing work that is interesting and satisfying. Fenner and Hales (1974) term this as work that a person looks forward to doing. The mean score for this scale was 33.3 , indicating that the respondents assigned the greatest importance to this value. The standard deviation for the scale was 2.6 , the lowest standard deviation among the scales for work values.

Solitude. With a mean of 17.9 , the value of solitude was scored the lowest. They placed little value on work that could be accomplished in solitude mostly by one person. The standard deviation for this value was 6.0 .

Ideas/Data Orientation. The mean for Ideas/Data Orientation was 25.7 , suggesting that some importance was given to this value in this sample. The standard deviation 
was 5.1. The value suggests a preference for working with facts and ideas, making sense out of the ideas and communicating this information to others.

Prestige. The desire or the importance people place on work where they may be recognized and receive material or psycholocical rewards for their efforts relates to the value for Prestige. Interest in meeting and associating with important people is also a part of this value. The mean score was 18.9, showing the respondents placed lesser importance on the value. The standard deviation was 6.9, greater than the standard deviations for the other work values; this suggests that there was a great diversity in the value assigned to prestige by these participants.

\section{Summary of Work Values for the Total Sample}

In summary, Task Satisfaction had the highest mean value for the total sample; Self-Realization had the second highest mean value; Altruism had the third highest mean value. These three work values had relatively small standard deviations. Doing work that one looks forward to doing, performing work that permits an individual to utilize their skills, and being involved in working with other people in supportive ways were seen as the most important values for this sample.

More moderate values were placed on Money and Security. Slightly less, yet comparable, value was given to Idea/Data Orientation and Independence. Making money and being secure 
were important to this sample; however, these work values were not perceived to be as important as Task Satisfaction, SelfRealization, and Altruism. The value of working independently and being able to work with facts and ideas was slightly less attractive to the student nurse sample.

Moderately lower value was placed on Object Orientation, Control, Prestige, and Solitude. Fixing, handling, operating or changing the appearance of things, receiving recognition and status as a result of the type of work done, having a leadership role with responsibility for others work, and working independently in somewhat isolation from others were valued less by this sample of nursing students.

The order of importance based on the mean for these work values (most important to least important) was: Task Satisfaction (33.3), Self Realization (32.2), Altruism (31.1), Security (27.8), Money (27.6), Independence (26.4), Ideas/ Data Orientation (25.7), Object Orientation (20.2), Control (19.8), Prestige (18.9), and Solitude (17.9).

\section{ANALYSIS OF PERSONAL VALUES BY TYPE OF INSTITUTION}

The next research question the investigator chose to analyze was "Do student nurses personal values differ in the different types of educational institutions (public, private)? In the sample were 379 students who were enrolled in public educational institutions and 72 students who were attending private institutions. Table XXIII presents the means and 
standard deviations on the personal value scales by type of institution.

TABLE XXIII

MEANS AND STANDARD DEVIATIONS ON PERSONAL VALUES BY TYPE OF EDUCATIONAL INSTITUTION

\begin{tabular}{llllll}
\hline & \multicolumn{2}{c}{ Public Institution } & & \multicolumn{2}{c}{ Private Institution } \\
\cline { 2 - 3 } Value & Mean & SD & & Mean & SD \\
\hline Intellectual & 32.07 & 3.56 & & 32.47 & 3.87 \\
Considerate & 34.60 & 3.11 & & 35.03 & 3.10 \\
Creative & 30.47 & 3.93 & & 31.97 & 4.60 \\
Recognition & 30.95 & 4.18 & & 33.49 & 4.32 \\
Artistic & 29.39 & 5.26 & & 30.81 & 5.57 \\
Achievement & 31.90 & 3.42 & 33.08 & 3.46 \\
Integrity & 29.31 & 5.23 & 28.83 & 6.27 \\
\hline
\end{tabular}

MANOVA was performed, using the seven scales of the Profile of Life Values as dependent variables and the type of institution (public, private) as the independent variable. The multivariate statistical hypothesis was rejected; using Wilks' Lambda (with 7, $449 \underline{\mathrm{df}}$ ), $\underline{\mathrm{F}}=4.56, \underline{\mathrm{p}}<.001$. Following rejection of the multivariate statistical hypothesis, ANOVAs were performed, using the PLV scales as dependent variables and the type of educational institution as 
the independent variable. These analyses are summarized in Table XXIV.

\section{TABLE XXIV}

\section{ANALYSIS OF VARIANCE FOR PERSONAL VALUES BY} TYPE OF INSTITUTION

\begin{tabular}{|c|c|c|c|c|c|c|}
\hline \multirow[b]{2}{*}{ Scale } & \multicolumn{2}{|c|}{ Hypothesis } & \multicolumn{2}{|c|}{ Error } & \multirow{2}{*}{$\underline{F}$} & \multirow{2}{*}{ 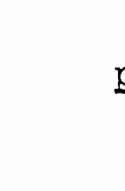 } \\
\hline & SS & MS & SS & MS & & \\
\hline Intellectual & 9.99 & 9.99 & 5847.30 & 13.02 & 0.77 & .382 \\
\hline Considerate & 10.99 & 10.99 & 4326.78 & 9.64 & 1.14 & .286 \\
\hline Creative & 136.60 & 136.60 & 7328.35 & 16.32 & 8.37 & .004 \\
\hline Recognition & 389.20 & 389.20 & 7914.03 & 17.63 & 22.08 & .000 \\
\hline Artistic & 121.61 & 121.61 & 12665.26 & 28.21 & 4.31 & .038 \\
\hline Achievement & 84.38 & 84.38 & 5268.89 & 11.73 & 7.19 & .008 \\
\hline Integrity & 13.52 & 13.52 & 13146.50 & 29.28 & 0.46 & .497 \\
\hline
\end{tabular}

Note: Hypothesis $\mathrm{df}=1$; $\mathrm{df}=449$

As can be seen, the statistical hypothesis based on form of educational institution was not rejected for Intellectual $(\underline{\underline{p}}=.382)$, Considerate $(\underline{\underline{p}}=.286)$, and Integrity $(\underline{\underline{p}}=.497)$.

The statistical hypothesis was rejected for four scales: Creative $(\underline{\underline{p}}=.004)$, Recognition $(\underline{\mathrm{p}}<.001)$, Artistic $(\underline{\mathrm{p}}=$ $.038)$, and Achievement $(\underline{\underline{D}}=.008)$. The means for the private institutions were greater than the means for the public institutions on all four variables. 
ANALYSIS OF PERSONAL VALUES BY EDUCATIONAL PREPARATION

Research question five was: "Do the personal values of nursing students differ across levels of educational preparation?" The sample consisted of 266 students from Associate Degree programs, 143 from Baccalaureate Degree programs, 43 from Graduate Degree programs. The means and standard deviations on the personal values scale by educational preparation are presented in Table XXV.

\section{TABLE XXV}

MEANS AND STANDARD DEVIATIONS FOR PERSONAL VALUES BY EDUCATIONAL PREPARATION

\begin{tabular}{|c|c|c|c|c|c|c|}
\hline \multirow[b]{2}{*}{ Value } & \multicolumn{2}{|c|}{ Associate } & \multicolumn{2}{|c|}{ Baccalaureate } & \multicolumn{2}{|c|}{ Graduate } \\
\hline & Mean & $S D$ & Mean & $\mathrm{SD}$ & Mean & SD \\
\hline Intellectual & 31.81 & 3.54 & 32.39 & 3.78 & 33.33 & 3.09 \\
\hline Considerate & 34.70 & 3.19 & 34.66 & 3.04 & 34.47 & 2.82 \\
\hline Creative & 30.44 & 3.78 & 31.10 & 4.42 & 31.12 & 4.52 \\
\hline Recognition & 30.78 & 4.37 & 32.33 & 4.23 & 31.65 & 3.39 \\
\hline Artistic & 29.25 & 5.27 & 30.25 & 5.65 & 29.84 & 4.35 \\
\hline Achievement & 31.82 & 3.44 & 32.39 & 3.37 & 32.72 & 3.63 \\
\hline Integrity & 29.83 & 5.24 & 28.32 & 5.87 & 28.30 & 4.60 \\
\hline
\end{tabular}

Using the seven personal value scales as dependent variables and the level of educational program (Associate, 
Baccalaureate, Graduate) as the independent variable, MANOVA was performed. The multivariate statistical hypothesis was rejected; with 7, $449 \underline{\mathrm{df}}$, Wilks' Lambda $\underline{F}=2.36, \underline{p}=.003$. Again, ANOVAs were performed, using the personal value scales as dependent variables, and educational preparation as the independent variable. These analyses are presented in Table XXVI.

TABLE XXVI

ANALYSIS OF VARIANCE FOR PERSONAL VALUES BY EDUCATIONAL PREPARATION

\begin{tabular}{|c|c|c|c|c|c|c|}
\hline \multirow[b]{2}{*}{ Scale } & \multicolumn{2}{|c|}{ Hypothesis } & \multicolumn{2}{|c|}{ Error } & \multirow{2}{*}{$\underline{F}$} & \multirow{2}{*}{$\underline{p}$} \\
\hline & SS & MS & SS & MS & & \\
\hline Intellectual & 98.91 & 49.46 & 5759.12 & 12.83 & 3.86 & .022 \\
\hline Considerate & 2.04 & 1.02 & 4342.85 & 9.67 & 0.11 & .900 \\
\hline Creative & 48.57 & 24.29 & 7416.46 & 16.52 & 1.47 & .231 \\
\hline Recognition & 227.84 & 113.92 & 8077.23 & 17.99 & 6.33 & .002 \\
\hline Artistic & 94.63 & 47.32 & 12697.92 & 28.28 & 1.67 & .189 \\
\hline Achievement & 49.04 & 24.52 & 5305.42 & 11.82 & 2.08 & .127 \\
\hline Integrity & 251.32 & 125.66 & 13057.95 & 29.08 & 4.32 & .014 \\
\hline
\end{tabular}

Note: hypothesis df $=2 ; \mathrm{df}=449$

The statistical hypothesis was not rejected for Considerate $(\underline{p}=.900)$, Creative $(\underline{p}=.231)$, Artistic $(\underline{p}=$ $.189)$, and Achievement $(\underline{p}=.127)$. The statistical hypotheses 
were rejected for three of the scales: Intellectual ( $\underline{p}=$ $.022)$, Recognition ( $\underline{p}=.002)$, and Integrity $(\underline{p}=.014)$.

Following significant ANOVAs, the statistical hypotheses for each pairwise mean comparisons were tested; Scheffe was used at the .10 level as recommended by Scheffe. Although interpretation is based on the Scheffe (.10) comparisons, the hypotheses were also examined at the .05 level with both Scheffe and Tukeyb. (See Table XXVII.)

TABLE XXVII

POST HOC COMPARISONS: PERSONAL VALUES WITH EDUCATIONAL PREPARATION

Value Scheffe (.10) Scheffe (.05) Tukeyb (.05)

\begin{tabular}{|c|c|c|c|}
\hline Intellectual & I-III & I-III & I-III \\
\hline Recognition & I-II & I-II & I-II \\
\hline Integrity & $I-I I$ & I-II & $I-I I$ \\
\hline
\end{tabular}

Significant group differences in the pairwise mean comparisons were found. The mean for Intellectual was significantly higher for the Graduate students (33.3) than for the Associate Degree students (31.8). On Recognition, the mean (32.3) for Baccalaureate students was higher than the mean for Associate Degree students (30.8). On Integrity, the mean (29.8) for Associate Degree students was higher than the 
mean (28.3) for Baccalaureate and Graduate degree students. It should be noted that the statistical hypotheses were tested with Scheffe (.10); this result would have been the same with Scheffe (.05) and Tukeyb (.05).

\section{ANALYSIS OF WORK VALUES BY TYPE OF INSTITUTION}

The work values of 379 students in public school nursing education programs and 72 students enrolled in private school nursing education programs were analyzed, using the work value scales as dependent variables and the type of educational institution (public, private) as the independent variable. Table XXVIII presents the means and standard deviations on the work values scales by type of institution.

MANOVA was performed, using the eleven work value scales as dependent variables and the type of institution (public, private) as the independent variable. The multivariate statistical hypothesis was rejected; with 1, 449 df , Wilks' Lambda $\underline{F}=2.54, \underline{p}=.004$.

Following rejection of the multivariate statistical hypothesis, ANOVAs were also performed. As can be seen in Table XXIX, the statistical hypothesis was not rejected for Altruism ( $\underline{p}=.865)$, Object Orientation $(\underline{p}=.137)$, Security $(\underline{p}=.389)$, Self Realization $(\underline{p}=.793)$, Money $(\underline{p}=.597)$, and Task Satisfaction $(\underline{p}=.187)$. The statistical hypothesis was rejected for five scales: Control ( $\underline{p}=.033)$, Independence ( $\underline{p}$ $=.002)$, Solitude $(\underline{p}=.015)$, Ideas/ Data Orientation ( $\underline{p}=$ 
TABLE XXVIII

MEANS AND STANDARD DEVIATION FOR WORK VALUES BY TYPE OF EDUCATIONAL INSTITUTION

\begin{tabular}{lcccccc}
\hline & \multicolumn{2}{c}{ Public Institution } & & \multicolumn{2}{c}{ Private Institution } \\
\cline { 2 - 3 } Scale & Mean & SD & & Mean & SD \\
\hline Altruism & 31.05 & 4.19 & & 31.14 & 4.92 \\
Object Orientation & 20.02 & 6.34 & & 21.28 & 7.62 \\
Security & 27.68 & 6.33 & & 28.38 & 6.23 \\
Control & 19.36 & 6.65 & & 21.39 & 7.02 \\
Self Realization & 32.25 & 3.20 & & 32.14 & 3.38 \\
Independence & 26.08 & 5.29 & & 28.25 & 5.55 \\
Money & 27.52 & 6.87 & & 27.99 & 6.74 \\
Task Satisfaction & 33.25 & 2.69 & & 33.70 & 2.29 \\
Solitude & 17.60 & 5.76 & & 19.49 & 6.97 \\
Ideas/Data Orientation & 25.49 & 5.05 & & 26.92 & 5.42 \\
Prestige & 18.40 & 6.52 & & 21.39 & 8.03 \\
& & & & & &
\end{tabular}

$.030)$, and Prestige $(\underline{p}=.001)$. The means for the private institutions were higher than the means for the public institutions on these scales. 
TABLE XXIX

ANALYSIS OF VARIANCE FOR WORK VALUES BY TYPE OF INSTITUTION

\begin{tabular}{|c|c|c|c|c|c|c|}
\hline \multirow[b]{2}{*}{ Scale } & \multicolumn{2}{|c|}{ Hypothesis } & \multicolumn{2}{|c|}{ Error } & \multirow{2}{*}{$\underline{F}$} & \multirow{2}{*}{$\underline{p}$} \\
\hline & SS & MS & SS & MS & & \\
\hline Altruism & 0.54 & 0.54 & 8340.85 & 18.58 & 0.03 & .865 \\
\hline obj. Orient. & 95.15 & 95.15 & 19295.23 & 42.97 & 2.21 & .137 \\
\hline security & 29.61 & 29.61 & 17873.96 & 39.81 & 0.74 & .389 \\
\hline Control & 207.22 & 207.22 & 20233.31 & 45.06 & 4.60 & .033 \\
\hline Self Real. & 0.72 & 0.72 & 4671.30 & 10.40 & 0.07 & .793 \\
\hline Independence & 285.14 & 285.14 & 12747.13 & 28.39 & 10.04 & .002 \\
\hline Money & 13.16 & 13.16 & 21065.59 & 46.92 & 0.28 & .597 \\
\hline Task Sat. & 12.06 & 12.06 & 3099.96 & 6.90 & 1.75 & .187 \\
\hline solitude & 214.28 & 214.28 & 16004.62 & 35.64 & 6.01 & .015 \\
\hline Id/Data or. & 123.93 & 123.93 & 11722.17 & 26.11 & 4.75 & .030 \\
\hline Prestige & 542.05 & 542.05 & 20631.74 & 45.95 & 11.80 & .001 \\
\hline
\end{tabular}

Note: Object Orientation (obj. Orient.); Self Realization (Self Real.); Ideas/Data Orientation (Id/Data Or.)

hypothesis $\mathrm{df}=1 ; \mathrm{df}=449$

\section{ANALYSIS OF WORK VALUES BY EDUCATIONAL PREPARATION}

Question number six asked: "Is there a difference in the work values of students across levels of educational preparation?" The sample consisted of 266 students in Associate Degree programs, 143 students in Baccalaureate programs, and 
43 students in Graduate Degree programs. Table XXX

presents the means and standard deviations in the work values.

TABLE XXX

MEANS AND STANDARD DEVIATIONS FOR WORK VALUES

BY EDUCATIONAL PREPARATION

\begin{tabular}{|c|c|c|c|c|c|c|}
\hline \multirow[b]{2}{*}{ Value } & \multicolumn{2}{|c|}{ Associate } & \multicolumn{2}{|c|}{ Baccalaureate } & \multicolumn{2}{|c|}{ Graduate } \\
\hline & Mean & $S D$ & Mean & $S D$ & Mean & $S D$ \\
\hline Altruism & 31.20 & 4.12 & 30.98 & 4.62 & 30.58 & 4.38 \\
\hline Object Orientation & 20.38 & 6.41 & 21.06 & 6.62 & 16.42 & 6.07 \\
\hline Security & 28.57 & 6.00 & 27.69 & 6.24 & 22.91 & 6.73 \\
\hline Control & 19.53 & 6.91 & 20.85 & 6.58 & 18.16 & 5.76 \\
\hline Self Realization & 32.18 & 3.22 & 32.39 & 3.17 & 32.09 & 3.43 \\
\hline Independence & 25.71 & 5.39 & 27.64 & 5.07 & 26.81 & 5.62 \\
\hline Money & 28.50 & 6.51 & 27.04 & 6.97 & 23.79 & 7.03 \\
\hline Task Satisfaction & 33.17 & 2.88 & 33.62 & 2.09 & 33.26 & 2.56 \\
\hline Solitude & 17.62 & 5.93 & 18.69 & 6.07 & 16.98 & 6.09 \\
\hline Ideas/Date orient. & 25.37 & 5.17 & 26.00 & 4.92 & 26.81 & 5.40 \\
\hline Prestige & 18.27 & 6.63 & 19.99 & 7.32 & 18.65 & 6.87 \\
\hline
\end{tabular}

Note: Ideas/Data Orientation (Ideas/Data Orient.)

MANOVA was performed, using the 11 work value scales as dependent variables and the level of educational programs (Associate, Baccalaureate, Graduate) as the independent variable. The multivariate statistical hypothesis was rejected; with 2, $449 \underline{\text { df }}$, Wilks' Lambda $\underline{F}=6.67, \underline{p}<.001$. 
Following rejection of the multivariate statistical hypothesis, ANOVAs were performed, using the 11 work value scales as dependent variables and the level of educational preparation as the independent variable. These results are presented in Table XXXI.

\section{TABLE XXXI}

ANALYSIS OF VARIANCE ON WORK VALUES BY EDUCATIONAL PREPARATION

\begin{tabular}{|c|c|c|c|c|c|c|}
\hline \multirow[b]{2}{*}{ Scale } & \multicolumn{2}{|c|}{ Hypothesis } & \multicolumn{2}{|c|}{ Error } & \multirow{2}{*}{$\underline{F}$} & \multirow{2}{*}{$\underline{p}$} \\
\hline & SS & MS & SS & MS & & \\
\hline Altruism & 15.64 & 7.82 & 8341.24 & 18.58 & 0.42 & .421 \\
\hline obj. Orient. & 729.77 & 364.88 & 18665.55 & 41.57 & 8.78 & .000 \\
\hline security & 1188.64 & 594.32 & 16963.61 & 37.78 & 15.73 & .000 \\
\hline Control & 292.51 & 146.26 & 20181.97 & 44.95 & 3.25 & .040 \\
\hline Self Real. & 4.86 & 2.43 & 4674.81 & 10.41 & 0.23 & .792 \\
\hline Independence & 353.13 & 176.56 & 12681.61 & 28.24 & 6.25 & .002 \\
\hline Money & 882.10 & 441.05 & 20203.36 & 45.00 & 9.80 & .000 \\
\hline Task Sat. & 19.00 & 9.50 & 3094.75 & 6.89 & 1.38 & .253 \\
\hline Solitude & 145.65 & 72.82 & 16088.47 & 35.83 & 2.03 & .132 \\
\hline Ideas/Data & 94.79 & 47.39 & 11758.67 & 26.18 & 1.81 & .165 \\
\hline Prestige & 278.96 & 139.48 & 21012.81 & 46.80 & 2.98 & .052 \\
\hline
\end{tabular}


Based on these results, the statistical hypothesis was not rejected for the work values of Aitruism ( $\underline{p}=.657)$, Self Realization $(\underline{p}=.792)$, Task Satisfaction $(\underline{p}=.253)$, Solitude $(\underline{p}=.132)$, Ideas/Data Orientation $(\underline{p}=.165)$, and Prestige ( $\underline{x}$ $=.052)$. The statistical hypothesis was rejected for five scales: Object Orientation $(\underline{p}<.001)$, Security $(\underline{p}<.001)$, Control $(\underline{p}=.040)$, Independence $(\underline{p}=.002)$, and Money ( $p<$ $.001)$.

Following significant ANOVAs, the statistical hypotheses for all pairwise mean comparisons were tested. Scheffe was used at the .10 level as recommended by Scheffe. Although interpretation is based on the Scheffe (.10) comparisons, the hypotheses were also tested at the .05 level with Scheffe and Tukeyb. (See Table XXXII.)

The mean on Object Orientation was significantly higher for the Associate Degree students (20.4) than for the students in Graduate Degree program (16.4). The mean for object Orientation was also significantly higher for Baccalaureate Degree students (21.1) than for Graduate Degree students (16.4). For security, the mean was significantly higher for students in Associate Degree programs (28.6) than for students in Graduate Degree programs (22.9). Again, the mean for Security was higher for students in Baccalaureate Degree programs (27.7) than for Graduate Degree students (22.9). For the value, Control, the mean was also significantly higher for 
Graduate and Associate Degree programs. Students in Associate Degree programs placed more value on Altruism, security, and Money than Graduate and Baccalaureate Degree students.

\section{RELATIONSHIPS BETWEEN PERSONAL VALUES AND JOB INTERESTS}

Question seven asked "Do personal values differ with job interests?" Greater numbers of student nurses stated they were interested in employment in medical/surgical nursing (161), critical care (57), obstetrical nursing (57), other specialties (54), and geriatric nursing (31). The number of nursing students interested in the Nurse Practitioner or Clinical specialization combined totaled 35. Fewer students expressed an interest in Pediatrics (25), Mental Health (20), Administration (5), and Education (7). To analyze the data, interests in the Nurse Practitioner and Clinical Specialist were combined. Interests in Administration and Education were not included in the analysis; too few students expressed an interest in these areas for analysis.

MANOVA and ANOVAs were performed on the relationships between the personal values scales and job interests of 440 subjects. The means and standard deviations are presented in Table XXXIII.

MANOVA, using the seven personal value scales as dependent variables and job interests as the independent variable, was performed. The multivariate statistical hypothesis was

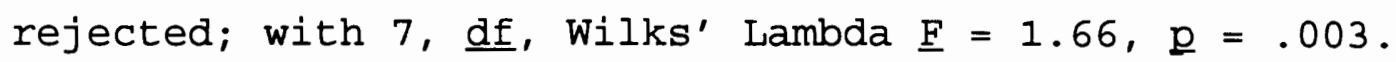


TABLE XXXIII

MEANS AND STANDARD DEVIATIONS FOR PERSONAL VALUES BY JOB INTEREST

\begin{tabular}{|c|c|c|c|c|c|c|c|c|}
\hline & $M / S$ & Ger & $\mathrm{CC}$ & $O B$ & Ped & MH & $\mathrm{NP} / \mathrm{CS}$ & $S P$ \\
\hline Value & $\begin{array}{c}\text { Mean } \\
\text { (SD) }\end{array}$ & $\begin{array}{l}\text { Mean } \\
\text { (SD) }\end{array}$ & $\begin{array}{l}\text { Mean } \\
\text { (SD) }\end{array}$ & $\begin{array}{l}\text { Mean } \\
\text { (SD) }\end{array}$ & $\begin{array}{l}\text { Mean } \\
\text { (SD) }\end{array}$ & $\begin{array}{l}\text { Mean } \\
\text { (SD) }\end{array}$ & $\begin{array}{l}\text { Mean } \\
\text { (SD) }\end{array}$ & $\begin{array}{l}\text { Mean } \\
\text { (SD) }\end{array}$ \\
\hline
\end{tabular}

\begin{tabular}{|c|c|c|c|c|c|c|c|c|}
\hline Intellectual & $\begin{array}{c}31.62 \\
(3.6)\end{array}$ & $\begin{array}{c}30.84 \\
(3.1)\end{array}$ & $\begin{array}{r}32.47 \\
(4.2)\end{array}$ & $\begin{array}{c}31.58 \\
(3.4)\end{array}$ & $\begin{array}{c}34.04 \\
(3.5)\end{array}$ & $\begin{array}{l}32.85 \\
(3.5)\end{array}$ & $\begin{array}{l}33.34 \\
(3.4)\end{array}$ & $\begin{array}{r}32.59 \\
(3.1)\end{array}$ \\
\hline Considerate & $\begin{array}{l}34.39 \\
(3.2)\end{array}$ & $\begin{array}{c}34.42 \\
(3.4)\end{array}$ & $\begin{array}{c}34.64 \\
(3.1)\end{array}$ & $\begin{array}{c}34.78 \\
(2.8)\end{array}$ & $\begin{array}{c}37.20 \\
(2.5)\end{array}$ & $\begin{array}{c}34.20 \\
(3.2)\end{array}$ & $\begin{array}{l}34.54 \\
(3.3)\end{array}$ & $\begin{array}{r}34.6 \\
13.0\end{array}$ \\
\hline Creative & $\begin{array}{c}30.14 \\
(3.8)\end{array}$ & $\begin{array}{c}31.38 \\
(4.0)\end{array}$ & $\begin{array}{c}31.21 \\
(4.5)\end{array}$ & $\begin{array}{l}30.32 \\
(3.8)\end{array}$ & $\begin{array}{c}31.84 \\
(4.6)\end{array}$ & $\begin{array}{c}30.25 \\
(4.9)\end{array}$ & $\begin{array}{l}30.77 \\
(4.4)\end{array}$ & $\begin{array}{l}31 \\
(3 .\end{array}$ \\
\hline Recognition & $\begin{array}{r}30.65 \\
(4.5)\end{array}$ & $\begin{array}{r}32.42 \\
(4.0)\end{array}$ & $\begin{array}{r}31.76 \\
(4.5)\end{array}$ & $\begin{array}{r}31.81 \\
(3.6)\end{array}$ & $\begin{array}{r}33.20 \\
(4.0)\end{array}$ & $\begin{array}{r}30.25 \\
(4.2)\end{array}$ & $\begin{array}{r}31.97 \\
(4.2)\end{array}$ & $\begin{array}{r}31.13 \\
(4.3\end{array}$ \\
\hline Artistic & $\begin{array}{r}29.14 \\
(5.2)\end{array}$ & $\begin{array}{r}28.35 \\
(5.6)\end{array}$ & $\begin{array}{r}29.00 \\
(6.0)\end{array}$ & $\begin{array}{r}29.38 \\
(5.4)\end{array}$ & $\begin{array}{r}31.68 \\
(6.5)\end{array}$ & $\begin{array}{r}32.65 \\
(3.8)\end{array}$ & $\begin{array}{r}30.31 \\
(4.2)\end{array}$ & $\begin{array}{r}30.15 \\
(5.2)\end{array}$ \\
\hline Achievement & $\begin{array}{r}31.45 \\
(3.3)\end{array}$ & $\begin{array}{r}31.65 \\
(4.0)\end{array}$ & $\begin{array}{r}32.53 \\
(4.0)\end{array}$ & $\begin{array}{r}32.05 \\
(2.8)\end{array}$ & $\begin{array}{r}33.92 \\
(3.0)\end{array}$ & $\begin{array}{r}32.70 \\
(3.7)\end{array}$ & $\begin{array}{r}32.34 \\
(3.5)\end{array}$ & $\begin{array}{r}32.33 \\
(3.3)\end{array}$ \\
\hline Integrity & $\begin{array}{r}29.18 \\
(5.4)\end{array}$ & $\begin{array}{r}30.36 \\
(4.8)\end{array}$ & $\begin{array}{r}28.90 \\
(5.5)\end{array}$ & $\begin{array}{c}29.44 \\
(5.6)\end{array}$ & $\begin{array}{r}30.20 \\
(5.8)\end{array}$ & $\begin{array}{r}29.15 \\
(5.8)\end{array}$ & $\begin{array}{r}27.37 \\
(5.8)\end{array}$ & $\begin{array}{r}29 . \\
(5\end{array}$ \\
\hline
\end{tabular}

Note: Medical/Surgical (M/S); Geriatrics (Ger); Critical Care (CC); Obstetrics (OB); Pediatrics (Ped); Nurse Practitioner/ Clinical Specialist (NP/CS); Special Areas (SP)

Upon rejection of the multivariate statistical hypothesis hypothesis, ANOVAs were performed, using the personal values scales as dependent variables and job interests as the independent variable. Table XXXIV summarizes these ANOVAs.

As can be seen, the statistical hypothesis was not rejected for Creative $(\underline{p}=.285)$ and Integrity $(\underline{p}=.480)$; 
TABLE XXXIV

ANALYSIS OF VARIANCE FOR PERSONAL VALUES BY JOB INTEREST

\begin{tabular}{|c|c|c|c|c|c|c|}
\hline \multirow[b]{2}{*}{ Scale } & \multicolumn{2}{|c|}{ Hypothesis } & \multicolumn{2}{|c|}{ Error } & \multirow{2}{*}{$\underline{E}$} & \multirow{2}{*}{$\mathrm{p}$} \\
\hline & SS & MS & SS & MS & & \\
\hline Intellectual & 282.00 & 40.29 & 5460.62 & 12.64 & 3.187 & .003 \\
\hline Considerate & 180.29 & 25.76 & 4105.89 & 9.50 & 2.709 & .009 \\
\hline Creative & 142.61 & 20.37 & 7164.11 & 16.58 & 1.228 & .285 \\
\hline Recognition & 267.68 & 38.24 & 7868.94 & 18.22 & 2.099 & .042 \\
\hline Artistic & 433.91 & 61.99 & 12187.95 & 28.21 & 2.197 & .034 \\
\hline Achievement & 179.70 & 25.67 & 5065.88 & 11.73 & 2.189 & .034 \\
\hline Integrity & 195.26 & 27.89 & 12914.33 & 29.89 & 0.933 & .480 \\
\hline
\end{tabular}

Note: Hypothesis $\mathrm{df}=7, \mathrm{df}=432$

student nurses with different job interests did not differ significantly on these values. The statistical hypothesis that student nurses with different job interests will not differ in their personal values was rejected for Intellectual $(\underline{p}=.003)$, Considerate $(\underline{p}=.009)$, Recognition $(\underline{p}=.042)$, Artistic $(\underline{p}=.034)$, and Achievement $(\underline{p}=.034)$. Following significant ANOVAs, statistical hypotheses for all pairwise mean comparisons were tested. Scheffe was used at the .10 level as recommended by Scheffe. Although interpretations is based on scheffe's (.10) comparisons, the 
hypothesis were also examined at the .05 level with Scheffe and Tukeyb. (See Table XxxV.)

TABLE XXXV

SIGNIFICANT PAIRWISE MEAN COMPARISONS ON JOB INTEREST FOR PERSONAL VALUES

Value Scheffe (.10) Scheffe (.05) Tukeyb (.05)

Intellectual

$V-I, V-I I$

Considerate V-I

$\mathrm{V}-\mathrm{I}$

V-ALI OTHERS

Achievement

$\mathrm{V}-\mathrm{I}$

Note: Medical/Surgical (I), Geriatric (II), Critical Care (III), Obstetric (IV), Pediatric (V), Mental Health (VI), Nurse Practitioner /Clinical Specialist (VII), and Speciality (VIII)

As can be seen in Table XXXVI, only one significant difference was found for Considerate: the mean for Pediatrics nursing (37.2) was higher than the mean for Medical/Surgical nursing $(34.4)$.

The less conservative Tukeyb approach suggests that other significant differences may exist at the .05 level. The difference noted between the results of Scheffe and Tukeyb rest on the adjustment made by Scheffe for the 28 pairwise mean comparisons being made for each variable. Tukeyb found significant differences on the Intellectual scale between Pediatric and Medical/Surgical nursing, and Pediatrics and Geriatric nursing. Student nurses interested in Pediatrics 
$(\overline{\mathrm{X}}=34.0)$ placed more value on Intellectual than did student nurses interested in Medical/Surgical $(\overline{\mathrm{X}}=31.6)$ and in Geriatric $(\overline{\mathrm{X}}=30.8)$ nursing. Student nurses interested in Pediatrics also placed more value on being Considerate $(\bar{x}=37.2)$ than student nurses interested in all the other job interests ( $\overline{\mathrm{X}} \mathrm{s}$ from 34.4 to 37.2 ). The mean on Pediatrics for Achievement was 33.9 while the mean on Medical/Surgical nursing was 31.4 .

\section{RELATIONSHIP BETWEEN WORK VALUES AND JOB INTERESTS}

Research question eight asked "Do work values differ with job interests?" Interests in Medical/Surgical nursing (161), Critical Care (57), Obstetrical nursing (57), other specialities such as Emergency Room and Operating Room (54), Geriatric nursing (31), Nurse Practitioner/Clinical Specialist combined (35), Mental Health (20), Geriatrics (31), and Pediatrics (25) were the job choices used for the analysis. A total of 440 responses out of 452 were interested in these areas of practice. MANOVA and ANOVA were performed, using the eleven work value scales as dependent variables and job interests as the independent variable. Table XXXVI presents the means and standard deviations for the scales.

MANOVA was performed, using the eleven work value scales as dependent variables and the job interests as the independent variable. The multivariate statistical hypothesis was rejected; Wilks' Lambda, (with $7,432 \underline{\mathrm{df}}$ ), $\underline{\mathrm{F}}=1.89, \underline{\underline{p}}=.001$. 


\section{TABLE XXXVI}

MEANS AND STANDARD DEVIATIONS FOR WORK VALUE SCALES BY JOB INTEREST

\begin{tabular}{|c|c|c|c|c|c|c|c|c|}
\hline & $\mathrm{M} / \mathrm{S}$ & Ger & $\mathrm{CC}$ & $O B$ & Ped & $\mathrm{MH}$ & $\mathrm{NP} / \mathrm{CS}$ & $\mathrm{SP}$ \\
\hline Scale & $\begin{array}{c}\text { Mean } \\
(S D)\end{array}$ & $\begin{array}{c}\text { Mean } \\
\text { (SD) }\end{array}$ & $\begin{array}{c}\text { Mean } \\
\text { (SD) }\end{array}$ & $\begin{array}{c}\text { Mean } \\
(S D)\end{array}$ & $\begin{array}{c}\text { Mean } \\
(\mathrm{SD})\end{array}$ & $\begin{array}{c}\text { Mean } \\
(S D)\end{array}$ & $\begin{array}{c}\text { Mean } \\
\text { (SD) }\end{array}$ & $\begin{array}{c}\text { Mean } \\
\text { (SD) }\end{array}$ \\
\hline Altruism & $\begin{array}{c}30.94 \\
(4.4)\end{array}$ & $\begin{array}{c}31.07 \\
(4.9)\end{array}$ & $\begin{array}{c}31.28 \\
(3.8)\end{array}$ & $\begin{array}{l}30.91 \\
(5.2)\end{array}$ & $\begin{array}{c}32.92 \\
(3.1)\end{array}$ & $\begin{array}{l}31.80 \\
(3.4)\end{array}$ & $\begin{array}{c}30.97 \\
(3.8)\end{array}$ & $\begin{array}{c}30.70 \\
(4.1)\end{array}$ \\
\hline obj. Orient. & $\begin{array}{r}19.91 \\
(6.4)\end{array}$ & $\begin{array}{r}20.87 \\
(5.6)\end{array}$ & $\begin{array}{r}22.19 \\
(6.2)\end{array}$ & $\begin{array}{r}18.38 \\
(6.8)\end{array}$ & $\begin{array}{r}22.76 \\
(6.4)\end{array}$ & $\begin{array}{r}16.70 \\
(6.5)\end{array}$ & $\begin{array}{c}17.942 \\
(6.2)^{2}\end{array}$ & $\begin{array}{r}22.91 \\
(6.4)\end{array}$ \\
\hline Security & $\begin{array}{c}28.04 \\
(6.1)\end{array}$ & $\begin{array}{l}27.77 \\
(7.4)\end{array}$ & $\begin{array}{r}28.23 \\
(6.4)\end{array}$ & $\begin{array}{c}28.21 \\
(5.7)\end{array}$ & $\begin{array}{c}29.48 \\
(6.1)\end{array}$ & $\begin{array}{c}28.30 \\
(6.5)\end{array}$ & $\begin{array}{c}24.51 \\
(6.4)\end{array}$ & $\begin{array}{c}28.63 \\
(5.9)\end{array}$ \\
\hline Control & $\begin{array}{c}18.98 \\
(6.7)\end{array}$ & $\begin{array}{c}21.42 \\
(6.4)\end{array}$ & $\begin{array}{c}21.67 \\
(7.0)\end{array}$ & $\begin{array}{c}21.26 \\
(6.4)\end{array}$ & $\begin{array}{c}21.08 \\
(8.2)\end{array}$ & $\begin{array}{c}20.40 \\
(5.4)\end{array}$ & $\begin{array}{c}17.37 \\
(5.8)\end{array}$ & $\begin{array}{c}18.96 \\
(7.0)\end{array}$ \\
\hline Self Real. & $\begin{array}{l}32.18 \\
(3.4)\end{array}$ & $\begin{array}{c}31.90 \\
(3.9)\end{array}$ & $\begin{array}{l}32.72 \\
(3.1)\end{array}$ & $\begin{array}{l}32.14 \\
(2.9)\end{array}$ & $\begin{array}{c}33.52 \\
(2.3)\end{array}$ & $\begin{array}{c}31.00 \\
(3.8)\end{array}$ & $\begin{array}{c}32.89 \\
(2.5)\end{array}$ & $\begin{array}{l}32.02 \\
(3.1)\end{array}$ \\
\hline Independence & $\begin{array}{c}25.66 \\
(5.3)\end{array}$ & $\begin{array}{c}26.84 \\
(4.8)\end{array}$ & $\begin{array}{c}27.11 \\
(5.8)\end{array}$ & $\begin{array}{c}26.18 \\
(5.4)\end{array}$ & $\begin{array}{c}27.64 \\
(5.7)\end{array}$ & $\begin{array}{r}27.85 \\
(3.6)\end{array}$ & $\begin{array}{c}27.89 \\
(5.6)\end{array}$ & $\begin{array}{c}26.41 \\
(5.4)\end{array}$ \\
\hline Money & $\begin{array}{c}27.58 \\
(7.2)\end{array}$ & $\begin{array}{c}27.81 \\
(6.2)\end{array}$ & $\begin{array}{c}29.54 \\
(5.8)\end{array}$ & $\begin{array}{l}27.42 \\
(7.0)\end{array}$ & $\begin{array}{c}29.16 \\
(4.6)\end{array}$ & $\begin{array}{c}27.05 \\
(7.3)\end{array}$ & $\begin{array}{c}24.94 \\
(6.4)\end{array}$ & $\begin{array}{l}27.57 \\
(7.4)\end{array}$ \\
\hline Task Sat. & $\begin{array}{l}33.17 \\
(2.7)\end{array}$ & $\begin{array}{l}32.90 \\
(3.7)\end{array}$ & $\begin{array}{l}33.30 \\
(2.6)\end{array}$ & $\begin{array}{l}33.58 \\
(2.6)\end{array}$ & $\begin{array}{c}34.52 \\
(0.9)\end{array}$ & $\begin{array}{c}33.15 \\
(3.0)\end{array}$ & $\begin{array}{c}33.46 \\
(1.9)\end{array}$ & $\begin{array}{l}33.39 \\
(2.3)\end{array}$ \\
\hline Solitude & $\begin{array}{l}17.86 \\
(5.9)\end{array}$ & $\begin{array}{l}19.87 \\
(6.4)\end{array}$ & $\begin{array}{c}18.12 \\
(6.9)\end{array}$ & $\begin{array}{c}17.70 \\
(5.6)\end{array}$ & $\begin{array}{c}19.36 \\
(6.9)\end{array}$ & $\begin{array}{c}17.35 \\
(5.8)\end{array}$ & $\begin{array}{c}17.43 \\
(5.9)\end{array}$ & $\begin{array}{c}17.39 \\
(5.3)\end{array}$ \\
\hline I/D Orient. & $\begin{array}{c}25.22 \\
(5.0)\end{array}$ & $\begin{array}{c}26.10 \\
(4.7)\end{array}$ & $\begin{array}{c}26.49 \\
(4.9)\end{array}$ & $\begin{array}{c}24.90 \\
(5.1)\end{array}$ & $\begin{array}{c}27.44 \\
(6.1)\end{array}$ & $\begin{array}{c}25.05 \\
(6.0)\end{array}$ & $\begin{array}{c}26.63 \\
(5.2)\end{array}$ & $\begin{array}{c}25.78 \\
(5.1)\end{array}$ \\
\hline Prestige & $\begin{array}{c}17.90 \\
(6.6)\end{array}$ & $\begin{array}{c}19.90 \\
(6.4)\end{array}$ & $\begin{array}{c}20.58 \\
(7.0)\end{array}$ & $\begin{array}{c}18.90 \\
(6.5)\end{array}$ & $\begin{array}{c}20.08 \\
(8.5)\end{array}$ & $\begin{array}{c}20.15 \\
(7.5)\end{array}$ & $\begin{array}{c}18.06 \\
(6.0)\end{array}$ & $\begin{array}{c}19.06 \\
(7.3)\end{array}$ \\
\hline $\begin{array}{l}\text { Note: Objec } \\
\text { (Self Real) } \\
\text { Orientation }\end{array}$ & $\begin{array}{l}\text { t Ori } \\
\text { Tas } \\
\text { I/D Or }\end{array}$ & Sat & $\mathrm{n} \quad \mathrm{Ob}$ & $\begin{array}{l}\text { j. Ori } \\
\text { ion }\end{array}$ & $\begin{array}{l}\text { ient); } \\
\text { Task }\end{array}$ & $\begin{array}{c}\text { Self } \\
\text { Sat) } ;\end{array}$ & $\begin{array}{l}\text { Realiz } \\
\text { Ideas }\end{array}$ & $\begin{array}{l}\text { ation } \\
\text { /Data }\end{array}$ \\
\hline
\end{tabular}


Again ANOVAs were performed, using the OWVI scales as dependent variables and job interests as the independent variable. The ANOVAs are presented in Table XXXVII.

TABLE XXXVII

ANALYSIS OF VARIANCE FOR WORK VALUES BY JOB INTEREST

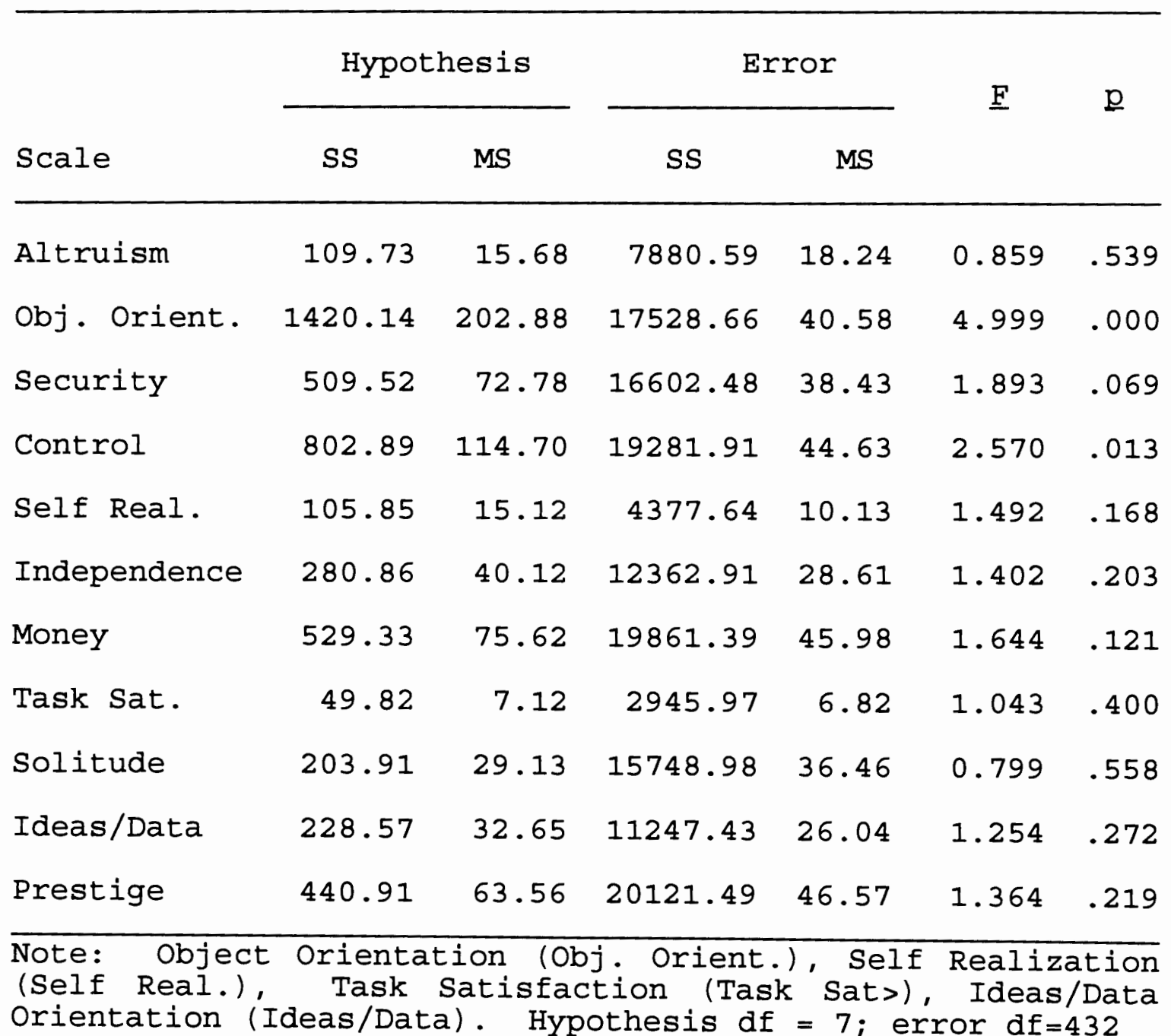

The statistical hypothesis was not rejected for Altruism $(\underline{p}=.539)$, Security $(\underline{p}=.069)$, Self Realization $(\underline{\underline{p}}=.168)$, Independence $(\underline{p}=.203)$, Money $(\underline{p}=.121$ ) Task Satisfaction ( $\underline{p}$ 
$=.400)$, Solitude $(\underline{p}=.588)$, Ideas/Data Orientation $(\underline{p}=$ $.272)$, and Prestige $(\underline{p}=.219)$. Work values did not differ significantly with job interests on these scales. The statistical hypothesis was rejected for two scales: Object Orientation $(\underline{p}<.001)$ and Control $(\underline{p}=.026)$.

Following significant ANOVAs, the statistical hypotheses for all pairwise mean comparisons were tested. Scheffe was used at the .10 level as recommended by Scheffe. Although the interpretation is based on the Scheffe (.10) comparisons, the hypotheses were also examined at the .05 level with Scheffe and Tukeyb. (See Table XXXVIII.)

TABLE XXXVIII

SIGNIFICANT PAIRWISE MEAN COMPARISONS ON JOB INTERESTS FOR WORK VALUES

Value Scheffe (.10) Scheffe (.05) Tukeyb (.05)

$\begin{array}{lll}\text { Object Orientation } & \text { VII-IV } & \text { III-IV, III-VI } \\ & \text { VII-VI } & \text { III-VIII, } \\ & \text { VII-VIII } & \text { VII-I, VII-IV } \\ & & \text { VII-VI,VII-III } \\ & \text { V-VI }\end{array}$

Note: Medical/Surgical (I); Geriatrics (II); Critical Care (III); Obstetrics (IV); Pediatrics (V); Mental Health (VI); Speciality, Operating Room/Emergency Room (VII); Nurse Practitioner/Clinical Specialist (VIII)

Using the .10 level of significance with Scheffe's pairwise mean comparisons, three significant differences were found on the object orientation value. The mean for 
Speciality areas (22.9), such as the emergency room or operating room, was higher than the mean for Obstetrics (18.4), Mental Health (16.7), and Nurse Practitioner/Clinical Specialist (17.9).

Further examination of the means for object Orientation, using the less vigorous Tukeyb statistic, suggests that the mean for Speciality areas was also greater than the mean for Medical/Surgical nursing (19.9). Other differences were also found. The mean for Critical Care nursing (22.2) was greater than the mean for Obstetrical nursing (18.4), Mental Health (16.7) and Nurse Practitioner/Clinical Specialist (17.9). Finally, the mean for Pediatric nursing (22.8) was higher than the mean for Mental Health nursing (16.7). Student nurses interested in working in speciality areas such as the operating room and emergency room value being involved with handling, operating, and changing the appearance of things more than student nurses interested in Obstetrics, Mental Health, and the Nurse Practitioner/Clinical Specialist role.

\section{ANALYSIS OF PERSONAI, VALUES BY AGE GROUP}

In this sample, ages ranged from 20 to 54 years. Therefore, analyses of personal values by age were performed on age groups (research question nine). Subjects were placed in three groups. Those between the ages of 20 and 29 were placed in one group; those between the ages of 30 and 39 were placed 
in a second group, and those between the ages of 40 and 54 were placed in a third group. The first grouping had 144 students. The second grouping had 173 students, and the third grouping had 130 students in the sample. Ages of five people were unknown. Table XXXIX presents the means and standard deviations for the personal values by age groups.

TABLE XXXIX

MEANS AND STANDARD DEVIATIONS OF PERSONAL VALUES BY AGE GROUP

\begin{tabular}{|c|c|c|c|c|c|c|}
\hline \multirow{2}{*}{ scale } & \multicolumn{2}{|c|}{$\begin{array}{l}\text { Group I } \\
(20-29)\end{array}$} & \multicolumn{2}{|c|}{$\begin{array}{l}\text { Group II } \\
(30-39)\end{array}$} & \multicolumn{2}{|c|}{$\begin{array}{l}\text { Group III } \\
(40-54)\end{array}$} \\
\hline & Mean & $\mathrm{SD}$ & Mean & $S D$ & Mean & $S D$ \\
\hline Intellectual & 31.45 & 3.6 & 32.27 & 3.5 & 32.73 & 3.6 \\
\hline Considerate & 34.58 & 3.4 & 34.71 & 2.9 & 34.70 & 3.0 \\
\hline Creative & 30.30 & 4.1 & 30.65 & 4.1 & 31.25 & 3.9 \\
\hline Recognition & 32.16 & 4.4 & 31.16 & 4.1 & 30.67 & 4.2 \\
\hline Artistic & 28.80 & 5.6 & 29.91 & 5.1 & 30.16 & 5.2 \\
\hline Achievement & 32.13 & 3.6 & 32.04 & 3.2 & 32.10 & 3.6 \\
\hline Integrity & 29.08 & 5.8 & 29.46 & 5.2 & 29.00 & 5.3 \\
\hline
\end{tabular}

MANOVA, using the seven scales on the PLV as dependent variables and age groups as the independent variable was performed. The multivariate statistical hypothesis was rejected; using Wilks' Lambda (with 2, $449 \underline{\text { df }), ~} \underline{F}=1.66$, $\underline{p}=.003$. 
Following rejection of the multivariate statistical hypothesis, ANOVAs were performed, using the seven PLV scales as dependent variables and age groups as the independent variable. (See Table Xxxx.)

TABLE XXXX

ANALYSIS OF VARIANCE OF PERSONAL VALUES BY AGE GROUP

\begin{tabular}{|c|c|c|c|c|c|c|}
\hline \multirow{2}{*}{ Scale } & \multicolumn{2}{|c|}{ Hypothesis } & \multicolumn{2}{|c|}{ Error } & \multirow{2}{*}{$\underline{F}$} & \multirow{2}{*}{$\underline{p}$} \\
\hline & SS & MS & SS & MS & & \\
\hline Intellectual & 119.35 & 59.68 & 5738.68 & 12.78 & 4.67 & .010 \\
\hline Considerate & 1.42 & 0.71 & 4343.47 & 9.67 & 0.07 & .929 \\
\hline Creative & 63.12 & 31.56 & 7401.91 & 16.49 & 1.91 & .149 \\
\hline Recognition & 164.02 & 82.01 & 8141.05 & 18.13 & 4.52 & .011 \\
\hline Artistic & 151.89 & 75.94 & 12640.66 & 28.15 & 2.70 & .068 \\
\hline Achievement & 0.73 & 0.36 & 5353.73 & 11.92 & 0.03 & .970 \\
\hline Integrity & 18.32 & 9.16 & 13290.95 & 29.60 & 0.31 & .734 \\
\hline
\end{tabular}

The statistical hypothesis that student nurses in different age groups will not differ in their personal values was not rejected for Considerate $(\underline{p}=.929)$, Creative ( $\underline{p}=$ .149), Artistic $(\underline{\underline{p}}=.068)$, Achievement $(\underline{\underline{p}}=.970)$, and Integrity $(\underline{\underline{p}}=.734)$. The statistical hypothesis was rejected for Intellectual $(\underline{p}=.010)$ and Recognition ( $\underline{p} .011)$.

The statistical hypotheses for each pairwise mean comparison were tested; Scheffe was used at the .10 level as 
recommended by Scheffe. Interpretation was based on Scheffe (.10); the hypotheses were also examined at the .05 level with Scheffe and Tukeyb. Using Scheffe (.10), significant difference in the pairwise mean comparisons were found on both variables. The 40-54 age group $(\overline{\mathrm{x}}=32.7)$ placed more value on Intellectual than did the 20-29 age group $(\bar{X}=31.5)$. The younger group $(\overline{\mathrm{X}}=32.2)$ placed more value on Recognition than did the oldest age group $(\overline{\mathrm{X}}=30.7)$. See Table XXXXI.

TABLE XXXXI

SIGNIFICANT PAIRWISE MEAN COMPARISONS BY AGE GROUP FOR PERSONAL VALUES

\begin{tabular}{lccc} 
Value & Scheffe (.10) & Scheffe (.05) & Tukeyb \\
\hline Intellectual & I-III & I-III & I-III \\
Recognition & I-III & I-III & I-III
\end{tabular}

Note: Age 20-29 (I); Age 30-39 (II); Age 40-54 (III)

ANALYSIS OF WORK VALUES BY AGE GROUP

Research question ten was "Does age influence nursing students work values? Again, the student nurses were placed in three age groups: ages 20 to 29 were in one group, ages 30 to 39 were in a second group, and ages 40 to 54 were in a third group. Table XXXXII presents the means and standard deviations of the work values for these subjects. 
TABLE XXXXII

MEANS AND STANDARD DEVIATIONS FOR WORK VALUES BY AGE GROUP

\begin{tabular}{|c|c|c|c|c|c|c|}
\hline \multirow{2}{*}{ Scale } & \multicolumn{2}{|c|}{$\begin{array}{l}\text { Group I } \\
(20-29)\end{array}$} & \multicolumn{2}{|c|}{$\begin{array}{l}\text { Group II } \\
(30-39)\end{array}$} & \multicolumn{2}{|c|}{$\begin{array}{l}\text { Group III } \\
(40-54)\end{array}$} \\
\hline & Mean & SD & Mean & SD & Mean & $S D$ \\
\hline Altruism & 31.26 & 4.6 & 30.97 & 4.2 & 30.97 & 4.1 \\
\hline obj. Orient. & 20.92 & 6.4 & 19.67 & 6.3 & 20.14 & 7.1 \\
\hline Security & 28.91 & 6.1 & 27.62 & 6.2 & 26.59 & 6.7 \\
\hline Control & 20.96 & 7.2 & 18.94 & 6.1 & 19.69 & 6.7 \\
\hline Self Real. & 32.48 & 3.2 & 32.08 & 3.3 & 32.17 & 3.2 \\
\hline Independence & 26.34 & 5.5 & 26.23 & 5.3 & 26.80 & 5.3 \\
\hline Money & 28.31 & 6.4 & 28.26 & 6.2 & 25.86 & 7.7 \\
\hline Task Sat. & 33.53 & 2.4 & 33.30 & 2.7 & 33.09 & 2.8 \\
\hline Solitude & 18.60 & 6.5 & 17.33 & 5.6 & 17.85 & 6.0 \\
\hline Ideas/Data & 25.48 & 5.1 & 25.72 & 5.1 & 25.95 & 5.3 \\
\hline Prestige & 20.89 & 7.3 & 17.81 & 6.3 & 17.89 & 6.6 \\
\hline
\end{tabular}

Note: Object Orientation (Obj. Orient.), Self Realization (Self Real.), Task Satisfaction (Task Sat.), Ideas/Data Orientation (Ideas/Data)

MANOVA was performed, using the eleven work value scales as dependent variables and age groups as the independent variable. The multivariate statistical hypothesis was rejected; using Wilks' Lambda (with 2, $449 \underline{\text { df }), F=1.89, ~} \underline{p}<$ .001 . 
Upon rejection of the multivariate statistical

hypothesis, ANOVAs were performed. The work value scales were used as dependent variables and age groups were used as the independent variable. See Table XXXXIII.

TABLE XXXXIII

ANALYSIS OF VARIANCE OF WORK VALUES BY AGE GROUP

\begin{tabular}{|c|c|c|c|c|c|c|}
\hline \multirow{2}{*}{$\begin{array}{l}\text { Scale } \\
\text { Scale }\end{array}$} & \multicolumn{2}{|c|}{ Hypothesis } & \multicolumn{2}{|c|}{ Error } & \multirow{2}{*}{$\underline{\mathbf{E}}$} & \multirow{2}{*}{$\underline{p}$} \\
\hline & SS & MS & SS & MS & & \\
\hline Altruism & 8.30 & 4.15 & 8348.58 & 18.59 & 0.223 & .800 \\
\hline Obj. Orient. & 127.40 & 63.70 & 19267.92 & 42.91 & 1.484 & .228 \\
\hline Security & 378.41 & 189.21 & 17773.84 & 39.59 & 4.779 & .009 \\
\hline Control & 330.73 & 165.37 & 20143.75 & 44.86 & 3.686 & .026 \\
\hline Self Real. & 14.16 & 7.08 & 4665.51 & 10.39 & 0.681 & .506 \\
\hline Independence & 25.96 & 12.98 & 13008.77 & 28.97 & 0.448 & .639 \\
\hline Money & 544.48 & 272.24 & 20540.98 & 45.75 & 5.950 & .003 \\
\hline Task sat. & 14.27 & 7.14 & 3099.49 & 6.90 & 1.034 & .357 \\
\hline Solitude & 129.14 & 64.57 & 16104.98 & 35.87 & 1.800 & .166 \\
\hline Ideas/Data & 15.88 & 7.94 & 11837.57 & 26.36 & 0.301 & .740 \\
\hline Prestige & 934.31 & 467.15 & 20357.46 & 45.34 & 10.303 & .000 \\
\hline
\end{tabular}

Note: Hypothesis $\mathrm{df}=2$, Error $\mathrm{df}=449$

Object Orientation (Obj. Orient.), Self Realization (Self Real.), Task Satisfaction (Task Sat.), Ideas/Data Orientation (Ideas/Data)

The statistical hypothesis that age groups of student nurses will not differ in their work values was not rejected 
for Altruism ( $\underline{p}=.800)$, Object Orientation $(\underline{p}=.228)$, self Realization $(\underline{p}=.506)$, Independence $(\underline{p}=.639)$, Task Satisfaction $(\underline{p}=.357)$, Solitude $(\underline{p}=.166)$, and Ideas/Data Orientation $(\underline{p}=.740)$. The statistical hypothesis was rejected for Security $(\underline{p}=.009)$, Control $(\underline{p}=.026)$, Money ( $\underline{p}$ $=.003)$, and Prestige $(\underline{p}<.001$.

Following significant ANOVAs, the statistical hypotheses for all pairwise comparisons were examined. Scheffe was used at the .10 level as recommended by Scheffe. Interpretation is based on the Scheffe (.10) comparison; the hypotheses were also examined at the .05 level with Scheffe and Tukeyb (Table XXXXIV) .

TABLE XXXXIV

SIGNIFICANT PAIRWISE MEAN COMPARISONS ON AGE GROUP FOR WORK VALUES

\begin{tabular}{lccc} 
Values & Scheffe (.10) & Scheffe (.05) & Tukeyb (.05) \\
\hline Security & I-III & I-III & I-III \\
Control & I-II & I-II & I-II \\
Money & I-II & I-III & I-III \\
& II-III & II-III & II-III \\
Prestige & I-II & I-II & I-II \\
& I-III & I-III & I-III
\end{tabular}

Note: Age 20-29 (I); Age 30-39 (II); Age 40-54 (III)

The mean for Security was significantly higher for the 20-29 year age group $(\overline{\mathrm{X}}=28.9)$ than the 40-54 year age 
group $(\bar{X}=26.6)$. The mean for control was significantly higher for the 20 to 29 year age group $(\bar{X}=21.0)$ than the 30 to 39 year age group $(\bar{x}=18.9)$. Furthermore, the mean for Money was significantly higher for the 20 to 2.9 year age group $(\bar{X}=28.3)$ than for the 40 to 54 year age group $(\bar{X}=25.9)$. The value for Prestige was also significantly higher for the 20 to 29 year age group $(\overline{\mathrm{X}}=20.9)$ than the other age groups $(\bar{X}=17.8, \bar{X}=17.9)$, respectively. Thus, on these four variables, the youngest age group placed significantly higher value on Security, Control, Money, and Prestige than did one or both of the other groups. The 40-54 age group placed less value on Money $(\bar{X}=25.9)$ than did either of the two younger groups (Group II, $\bar{X}=28.3$; Group $I, \bar{X}=28.3$ ).

\section{RELATIONSHIPS BETWEEN PERSONAL VALUES AND WORK VALUES}

Question eleven asked "What is the relationship between the personal values and work values of the students?" To answer this question, correlation coefficients were calculated, using each of the personal and work value scales. Correlation Coefficients with probabijities are summarized in Table XXXxV.

Table XXXXV shows that five OWVI and PLV scales had correlations above .40. The correlations of Ideas/Data Orientation with Intellectual, Creative, and Achievement were $.51, .60$, and .41 , respectively. The correlation of Prestige with Recognition was .51; the correlation of Altruism with 
TABLE XXXXV

CORRELATION COEFFICIENTS WITH PROBABILITIES

BETWEEN PERSONAL VALUES AND WORK VALUES

\section{PLV Scales}

OWVI Scales

Int Cons $\mathrm{Cr}$ Rec Art Ach Integ

Altruism

$\begin{array}{lllllllll} & .244 & .488 & .259 & .242 & .020 & .376 & .169\end{array}$

p $\quad .000 \quad .000 \quad .000 \quad .000 \quad .666 \quad .000 \quad .000$

Object

Orientation

$\begin{array}{llllllllll}\text { r } & .239 & .064 & .292 & .083 & .242 & .174 & -.021\end{array}$

Security

$\begin{array}{llllllll}\mathrm{p} & .000 & .172 & .000 & .078 & .000 & .000 & .660\end{array}$

$\begin{array}{lllllllll}r & .042 & .304 & .098 & .174 & -.024 & .188 & .123\end{array}$

Control

$\begin{array}{lllllllll}r & .160 & .137 & .302 & .320 & -.007 & .389 & -.089\end{array}$

p $\quad .001 \quad .003 \quad .000 \quad .000 \quad .880 \quad .000 \quad .059$

Self Realization

$\begin{array}{lllllllll}r & .337 & .373 & .282 & .219 & .057 & .364 & .086\end{array}$

$\begin{array}{llllllll}\mathrm{p} & .000 & .000 & .000 & .000 & .226 & .000 & .067\end{array}$

Independence

$\begin{array}{lllllllll} & .200 & .098 & .197 & .156 & .062 & .214 & -.136\end{array}$

Money

$\begin{array}{llllllll}\mathrm{p} & .000 & .038 & .000 & .001 & .004 & .000 & .004\end{array}$

Mon

$\begin{array}{lllllllll} & .104 & .132 & .124 & .212 & -.002 & .149 & -.046\end{array}$

$\begin{array}{llllllll}\mathrm{p} & .026 & .005 & .008 & .000 & .968 & .001 & .332\end{array}$

$\begin{array}{lllllllll}\text { Task Satisfaction } & r & .199 & .308 & .150 & .181 & .015 & .234 & .012 \\ & p & .000 & .000 & .001 & .000 & .751 & .000 & .792\end{array}$

Solitude

r $\quad .056-.042 \quad .146 \quad .068 \quad .016 \quad .115-.099$

p $\quad .235 \quad .377 \quad .002 \quad .148 \quad .737 \quad .014 \quad .036$

Ideas/Data

$\begin{array}{llllllll}r & .510 & .204 & .599 & .275 & .236 & .415 & .035\end{array}$

orientation

p $\quad .000 \quad .000 \quad .000 \quad .000 \quad .000 \quad .000 \quad .454$

Prestige

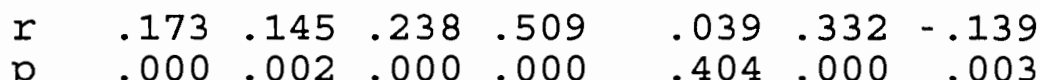

Note scale definitions: Intellectual (Int); Considerate (Cons); Creative (Cr); Recognition (Rec); Artistic (Art); Achievement (Ach); Integrity (Integ). 
Considerate was .49 . The probability for each of the correlations was less than .001.

Ten of the correlations between the OWVI subscales and the PLV subscales were between .30 and .39. These included the correlations between Altruism and Achievement (.38), Security and Considerate (.30), Control and Creative (.30), Control and Recognition (.32), Control and Achievement (.39), Self Realization and Intellectual (.34), Self Realization and Considerate (.37), Self Realization and Achievement (.36), Task Satisfaction and Considerate (.31), and Prestige and Achievement (.33). The probability for each of these correlations was less than .001 .

Eighteen correlations were between .20 and .29 . Correlations of Intellectual with Altruism, Object Orientation, Independence, and Task Satisfaction were $.24, .24, .20$, and .20, respectively. The correlation of Considerate with Ideas/Data Orientation was .20 . The correlation of being Creative with Altruism, Object Orientation, Self Realization, Independence, and Prestige was $.26, .29, .28, .20$, and .24 respectively. Correlations of Recognition with Altruism, self Realization, Money, and Ideas/Data Orientation were .24, .22, $.21, .27$, respectively. The correlation of Artistic with object Orientation and Ideas/Data Orientation were the same, .24. The correlation between Achievement and Independence was .21 while the correlation between Achievement and Task Satisfaction was .23. All probabilities were less than .001. 
Twenty correlations were between .10 and .19. The correlation of Altruism with Integrity was .17; probability was less than .001. The correlation of object Orientation with Achievement was . 17; probability was less than .000. The correlations for security with four of the PLV scales were Creative .10 ( $\mathrm{p}=.037)$, Recognition $.17(\underline{\mathrm{p}}=.001)$, Achievement .18 $(\underline{\underline{p}}=.001)$, and Integrity .12 ( $\underline{\mathrm{p}}=.009)$. Correlations of Control with Intellectual and Considerate were $.16(\underline{p}=.001)$ and $.14(\underline{p}=.003)$, respectively. The correlation of Independence with Considerate was .10 ( $\underline{p}=$ $.038)$, and with Recognition .16 ( $\mathrm{p}=.001)$. Four personal values on the Profile of Life Values, Intellectual, Considerate, Creative, and Achievement correlated with Money on the work value scales; correlation coefficients were.10, $.13, .12$, and .15, respectively; probabilities were .026, $.005, .008$, and .001 , respectively. The correlation of Task Satisfaction with Creative was .15 $(\underline{p}=.001)$; the correlation of Task Satisfaction with Recognition was .18 ( $p=.001)$. The correlation of Solitude with Creative was . 15; probability was .002 . The correlation of Solitude with Achievement was .12; probability was .014. The correlation of Prestige with Intellectual was $.17(\underline{\mathrm{g}}=.001)$, and with Considerate .15 $(\underline{p}=.002)$.

Ten negative correlations occurred: three were significant. Significant negative correlations occurred between Integrity on the PLV scale and Independence $(-.14$, 으 
$=.004)$, Solitude $(-.10, \underline{p}=.036)$, and Prestige $(-.14, \underline{p}=$ $.003)$.

Summary of Statistically Significant Correlations

Of the 77 coefficients, 58 were significant at the .05 criterion level; 39 correlations had probabilities of less than .001. Four correlations were at the .001 level of significance; eight correlations were between the .002 and .01 level of significance; and five correlations were between .014 and .038 level of significance.

With 58 of the 77 statistical hypotheses being rejected, statistical Hypothesis VII was viewed as rejected. Work values and personal values showed significant correlations between many of the subscales on the Lhio Work Value Inventory and the profile of Life values. This included the following: Intellectual with Altruism, object Orientation, Control, Self Realization, Independence, Money, Task Satisfaction, Idea/Data Orientation, and Prestige; Considerate with Altruism, Security, Control, Self Realization, Independence, Money, Task Satisfaction, Idea/Data Orientation, and Prestige; Creative with all subscales on the work value scales; Recognition with all subscales on the work values scales except object Orientation and Solitude; Achievement with all subscales on the work values; Artistic with Object Orientation and Idea/ Data Orientation; Integrity with Altruism, Security, Independence, Idea/Data Orientation, and Prestige. The 
personal value scales showing the least correlation to the work value scales were Artistic and Integrity. The statistical hypotheses were not rejected for those correlations where the probability was greater than .05 level of significance.

RELATIONSHIP BETWEEN EDUCATIONAL PREPARATION AND JOB INTEREST

Question twelve, the last research question was "Are educational preparation and job interests independent?" Chisquare was used to examine this relationship. In the sample were 43 students (9.5\%) who were enrolled in a Graduate Degree program, 143 students (31.6\%) who were enrolled in Baccalaureate Degree programs, and 266 students (59\%) who were enrolled in Associate Degree nursing programs.

The most frequent job interest expressed by the Graduate Degree students was that of a Nurse Practitioner $(44 \%)$ and Education (14\%). Of the Graduate students, $65 \%$ were in education programs that prepared the student for the Nurse Practitioner or Clinical Specialist role. Baccalaureate students expressed more interest in Medical/Surgical nursing (32\%), Critical Care (18\%), Obstetrics (15\%), and Speciality areas (13\%) such as nursing in the Emergency Room and Operating Room. Associate Degree nursing students expressed more interest in Medical/Surgical nursing (43\%), Obstetrics (14\%), Speciality areas (13\%), Critical Care (10\%), and Geriatrics (9\%). Table XXXXVI presents this data. 
TABLE XXXXVI

FREQUENCY OF EMPLOYMENT INTERESTS BY EDUCATIONAL PREPARATION

Employment Interests

Prog Total

M/S Ger CC OB Ped MH NP CS Adm Ed Sp

$\begin{array}{ccccccccccccc}\mathrm{GR} & 0 & 4 & 4 & 0 & 0 & 4 & 19 & 3 & 3 & 6 & 0 & 43 \\ \% & 0.0 & 9.3 & 9.3 & 0.0 & 0.0 & 9.3 & 44.1 & 7.0 & 7.0 & 14.0 & 0.0 & 9.5\end{array}$

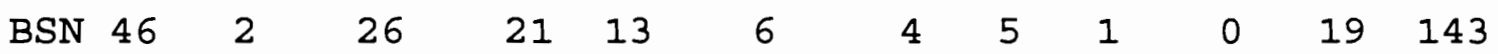

$\begin{array}{llllllllllllll}\circ & 32.4 & 1.4 & 18.2 & 14.7 & 9.0 & 4.2 & 2.8 & 3.5 & 0.7 & 0.0 & 13.3 & 31.6\end{array}$

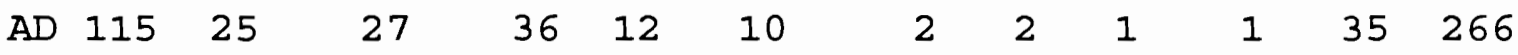

$\begin{array}{llllllllllllll}\circ & 43.2 & 9.4 & 10.1 & 13.5 & 4.5 & 3.7 & 0.8 & 0.8 & 0.4 & 0.4 & 13.3 & 58.9\end{array}$

$\begin{array}{llllllllllll}161 & 31 & 57 & 57 & 25 & 20 & 25 & 10 & 5 & 7 & 54 & 452\end{array}$

$\begin{array}{llllllllllllll}\circ & 35.6 & 6.9 & 12.6 & 12.6 & 5.5 & 4.4 & 5.5 & 2.2 & 1.1 & 1.5 & 11.9 & 100\end{array}$

Note: Frequency (f), Medical/Surgical (M/S), Ceriatrics (Ger), Critical Care (CC), Obstetrics (OB), Pediatrics (Ped), Mental Health (MH), Nurse Practitioner/Clinical Specialist (NP/CS), Administration (Adm), Education (Ed), Special Areas (Sp), Program (Prog), Graduate (Grad), Total (T)

A cursory study of Table XXXXVI suggests that nursing students in different programs may have different employment interests, i. e., that there may be a relationship between educational preparation and employment interests.

Therefore, using educational program and employment interests as independent variables, a Chi-Square test of 
independence was performed on the data in Table XXXXVI. Because $36 \%$ of the cells had expected frequencies less than five, Nurse Practitioners and Clinical Specialist were combined; Administration and Education were excluded in the analysis.

The statistical hypothesis that job interests and educational preparation are independent, was rejected $($ Chi-Square $=202.10$; with 14 df,$\underline{p}<.001)$. Caution must be exercised in interpreting this finding because $29 \%$ of the cells had expected frequencies less than five.

Because there was a relatively low number of students in graduate programs (43), an excessive number of cells with expected frequencies less than five occurred. A Chi-Square test of independence was repeated, using two levels of educational preparation (Baccalaureate and Associate Degree) as one variable and employment interests as the other. With only three students showing interest in Administration and Education, these categories were eliminated from this analysis. Nurse Practitioners and Clinical Specialist employment interests were combined. This resulted in only one cell (6\%) having an expected frequency less than five. (See Table XXXXVII.)

The statistical hypothesis that educational preparation and job interests were independent was rejected (Chi-Square $=$ 26.57 ; with 7 df, $\underline{p}<.001$ ). Baccalaureate Degree students differed from Associate Degree students on several employment 
TABLE XXXXVII

FREQUENCY OF EMPLOYMENT INTERESTS BY ASSOCIATE AND BACCALUAREATE DEGREE STUDENTS

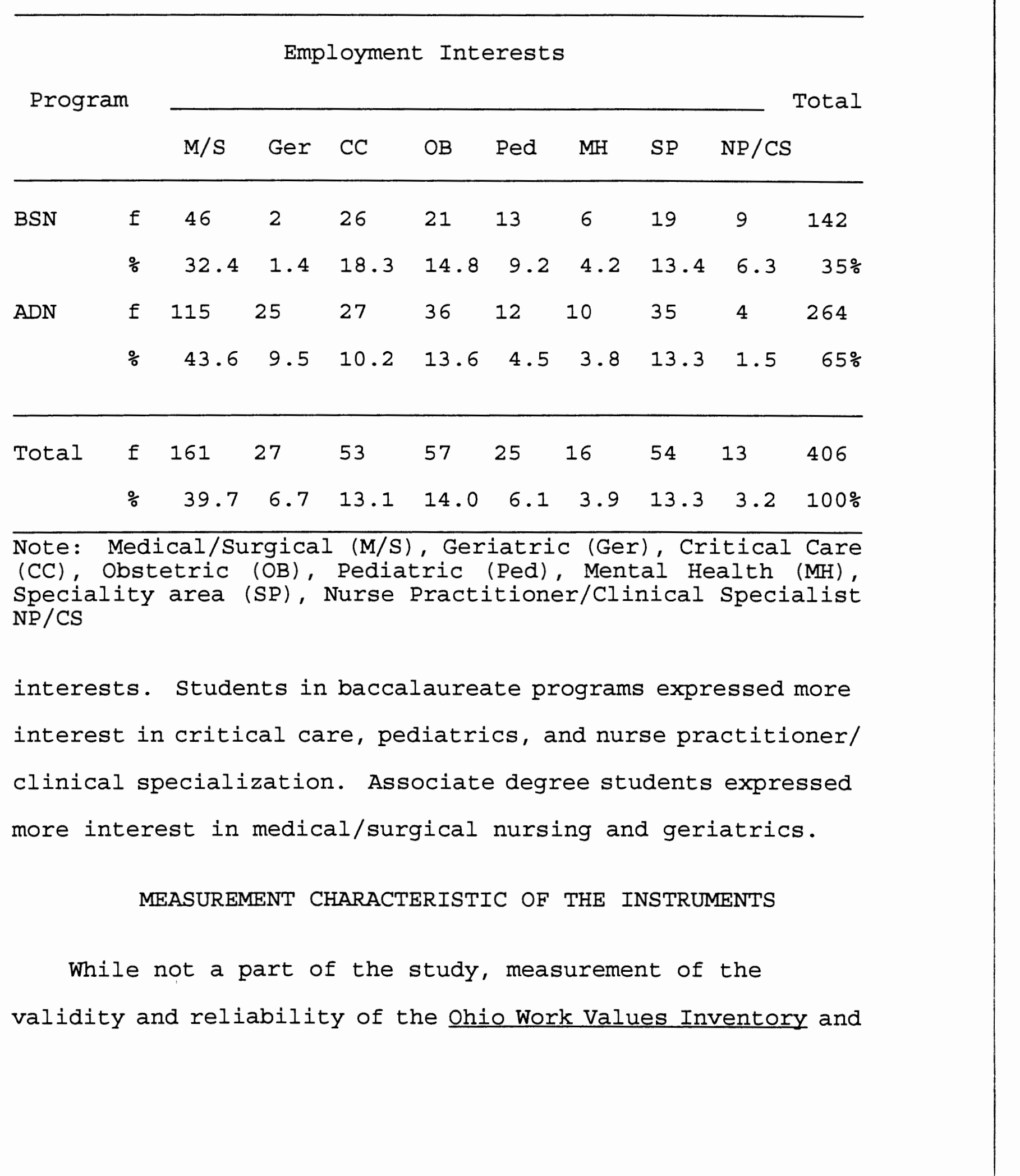


the Profile of Life Values instruments were performed for the sample. Coefficients Alphas were reported in Tables XVII and XIX for internal consistency.

Scale Intercorrelations for the Profile of Life Values Intercorrelations ranged from .62 (Intellectual with Creative) to -.04 (Artistic with Integrity). The median value was approximately.29. Intercorrelations of the scale are presented in Table XXXXVIII.

TABLE XXXXVIII

INTERCORRELATION OF SCALES FOR PROFILE OF LIFE VALUES

Scale Intel Cons Creat Rec Art Ach Integr

Intellectual

$\begin{array}{llllll}.34 & .62 & .24 & .49 & .47 & .00\end{array}$

Considerate

$\begin{array}{lllll}.33 & .29 & .11 & .49 & .21\end{array}$

Creative

$\begin{array}{llll}.29 & .39 \quad .50 \quad .06\end{array}$

Recognition

$.07 \quad .43 \quad-.02$

Artistic

$.16-.04$

Achievement

.12

Integrity

\section{Validity of the Profile of Life Values}

Using varimax rotation, a factor analysis was performed on the responses from the subjects to the 56 personal value items on the scales. The factor analysis produced seven factors. Five factors coincided with five of the 
scales. For five scales, the largest factor loading of each item was on the same factor: Creative, Integrity, Artistic, Considerate, and Achievement; however, on Achievement, two items loaded below 0.50 . One item associated with the Intellectual scale loaded higher on the Creative scale; one item from the Recognition scale loaded higher on the achievement scale; and one item on the Intellectual scale split its loading among three factors. Coefficient Alphas ranged from .78 for Intellectual to .88 for Creative. The combinations on these particular scales is not particularly surprising, as the aspects of Intellectual, Achievement, and Creative are parts of learning. Table XXXXIX presents these findings.

\section{Scale Intercorrelations for the ohio work Values Inventory}

Correlation coefficient for each of the scales with each other in the OWVI were calculated. Scale intercorrelations ranged from .67 (Task Satisfaction with Self-Realization) to a -.02 (Solitude with Altruism). Correlation coefficients are presented in Table $\mathrm{L}$.

\section{Validity of Ohio Work Values Inventory Scales}

Factor analysis with varimax rotation, were performed on the subjects responses to the 77 items on the ohio Work Values Inventory. Using the criterion that all items of a scale have their primary factor loading on a single factor, the rotated factor matrix fell on 11 factors. Nine of the 
TABLE XXXXIX

FACTOR ANALYSIS OF PERSONAL VALUES FOR STUDENT NURSES

\begin{tabular}{lll}
\hline & & Eigen- $\%$ of \\
Factor Scale Item Number \& Factor Loading Value variance
\end{tabular}

$\begin{array}{lrlllll}1 \text { Creative } & 3 & (.59) & 10 & (.73) & 17 & (.75) \\ & 24 & (.74) & 31 & (.70) & 38 & (.78) \\ 45 & (.63) & 52 & (.63) & 43 & (.40) a\end{array}$

$10.89 \quad 19.4$

2 Integrity $\quad 7(.65) \quad 14(.58) \quad 21(.73)$

$28 \quad(.77) \quad 35 \quad(.73) \quad 42 \quad(.58)$

$\begin{array}{lllll}49 & (.84) \quad 56 & (.84) & 4.98 & 8.9\end{array}$

3 Recognition $4(.76) \quad 11(.72) \quad 18 \quad(.33) \mathrm{d}$

$25(.58) \quad 32(.88) \quad 39(.17) \mathrm{c}, \mathrm{d}$

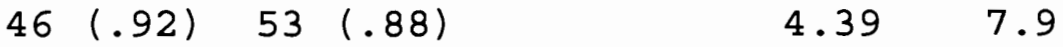

4 Artistic $\quad 5 \quad(.71) \quad 12(.51) \quad 19(.78)$

$26(.67) \quad 33(.81) \quad 40(.79)$

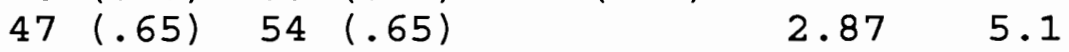

5 Considerate $2\left(\begin{array}{llllll} & (.72) & 9 & (.72) & 16 & (.72)\end{array}\right.$

$23(.58) \quad 30 \quad(.59) \quad 37 \quad(.57)$

$\begin{array}{lllll}44 & (.69) \quad 51 & (.35) \mathrm{d} & 2.42 & 4.3\end{array}$

6 Achievement $6(.68) \quad 13(.55) \quad 20 \quad(.67)$

$27(.44) \quad 34(.72) \quad 41(.67)$

$48 \quad(.35) \mathrm{b} 55 \quad(.53) \quad 39 \quad(.53) \mathrm{c}$

$1.90 \quad 3.4$

7 Intellectual $1(.68) \quad 8 \quad(.62) \quad 15 \quad(.46)$

$22(.54) \quad 29(.40) \quad 50(.40)$

$43(.19) \mathrm{a}, \mathrm{d} \quad 36(.27) \mathrm{b}, \mathrm{d} \quad 1.64 \quad 2.9$

a. This item (43) belongs on the Intellectual scale, but had its highest loading $(.40)$ on the Creative scale.

b. This item (36) belongs on the Intellectual scale, but split its loading among three factors: Creative (.29) Intellectual (.27), and Artistic (.26).

c. This item (39) belongs on the Recognition scale, but loaded on the Achievement scale (.53)

d. These items loaded below .40 on the scales. 
TABLE L

INTERCORRELATION OF SCALES FOR OHIO WORK VALUES INVENTORY

Alt obj Sec Con SR Ind Mon TS Sol Ide Pr

\begin{tabular}{|c|c|c|c|c|c|c|c|c|c|c|}
\hline Alt & .11 & .32 & .13 & .61 & .15 & .13 & .50 & -.02 & .32 & .14 \\
\hline obj & & .21 & .30 & .15 & .30 & .23 & .12 & .33 & .45 & .29 \\
\hline Sec & & & .27 & .37 & .34 & .43 & .35 & .27 & .26 & .27 \\
\hline Con & & & & .16 & .43 & .39 & .10 & .31 & .42 & .63 \\
\hline$S R$ & & & & & .32 & .25 & .67 & .08 & .44 & .17 \\
\hline Ind & & & & & & .48 & .38 & .52 & .38 & .37 \\
\hline Mon & & & & & & & .33 & .27 & .29 & .49 \\
\hline TS & & & & & & & & .12 & .29 & .13 \\
\hline Sol & & & & & & & & & .30 & .32 \\
\hline Ide & & & & & & & & & & .40 \\
\hline Pr & & & & & & & & & & \\
\hline
\end{tabular}

eleven factors were congruent with the ohio Work Values Inventory scales: Money, Security, Control, Altruism, Prestige, Solitude, object Orientation, Ideas/Date Orientation, and Independence. All items on the self Realization scale loaded on the same factor. However, four items from Task satifaction scale had higher loadings on the factors associated with the Self-Realization scale. While the loading was intermixed on these two scales, Coefficients Alphas for the scales ranged from .84 and .94 with the 
Coefficient Alpha for Task Satisfaction being .84 and the Coefficient Alpha for Self-Realization being .87.

The higher loading of the particular items on the selfRealization scale does not seem to be too unusual. Both scales contain items that are aspects of self-actualization, as postulated in a self-theory approach to personality. This data is presented in Table LI.

\section{VALUES BY RANK ORDER}

In comparative research studies, it is normative to select statistical models which will help identify group differences. However, this approach is relatively insensitive to the similarities among groups. This was done in the current study and statistically significant differences among the means of values in relationship to type of educational institution, educational preparation, and age were found. To partially respond to this problem, the investigator chose to use means carried to one decimal place to rank order the values for each comparison group, and then examine the rankings within each of the aforementioned independent variables. This ranking was done for the personal values (Profile of life Values) and work values (Ohio Work Values Inventory). 


\section{TABLE LI}

FACTOR ANALYSIS OF WORK VALUES FOR STUDENT NURSES

Eigen- $\%$ of

Factor Scale Item number and Factor Loading Value Variance

$$
\begin{aligned}
& 1 \text { Self } 5(.54) \quad 16(.72) \quad 27(.66) \quad 38(.57) \\
& \text { Realization } 49(.70) \quad 60(.68) \quad 71(.72) \\
& 8(.53) \text { a } 19(.48) \text { a } 63(.65) \text { a } \\
& 74(.63) a \quad 17.84 \quad 23.2 \\
& 2 \text { Money } 7(.80) \quad 18(.74) \quad 29(.77) \quad 40(.85)
\end{aligned}
$$

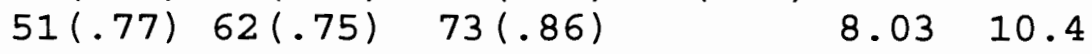

$$
\begin{aligned}
& \begin{array}{lrlllll}
3 \text { Security } & 3(.60) & 14(.81) & 25(.82) & 36(.75) & & \\
& 47(.85) & 58(.82) & 69(.82) & & 4.64 & 6.0
\end{array} \\
& 4 \text { Control } 4(.76) \quad 15(.72) \quad 26(.83) \quad 37(.83)
\end{aligned}
$$

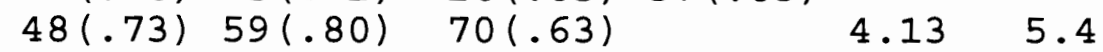

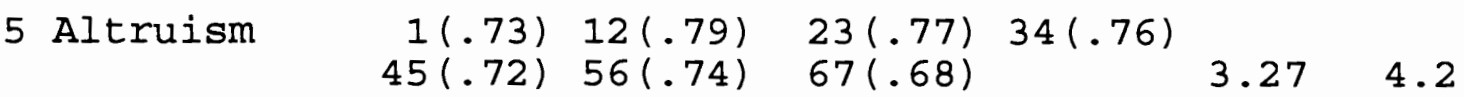

$$
\begin{aligned}
& \begin{array}{lllllll}
6 \text { Prestige } & 11(.59) & 22(.76) & 33(.68) & 44(.77) & & \\
& 55(.70) & 66(.80) & 77(.60) & 2.93 & 3.8
\end{array} \\
& \begin{array}{lrlllll}
7 \text { Solitude } & 9(.67) & 20(.64) & 31(.76) & 42(.58) & & \\
& 53(.80) & 64(.61) & 75(.76) & & 2.14 & 2.8
\end{array} \\
& 8 \text { Object } 2(.78) \quad 13(.77) \quad 24(.72) \quad 35(.81)
\end{aligned}
$$

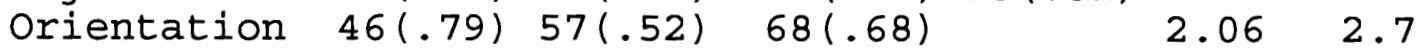

$$
\begin{aligned}
& \begin{array}{lllllll}
9 \text { Ideas/Date } & 10(.55) & 21(.59) & 32(.65) & 43(.72) & & \\
\text { Orientation } & 54(.51) & 65(.70) & 76(.76) & & 1.75 & 2.3
\end{array} \\
& 10 \text { Independence } 6(.70) \quad 17(.72) \quad 28(.47) \quad 39(.72) \\
& \begin{array}{lllll}
50(.65) & 61(.63) & 72(.58) & 1.48 & 1.9
\end{array} \\
& 11 \text { Task } 30(.54) \quad 41(.61) \quad 52(.60) \quad 19(.38) \mathrm{a}
\end{aligned}
$$

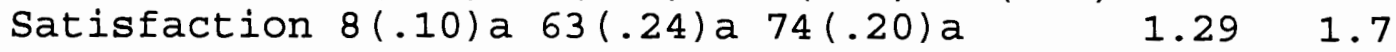


Personal Values

Table LII presents a ranking of personal values by institution, educational preparation, and age.

TABLE LII

RANK ORDER OF PERSONAL VALUES BY MEANS

\begin{tabular}{|c|c|c|c|c|c|c|c|c|c|}
\hline \multirow[b]{2}{*}{ Variable } & \multirow{2}{*}{$\mathrm{T} / \mathrm{S}$} & \multicolumn{2}{|c|}{ Type Instit. } & \multicolumn{3}{|c|}{ Ed. Prep. } & \multicolumn{3}{|c|}{ Age } \\
\hline & & Priv. & Pub. & $\mathrm{AD}$ & $\mathrm{BSN}$ & Gr. & $20-29$ & $30-39$ & $40-54$ \\
\hline Considerate & 1 & 1 & 1 & 1 & 1 & 1 & 1 & 1 & 1 \\
\hline Intellectual & 2.5 & $4 *$ & 2 & 2.5 & 2.5 & 2 & 4 * & 2 & 2 \\
\hline Achievement & 2.5 & 3 & 3 & 2.5 & 2.5 & 3 & 3 & 3 & 3 \\
\hline Recognition & 4 & $2 *$ & 4 & 4 & 4 & 4 & 2 * & 4 & $5 *$ \\
\hline Creative & 5 & 5 & 5 & 5 & 5 & 5 & 5 & 5 & 4 * \\
\hline Artistic & 6 & 6 & 6 & $7 \star$ & 6 & 6 & $7 *$ & 6 & 6 \\
\hline Integrity & 7 & 7 & 7 & $6 *$ & 7 & 7 & $6 *$ & 7 & 7 \\
\hline
\end{tabular}

Note: * Differing rank order

Total sample ( $\mathrm{T} / \mathrm{S})$; Type of institution (Type Instit.); Educational preparation (Ed Prep.), Private (Priv.): Public (Pub.)

Considerate remained the most important when rank ordered by type of institution, form of educational preparation, and age. Intellectual was ranked second or 2.5 with two exceptions: students in private institutions and students between ages 20-29 ranked Intellectual fourth, while ranking Recognition second. Achievement was ranked third or equally 
with Intellectual (rank of 2.5) for all groups. The 40-54 age group ranked Creative above Recognition. With the exceptions noted, Recognition was fourth and Creative was fifth for all other groups. Artistic was ranked above Integrity with two exceptions: Associate Degree students and students between ages 20-29 ranked Integrity above Artistic. While a commonality of personal values seems to exist among student nurses, other factors, such as age, educational preparation, and type of educational institution seem to be related to the importance of personal values in some way. Nevertheless, similarities among the groups in the order of their values is noteworthy.

In rank ordering the means for personal values by job interest for all groups, Considerate was first. However, student nurses interested in Geriatrics, Obstetrics, and Mental Health differed the most in the order of importance for personal values. For all groups, Considerate was the most important value. Recognition ranked second for student nurses interested in Geriatrics and third for student nurses interested in Obstetrics, while ranking sixth for student nurses interested in Mental Health. Intellectual ranked fifth for students nurses interested in Geriatrics, and fourth for student nurses interested in obstetrics. Nevertheless, the rank order of the personal values of two groups (Pediatric and Nurse Practitioner/Clinical specialist) was identical with that of the total sample. Only minor variations were 
exhibited by three groups: Critical Care (two adjacent values in total sample were tied) and Medical/Surgical and Speciality (two adjacent values were reversed in their groups). These rankings are presented in Table LIII.

TABLE LIII

PERSONAL VALUES RANK ORDERED BY MEANS FOR JOB INTERESTS

Variable

Job Interest

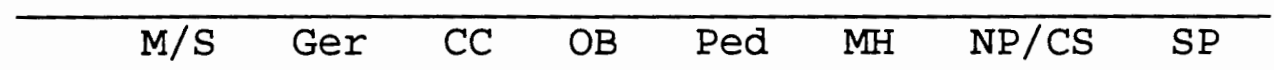

\begin{tabular}{lllllllll} 
Considerate & 1 & 1 & 1 & 1 & 1 & 1 & 1 & 1 \\
Intellectual & 2 & $5 *$ & 2.5 & $4 *$ & 2 & 2 & 2 & 2 \\
Achievement & 3 & 3 & 2.5 & $2 *$ & 3 & 3.5 & 3 & 3 \\
Recognition & 4 & $2 *$ & 4 & $3 *$ & 4 & $6 *$ & 4 & $5 *$ \\
Creative & 5 & $4 *$ & 5 & 5 & 5 & 5 & 5 & $4 *$ \\
Artistic & $7 *$ & $7 *$ & 6 & 6.5 & 6 & $3.5 *$ & 6 & 6 \\
Integrity & $6 *$ & $6 *$ & 7 & 6.5 & 7 & 7 & 7 & 7 \\
\hline
\end{tabular}

Note: Medical/Surgical (M/S), Geriatrics (Ger), Critical Care (CC), Obstetrics (OB), Pediatrics (Ped), Mental Health (MH), Nurse Practitioner/Clinical Specialist (NP/CS), Speciality such as Operating Room, Emergency Room (SP).

* Difference in rank order

Correlations Between Rankings of Personal Values

Spearman coefficients of correlation were calculated on the rank ordering of the personal value scales by type of educational institution, educational preparation, and age. (See Table LIV.) Coefficients were signicant at or beyond the .05 level for type of educational institution and educational 
TABLE LIV

SPEARMAN CORRELATION COEFFICIENTS BETWEEN TYPE OF EDUCATIONAL INSTITUTION, EDUCATIONAL PREPARATION, AND AGE ON PERSONAL VALUES RANKING

\begin{tabular}{|c|c|c|c|c|c|c|c|c|}
\hline \multirow[b]{2}{*}{ Variable } & \multicolumn{2}{|c|}{ Type Inst } & \multicolumn{3}{|c|}{ Ed Prep } & \multicolumn{3}{|c|}{ Age } \\
\hline & Priv. & Pub. & $A D$ & BSN & GR & $20-29$ & $30-39$ & $40-54$ \\
\hline Private & & .857 & & & & & & \\
\hline Public & $(.014)$ & & & & & & & \\
\hline $\mathrm{AD}$ & & & & .964 & .955 & & & \\
\hline BSN & & & $(.000)$ & & .991 & & & \\
\hline GR & & & $(.001)$ & $(.000)$ & & & & \\
\hline $20-29$ & & & & & & & .821 & .714 \\
\hline $30-39$ & & & & & & $(.023)$ & & .964 \\
\hline $40-54$ & & & & & & $(.071)$ & $(.000)$ & \\
\hline
\end{tabular}

Note: Type of Educational Institution (Type Inst), Educational Preparation (Ed Prep), Private (Priv), Public (Pub), Associate Degree (AD), Baccalaureate Degree (BSN), Graduate Degree (GR). Probabilities are shown in parentheses.

preparation. The rankings of private and public institutions were significantly related. The rankings of Associate, Baccalaureate, and Graduate Degree students were significantly related in a positive direction. The rankings of age groups were significantly related for age groups 20-29, and for age group 30-39. Correlation coefficients between age group 20-29 and 40-54 were not significant $(\underline{p}=.071)$. Caution must be 
exercised in the interpretation of this data; the presence of these significant correlation coefficients does not necessarily demonstrate that a casual relationship exists between the specific variables.

Spearman coefficients of correlation were also calculated on the ranking of the personal value scales by job interests. (See Table LV) Correlations coefficients between the Profile of Iife Values and job interests were not signifcant for Medical/Surgical Nursing and Geriatrics ( $\underline{p}=.052)$,

TABLE LV

SPEARMAN CORRELATION COEFFICIENT BY PERSONAL VALUE RANKING AND JOB INTEREST

\begin{tabular}{lccccccc}
\hline Variable M/S & Ger & CC & OB & Ped & MH & NP/CS & SP \\
\hline M/S & .750 & .955 & .883 & .964 & .685 & .964 & .955 \\
Ger $(.052)$ & & .757 & .919 & .714 & .288 & .714 & .643 \\
$\mathrm{CC}(.001)(.049)$ & & .927 & .991 & .791 & .991 & .955 \\
OB $(.008)(.003)$ & $(.003)$ & & .883 & .555 & .883 & .811 \\
$\mathrm{Ped}(.000)(.071)$ & $(.000)$ & $(.000)$ & & .811 & 1.000 & .964 \\
$\mathrm{MH}(.090)(.531)$ & $(.034)$ & $(.196)$ & $(.027)$ & & .811 & .847 \\
$\mathrm{NP} / \mathrm{CS}(.000)(.071)$ & $(.000)$ & $(.008)$ & $(.000)$ & $(.027)$ & & .964 \\
$\mathrm{SP}$ & $(.003)(.119)$ & $(.001)$ & $(.027)$ & $(.000)$ & $(.016)$ & $(.000)$ &
\end{tabular}

Note: Medical/Surgical (M/S), Geriatric (Ger), Critical Care (CC), Obstetrics (OB), Pediatrics (Ped), Mental Health (MH), Nurse Practitioner/Clinical Specialist (NP/CS), Specialty (SP) Probabilities are shown in parentheses. 
Medical/Surgical Nursing and Mental Health ( $\underline{0}=.090$ ), Geriatrics and Mental Health ( $\underline{\underline{p}}=.531)$, Geriatrics and Specialty areas ( $\underline{\mathrm{p}}=.119)$, and Obstetrics and Mental Health $(\underline{p}=.196)$. All other correlation coefficients among job interest scales were significant at or beyond the .05 level. All coefficients were positive.

Rank Order of Work Values

A rank order comparison of work values with type of institution, educational preparation, and age resulted in the findings shown in Table LVI. For all groups, Task Satisfaction, self Realization, and Altruim were consistently in first, second, and third place, respectively. Security, Money, Independence, and Ideas/Data Orientation for the most part were in fourth, fifth, sixth, and seventh place, respectively. Money and Independence were reversed for students in private schools and baccalaureate nursing education. Security and Money were reversed for the 30-39 year age group. The greatest differences in ranking of these values occurred in the Graduate students' rankings, where Independence and Ideas/Data Orientation moved above Money and Security, and the 40-54 age group, with Independence in the fourth position and Money in the seventh. Object Orientation ranked eighth in five of the eight groups; it was replaced by Prestige in the Private school group and Graduate student groups. Object Orientation and Control were reversed for the 
TABLE LVI

RANK ORDER OF WORK VALUES BY MEANS

\begin{tabular}{|c|c|c|c|c|c|c|c|c|c|}
\hline \multirow{2}{*}{ Variable } & \multirow{2}{*}{ Sample } & \multicolumn{2}{|c|}{ Ed. Inst. } & Ed. & \multicolumn{2}{|c|}{ Preparation } & \multicolumn{3}{|c|}{ Age } \\
\hline & & Priv & Pub & $A D$ & $\mathrm{BSN}$ & Grad & $20-29$ & $30-39$ & $40-54$ \\
\hline Task Sat & 1 & 1 & 1 & 1 & 1 & 1 & 1 & 1 & 1 \\
\hline Self Real & 2 & 2 & 2 & 2 & 2 & 2 & 2 & 2 & 2 \\
\hline Altruism & 3 & 3 & 3 & 3 & 3 & 3 & 3 & 3 & 3 \\
\hline security & 4 & 4 & 4 & 4 & 4 & $7 *$ & 4 & $5 *$ & $5 *$ \\
\hline Money & 5 & $6 *$ & 5 & 5 & $6 *$ & $6 *$ & 5 & 4 * & $7 *$ \\
\hline Independence & 6 & $5 *$ & 6 & 6 & $5 *$ & 4 * & 6 & 6 & 4 * \\
\hline Ideas/Data & 7 & 7 & 7 & 7 & 7 & $5 *$ & 7 & 7 & $6 *$ \\
\hline obj. Orient & 8 & $10 *$ & 8 & 8 & 8 & $11 *$ & 9 * & 8 & 8 \\
\hline Control & 9 & 9 & 9 & 9 & 9 & 9 & 8 * & 9 & 9 \\
\hline Prestige & 10 & $8 *$ & 10 & 10 & 10 & $8 *$ & 10 & 10 & 10 \\
\hline Solitude & 11 & 11 & 11 & 11 & 11 & $10 *$ & 11 & 11 & 11 \\
\hline $\begin{array}{l}\text { Note: Task } \\
\text { Real), Ideas/ } \\
\text { (obj Orient) } \\
\text { * Different }\end{array}$ & $\begin{array}{l}\text { Sat } \\
\text { /Dat } \\
\text { rank }\end{array}$ & $\begin{array}{l}\text { Lsfact } \\
\text { ariel } \\
\text { order }\end{array}$ & $\begin{array}{l}\text { ion } 1 \\
\text { ntatic } \\
\text { n }\end{array}$ & $\begin{array}{l}\text { ask } \\
\text { (Id }\end{array}$ & $\begin{array}{l}\text { Sat) } \\
\text { leas /DA }\end{array}$ & $\begin{array}{l}\text { Self } R \\
\text { Ata), Ob }\end{array}$ & $\begin{array}{l}\text { Realiz } \\
\text { bject }\end{array}$ & $\begin{array}{l}\text { ation } \\
\text { orient }\end{array}$ & $\begin{array}{r}\text { (Self } \\
\text { ation }\end{array}$ \\
\hline $\begin{array}{l}\text { 20-29 year as } \\
\text { all groups. } \\
\text { schools and } \\
\text { students ran }\end{array}$ & $\begin{array}{l}\text { ge g } \\
\text { Pre: } \\
\text { gradr } \\
\text { Iked }\end{array}$ & $\begin{array}{l}\text { coup. } \\
\text { stige } \\
\text { sates } \\
\text { solite }\end{array}$ & $\begin{array}{l}\text { Other } \\
\text { was } r \\
\text { tuden } \\
\text { de te }\end{array}$ & $\begin{array}{l}\text { Nise, } \\
\text { nked } \\
\text { nurs } \\
\text { nth }\end{array}$ & $\begin{array}{l}\text { Contr } \\
\text { tenth } \\
\text { ses ran } \\
\text { and ob- }\end{array}$ & $\begin{array}{l}\text { rol was } \\
\text { by six } \\
\text { aked it } \\
\text { ject or }\end{array}$ & $\begin{array}{l}\text { ranke } \\
\text { group } \\
\text { eight } \\
\text { rienta }\end{array}$ & $\begin{array}{l}\text { ed nine } \\
\text { os; pri } \\
\text { h. Gra } \\
\text { tion }\end{array}$ & $\begin{array}{l}\text { eth by } \\
\text { ivate } \\
\text { iduate }\end{array}$ \\
\hline
\end{tabular}


When the means for work values were rank ordered by job interest, student nurses interested in Mental Health and the role of Nurse Practitioner/Clinical Specialist differed more from the other groups in their responses. Altruism replaced Self Realization as the most important value for students interested in Mental Health, while object Orientation was the least important work value for this group; Independence was more important than Money. Independence and Ideas/Data Orientation were more important to the Nurse Practitioner/ Clinical Specialist than Money and Security; Prestige was more important than object Orientation and Control. For Obstetrics, both Control and Prestige were more important than Object Orientation. Geriatrics, Critical Care, and Specialty areas, such as the operating room and emergency room, had one reversel of adjacent ranks each. The values of Medical/ Surgical and Pediatrics were identical with the total sample. Ranking of the work values means by job interests are presented in Table LVII.

\section{Correlations Between Rankings of Work Values}

Spearman correlations coefficients were than calculated on the rank ordering of the work scales by type of educational institution, educational preparation, and age. All coefficients were significant at or beyond the .05 level. The rankings of private and public institutions were significantly related. The coefficients for the ranking of Associate 
TABLE LVII

WORK VALUES WITH JOB INTERESTS ORDERED BY MEANS

\begin{tabular}{|c|c|c|c|c|c|c|c|c|}
\hline \multirow[t]{2}{*}{ Variable } & \multicolumn{8}{|c|}{ Job Interest } \\
\hline & $\bar{M} / \mathrm{S}$ & Ger & $\mathrm{CC}$ & $\mathrm{OB}$ & Ped & $\mathrm{MH}$ & NP/CS & $S P$ \\
\hline Task Sat. & 1 & 1 & $I$ & 1 & 1 & 1 & 1 & 1 \\
\hline Self Real. & 2 & 2 & 2 & 2 & 2 & $3 *$ & 2 & 2 \\
\hline Altruism & 3 & 3 & 3 & 3 & 3 & $2 *$ & 3 & 3 \\
\hline Security & 4 & 4 & $5 *$ & 4 & 4 & 4 & $7 *$ & 4 \\
\hline Money & 5 & 5 & $4 *$ & 5 & 5 & $6 *$ & $6 *$ & 5 \\
\hline Independence & 6 & 6 & 6 & 6 & 6 & $5 *$ & $4 *$ & 6 \\
\hline Ideas/Data & 7 & 7 & 7 & 7 & 7 & 7 & $5 *$ & 7 \\
\hline obj. Orient & 8 & $9 *$ & 8 & $10 *$ & 8 & $11 *$ & 9 * & 8 \\
\hline Control & 9 & $8 *$ & 9 & $8 *$ & 9 & $8 *$ & $10 *$ & $10 *$ \\
\hline Prestige & 10 & 10 & 10 & $9 *$ & 10 & $9 *$ & $8 *$ & $9 *$ \\
\hline Solitude & 11 & 11 & 11 & 11 & 11 & $10 *$ & 11 & 11 \\
\hline \multicolumn{9}{|c|}{$\begin{array}{l}\text { Note: Task Satisfaction (Task Sat.) } \\
\text { Real.), Ideas/Data Orientation } \\
\text { Orientation (Obj. Orient.) } \\
\text { * Different rank order }\end{array}$} \\
\hline \multicolumn{9}{|c|}{$\begin{array}{l}\text { Degree, Baccalaureate, and Graduate Degrees were significantly } \\
\text { related in a positive direction. Also, the rankings of all } \\
\text { age groups were significantly related in a positive direction. } \\
\text { Correlation coefficients for type of educational institution, } \\
\text { educational preparation, and age are presented in Table LVIII. }\end{array}$} \\
\hline
\end{tabular}


TABLE LVIII

SPEARMAN CORRELATION COEFFICIENTS BETWEEN TYPE OF EDUCATIONAL INSTITUTION, EDUCATIONAL PREPARATION AND AGE ON WORK VALUES RANKING

\begin{tabular}{|c|c|c|c|c|c|c|c|c|}
\hline \multirow[b]{2}{*}{ Variable } & \multicolumn{2}{|c|}{ Type Inst } & \multicolumn{3}{|c|}{ Ed Prep } & \multicolumn{2}{|c|}{ Age } & \multirow[b]{2}{*}{$40-54$} \\
\hline & Priv & Pub & $A D$ & BSN & GR & $20-29$ & $30-39$ & \\
\hline Priv & & .955 & & & & & & \\
\hline Pub & $(.000)$ & & & & & & & \\
\hline$A D$ & & & & .973 & .991 & & & \\
\hline BSN & & & $(.000)$ & & .873 & & & \\
\hline GR & & & $(.001)($ & $(.000)$ & & & & \\
\hline $20-29$ & & & & & & & .982 & .945 \\
\hline $30-39$ & & & & & & $(.000)$ & & .936 \\
\hline $40-54$ & & & & & & $(.000)$ & $(.000)$ & \\
\hline $\begin{array}{l}\text { Note: } \\
\text { Educatior } \\
\text { (Pub), A }\end{array}$ & $\begin{array}{c}\text { Type } \\
\text { nal Pr } \\
\text { Associa }\end{array}$ & $\begin{array}{l}\text { of } \\
\text { epara } \\
\text { te De }\end{array}$ & $\begin{array}{l}\text { Education } \\
\text { ion (Ed } \\
\text { gree ( } \mathrm{AD})\end{array}$ & $\begin{array}{l}\text { hal I } \\
\text { Prep) } \\
\text { ( Bac }\end{array}$ & $\begin{array}{l}\text { istitut } \\
\text { Priv } \\
\text { calaur }\end{array}$ & $\begin{array}{l}\text { tion } \\
\text { rate } \\
\text { ceate }\end{array}$ & $\begin{array}{l}\text { (Type } \\
\text { Priv), } \\
\text { Degree }\end{array}$ & $\begin{array}{l}\text { Inst), } \\
\text { Public } \\
\text { (BSN), }\end{array}$ \\
\hline
\end{tabular}

Spearman correlation coefficients on ranking of the work value scales by job interests were calculated. All spearman coefficient correlations were significant at or beyond the .05 level. Table IIX presents these findings. 
TABLE LIX

SPEARMAN CORRELATION COEFFICIENTS ON WORK VALUE RANKING BY JOB INTEREST

\begin{tabular}{|c|c|c|c|c|c|c|c|c|}
\hline Variable & $M / S$ & GER & $\mathrm{CC}$ & $O B$ & PED & $\mathrm{MH}$ & $\mathrm{NP} / \mathrm{CS}$ & SP \\
\hline$M / S$ & & .991 & .991 & .973 & 1.000 & .927 & .891 & .991 \\
\hline GER & $(.000)$ & & .982 & .991 & .991 & .955 & .882 & .973 \\
\hline $\mathrm{CC}$ & $(.000)$ & $(.000)$ & & .964 & .991 & .909 & .900 & .982 \\
\hline$O B$ & $(.000)$ & $(.000)$ & $(.000)$ & & .973 & .973 & .891 & .964 \\
\hline PED & $(.000)$ & $(.000)$ & $(.000)$ & $(.000)$ & & .927 & .891 & .991 \\
\hline MH & $(.000)$ & $(.000)$ & $(.000)$ & $(.000)$ & $(.000)$ & & .882 & .918 \\
\hline $\mathrm{NP} / \mathrm{CS}$ & $(.000)$ & $(.000)$ & $(.000)$ & $(.000)$ & $(.000)$ & $(.000)$ & & .909 \\
\hline$S P$ & $(.000)$ & $(.000)$ & $(.000)$ & $(.000)$ & $(.000)$ & $(.000)$ & $(.000)$ & \\
\hline $\begin{array}{l}\text { Note: } \\
\text { Medical/ } \\
\text { Care (CC } \\
\text { (MH), } \\
\text { Speciatl } \\
\text { Probabil }\end{array}$ & $\begin{array}{l}\text { Number } \\
\text { /Surgic } \\
\text { C), Ob } \\
\text { Nurse } \\
\text { ly sucr } \\
\text { lities }\end{array}$ & $\begin{array}{l}\text { of obse } \\
\text { :al nur } \\
\text { stetric } \\
\text { Pract } \\
\text { as ope } \\
\text { are she }\end{array}$ & $\begin{array}{l}\text { ervatic } \\
\text { sing } \\
\text { s (OB) } \\
\text { itione } \\
\text { erating } \\
\text { own in }\end{array}$ & $\begin{array}{l}\text { ons } 11 \\
\text { (M/S) } \\
\text { Pedi } \\
\text { 'r/Clin } \\
\text { g room } \\
\text { parent }\end{array}$ & $\begin{array}{l}\text { Geriat } \\
\text { Latrics } \\
\text { ical } \\
\text { and eme } \\
\text { theses. }\end{array}$ & $\begin{array}{l}\text { rics } \\
\text { (PED), } \\
\text { Specia } \\
\text { ergenc. }\end{array}$ & $\begin{array}{l}\text { (GER), } \\
\text { ' Mental } \\
\text { alist } \\
\text { y room }\end{array}$ & $\begin{array}{l}\text { Critical } \\
\text { I Health } \\
\text { (NP/CS), } \\
\text { (SP). }\end{array}$ \\
\hline
\end{tabular}


CHAPTER V

SUMMARY, CONCLUSIONS, AND RECOMMENDATIONS

This research investigated the values of students in the last year of their educational preparation for an Associate Degree, Baccalaureate Degree, or Graduate Degree in Nursing. The study used biographic data, personal values (Profile of Life Values), and work values (Ohio Work Values Inventory). A summary of the research is presented in this chapter, including the methodology and results. Conclusions, limitations, and recommendations are discussed.

\section{SUMMARY}

The purposes of this study were: (1) to describe the personal values and work values of nursing students in the last year of their present educational preparation; (2) using multivariate analyses of variance, to investigate the relationships between selected demographic variables used as independent variables (type of educational institution [private, public], present educational preparation [Associate, Baccalaureate, Graduate], job interests, and age) and values (personal and work) used as dependent variables; and (3) to examine the correlations between students' personal and work values. 
The sample of student nurses was drawn from public and private educational institutions with nursing programs in Oregon and Washington. Students were completing the final quarter/semester of their programs. In oregon, 312 students completed the survey; in Washinton, 148 students completed the survey. Each student in the study was asked to complete a biographical information form, the profile of Life Values, and the Ohio Work Values Inventory. Of the 460 returned surveys, 452 were complete and usable.

The sample consisted of 51 male and 401 female students. Their ages ranged from 20 to 54 years, with a mean age of 33.5 and a median age of 34.1 years. Most of the students entered their present educational program with the highest previous level of formal education being a high school diploma (276). However, 176 students entered their present program with some post high school preparation: Graduate level (9),

Baccalaureate level (80), Associate Degree level (76), and Hospital Diploma in Nursing (11). A total of 137 students had past employment experience in full-time positions; an additional 210 students had worked in both full-time and parttime positions. A total of 87 students had worked part-time only; 18 students had no previous work experience.

In the sample were 379 students from public, 72 from private educational institutions, and one unknown. The sample included 43 students in programs offering a Graduate Degree in Nursing, 143 students in programs offering a Baccalaureate 
Degree in Nursing, and 266 students in programs offering an Associate Degree in Nursing. The primary choice of work setting for employment upon graduation was the hospital; $79 \%$ of the students were going to seek employment in this location while $21 \%$ of the students were planning to seek employment in community health settings, physicians offices, nursing homes, and college or universities. In reference to job interest, 161 of the students were interested in Medical/Surgical nursing, 57 interested in Critical Care nursing, 57 interested in Obstetrical nursing, 54 in Speciality areas such as the Operating Room and Emergency Room, 31 in Geriatrics, 25 in Pediatrics, 25 in the role of Nurse Practitioner, 10 in Clinical Specialization, 7 in Nursing Education, and 5 in Administration.

Ordering the personal values from the profile of life Values by importance, from highest to lowest mean, the values were Considerate (34.7), Intellectual (32.1), Achievement (32.1), Recognition (31.4), Creative (30.7), Artistic (29.6), and Integrity (29.2). Ordered by magnitude of standard deviations, from the lowest to highest, the values were: Considerate (3.1), Achievement (3.5), Intellectual (3.6), Creative (4.1), Recognition (4.3), Artistic 95.3), and Integrity (5.4). Scale reliabilities were satisfactory. Coefficient Alphas for the scales ranged from .78 for Intellectual to .88 for Creative. 
Ordering the work values from the ohio work Values Inventory by importance, from highest to lowest mean, the values were: Task Satisfaction (33.3), Self Realization (32.2), Altruism (31.1), Security (27.8), Money (27.6), Independence (26.4), Idea/Data Orientation (25.7), Object Orientation (20.2), Control (19.8), Prestige (18.9), and Solitude (17.9). Ordered by magnitude of the standard deviations, from the lowest to the highest, the values were: Task Satisfaction (2.6), Self Realization (3.2), Altruism (4.3), Ideas/Data Orientation (5.1), Independence (5.4), Solitude (6.0), Security (6.3), Object Orientation (6.6), Control (6.7), Money (6.8), and Prestige (6.9). Scale reliabilities were satisfactory. Coefficient Alphas for the scales ranged from .84 for Task Satisfaction to .94 for Money.

Eight statistical hypotheses were generated for this study. Statistical Hypothesis I was: When examined by educational preparation, student nurses will not differ in their personal values. This hypothesis was examined in two ways. It was first examined using type of institution (public, private) as the independent variable. The multivariate statistical hypothesis was rejected (with 7, 449 df, Wilks' Lambda $\underline{F}=4.56 ; \underline{p}<.001)$. Using ANOVAs, the statistical hypotheses were not rejected for Intellectual ( $\underline{0}$ $=.382)$, Considerate $(\underline{\underline{p}}=.286)$, and Integrity $(\underline{\underline{p}}=.497)$. The statistical hypotheses were rejected for Creative $(\underline{p}=$ $.004)$, Recognition $(\underline{p}<.001)$, Artistic $(\underline{\underline{p}}=.038)$, and 
Achievement $(\underline{p}=.008)$. The means on these scales for the students from private institutions were significantly greater than the means for the students from public institutions.

Statistical Hypothesis I was then examined by level of educational preparation. The multivariate statistical hypothesis was again rejected (with 7, 449 df, Wilks' Lambda $\underline{F}=2.36 ; \underline{\underline{Q}}=.003)$. In the subsequent ANOVAs, the statistical hypotheses were not rejected for Considerate $(\underline{p}=.900)$, Creative $(\underline{\mathrm{p}}=.231)$, Artistic $(\underline{\mathrm{p}}=.189)$, and Achievement ( $\mathrm{p}$ $=.127)$. The statistical hypotheses were rejected for Intellectual $(\underline{p}=.022)$, Recognition $(\underline{p}=.002)$, and Integrity $(\underline{p}=.014)$. Pairwise mean comparisons were then performed, using scheffe at the .10 level as recommended by Scheffe. Significant group differences were found on three of the Profile of Iife Values scales. The mean for the Intellectual scale was significantly higher for students in Graduate degree programs (33.3) than for the students in Associate Degree programs (31.8). The mean for Recognition was significantly higher for Baccalaureate Degree students (32.3) than for Asssociate Degree students (30.8). The mean for Integrity was significantly higher for Associate Degree students (29.8) than for Baccalaureate (28.3) and Graduate (28.3) Degree students.

Hypothesis II was: When examined by educational preparation, students nurses will not differ in their work values as measured by the Ohio Work Values Inventory. This 
hypothesis was examined by type of educational institution and by level of educational preparation.

When work values were examined by type of educational institution, the multivariate statistical hypothesis was rejected (with $1,449 \underline{\mathrm{df}}, \mathrm{Wilks}$ ' Iambda $\underline{E}=2.54 ; \underline{\mathrm{p}}=$ .004). In subsequent ANOVAs, the statistical hypotheses were not rejected for Altruism $(\underline{p}=.865)$, Object Orientation $(\mathrm{p}=$ .137), Security ( $\underline{Q}=.389)$, Self Realization $(\underline{p}=.793)$, Money $(\underline{p}=.597)$, and Task Satisfaction $(\underline{p}=.187)$. The statistical hypotheses were rejected for Control $(\underline{p}=.033)$, Independence $(\underline{p}=.002)$, Solitude $(\underline{p}=.015)$, Ideas/Data Orientation $(\underline{p}=$ $.030)$, and Prestige ( $\mathrm{p}<.001)$; the means for the private institutions were significantly greater on these scales.

When work values were examined by level of educational preparation, the multivariate analysis of variance was also rejected (with $2,449 \underline{\mathrm{df}}$, Wilks' Lambda $\underline{E}=6.67 ; \underline{\underline{p}}<.001$ ). Following rejection of the multivariate statistical

hypothesis, ANOVAs were performed. The statistical hypotheses were not rejected for Altruism ( $\underline{Q}=.657)$, Self Realization $(\underline{\underline{p}}=.792)$, Task Satisfaction $(\underline{\underline{Q}}=.253)$, Solitude $(\underline{\underline{Q}}=.132)$, Ideas/Data Orientation $(\underline{p}=.165)$, and Prestige $(\underline{p}=.052)$. The statistical hypotheses were rejected for object Orientation $(\underline{p}<.001)$, security $(\underline{p}<.001)$, Control $(\underline{p}=$ $.040)$, Independence $(\underline{p}=.002)$, and Money $(\underline{p}<.001)$.

Following the finding of significant ANOVAs, pairwise mean comparisons were performed, using scheffe at the .10 
level. Students in Baccalaureate Degree programs placed significantly higher mean value on object orientation (21.1), Control (20.9), and Independence (27.7) than students in Graduate Degree programs (16.4, 18.2, and 26.8, respectively) and Associate Degree programs $(20.4,19.5$, and 25.7, respectively). Students in Associate Degree programs placed more value on Security $(28.6)$ and Money (28.5) than students in Graduate Degree (22.9 and 23.8, respectively) and Baccalaureate Degree (27.8 and 27.0, respectively) programs. Statistical hypothesis III was: Student nurses with different job interests will not differ in their personal values. The multivariate analysis of variance was rejected (with 7, $432 \underline{\mathrm{df}}$, Wilks' Lambda $E=1.66 ; \underline{p}=.003$ ). In the subsequent ANOVAs, the statistical hypotheses were not rejected for Creative $(\underline{p}=.285)$ and Integrity $(\underline{p}=.400)$, but were rejected for Intellectual $(\underline{p}=.003)$, Considerate $(\underline{p}=$ $.009)$, Recognition $(\underline{\underline{p}}=.042)$, Artistic $(\underline{\mathrm{p}}=.034)$, and Achievement $(\underline{p}=.034)$.

With the finding of significant ANOVAs, pairwise mean comparisons were performed, using Scheffe at the .10 level of significance for primary interpretation. One significant difference was found with Scheffe at the .10 level of significance; the mean on Considerate for students interested in Pediatric nursing (37.2) was significantly greater than the mean for Medical/Surgical nursing (34.4). 
The less conservative Tukeyb approach to the analysis suggested that other significant differences may exist. Student nurses interested in Pediatric nursing (37.2) placed more value on Considerate than did students who were interested in the other jobs (means from 34.4 to 34.8 ). Also, student nurses interested in Pediatric nursing (33.9) placed more value on Achievement than students interested in Medical/ Surgical nursing (31.4). Furthermore, student nurses interested in Pediatric (34.0) nursing also placed more value on Intellectual than student nurses interested in Medical/ Surgical (31.6) and Geriatric (30.8) nursing.

Hypothesis IV stated: Student nurses with different expressed job interests will not differ in their work values. The multivariate statistical hypothesis was rejected (with 7 , 432 df, Wilks' Lambda $\underline{E}=1.89 ; \underline{p}<.001$ ). In the subsequent ANOVAs, the statistical hypotheses were not rejected for Altruism $(\underline{p}=.539)$, Security $(\underline{Q}=.069)$, Self Realization ( $\underline{\text { D }}$ $=.168)$, Independence $(\underline{\underline{p}}=.203)$, Money $(\underline{\underline{p}}=.121)$, Task Satisfaction $(\underline{\underline{p}}=.400)$, Solitude $(\underline{\underline{p}}=.588)$, Ideas/Data Orientation $(\underline{p}=.272)$, and Prestige $(\underline{p}=.219)$. The statistical hypotheses were rejected object Orientation ( $\mathrm{Q}$ $<.001)$ and Control $(\underline{\underline{p}}=.026)$.

Following significant ANOVAs, pairwise mean comparisons were performed, using scheffe at the .10 level of significance. Three significant difference were found on object orientation. The mean for object orientation by job 
interest in speciality areas (22.9), such as the operating room or emergency room, was greater than the means for nurses interested in working in Mental Health (16.7), in Obstetrics (18.4), and as a Nurse Practitioner/Clinical specialist (17.9). No pairwise mean difference was found on control.

The less vigorous Tukeyb statistic was used for additional examination; it suggested the possibility of additional differences. On object orientation the mean for the Specialty areas (22.9) was significantly greater than the mean for Medical/Surgical Nursing (19.9). The mean for object Orientation was significantly greater for Critical Care nursing (22.2) than the means for Obstetrical nursing (18.4), Mental Health (16.7), and Nurse Practitioner/Clinical Specialist (17.9). Students interested in Pediatric nursing (22.8) also placed significantly greater value on object Orientation than students interested in Mental Health (16.7). Hypothesis $\mathrm{V}$ was: When examined by age, student nurses will not differ in their personal values. The students were placed in three age groups for the analysis: ages 20-29 (144 students), ages 30-39 (173 students), and ages 40-54 (130 students). The multivariate statistical hypothesis was rejected (with 2, $449 \underline{\mathrm{dE}}$, Wilks' Lambda $\underline{E}=1.66 ; \underline{\mathrm{p}}=.003$ ). In the subsequent ANOVAs, the statistical hypotheses were not rejected for Considerate $(\underline{Q}=.929)$, Creative $(\underline{p}=.149)$, Artistic $(\underline{p}=.068)$, Achievement $(\underline{p}=.970)$, and Integrity ( 
$=.734)$. The statistical hypotheses were rejected for Intellectual $(\underline{\underline{p}}=.010)$ and Recognition $(\underline{\mathrm{p}}<.001)$.

Using Scheffe at the .10 level of significance, pairwise means comparisons were made. On the Intellectual scale, the mean for the 40-54 age group (32.7) was significantly higher than the mean for the 20-29 age group (31.5). On Recognition, the mean for the 20-29 age group (32.2) was significantly greater than the mean for the 40-54 age group (30.7).

Hypothesis VI stated: When examined by age, student nurses will not differ in their work values. The multivariate statistical hypothesis was rejected (with 2, 449 df, Wilks' Lambda $\underline{E}=1.89 ; \underline{p}<.001)$. Upon rejection of the multivariate statistical hypothesis, ANOVAs were performed. The statistical hypotheses were not rejected for Altruism (p $=.800)$, Object Orientation $(\underline{p}=.228)$, Self Realization ( $\underline{p}=$ .506), Solitude $(\underline{\underline{p}}=.166)$, and Ideas/Data Orientation ( $\underline{\underline{Q}}=$ $.740)$, Task Satisfaction $(\underline{p}=.357)$, and Independence $(\underline{p}=$ .639). The statistical hypotheses were rejected for security $(\underline{p}=.009)$, Control $(\underline{\underline{p}}=.026)$, Money $(\underline{\underline{p}}=.003)$, and Prestige $(\underline{p}<.001)$

Again, following significant ANOVAs, pairwise mean comparisons were made, using Scheffe at the .10 level of significance for primary interpretation. The mean for Security was significantly higher for the 20-29 year age group (28.9) than for the 40-50 year age group (26.6). The mean for Control was significantly higher for the 20-29 year 
age group (21.0) than the mean for the 30-39 year age group (18.9). Furthermore, the mean for Money was significantly higher for the 20-29 year age group (28.3) than for the 40-54 year age group (25.9). The mean for Prestige was greater for the 20-29 year age group (20.9) than for the 30-39 and 40-54 age groups ( 17.8 and 17.9 respectively).

Hypothesis VII was: There will be no correlation between the work values and personal values of the students. With 58 of the 77 coefficients significant at the .05 level, the statistical hypothesis was viewed as rejected.

The statistical hypothesis (VIII) that educational preparation and job interests are independent was rejected $($ Chi Square $=202.10 ;$ with $14 \underline{\mathrm{df}}, \underline{\mathrm{p}}<.001)$ for the three levels of educational preparation. In comparison with the other two groups, students in Graduate Degree programs were primarily interested in the Nurse Practitioner/Clinical Specialist role. However, $36 \%$ of the cells had expected frequencies of less than five. To correct for the expected frequency problem, the hypothesis was examined, using only the Baccaluareate and Associate Degree levels of educational preparation. The statistical hypothesis was also rejected (Chi Square $=26.57 ;$ with $7 \underline{\mathrm{d} f}, \underline{\mathrm{p}}<.001$. Students in Baccalaureate Degree programs expressed more interest in Critical Care and Pediatrics, while students in Associate Degree programs expressed more interest in Medical/Surgical nursing and Geriatrics. 
CONCLUSIONS

In general, across all groups on both instruments, student nurses exhibited a value system reflective of a social service orientation and a valuing of Self Actualization as suggested by Combs and Snygg's (1949). The correlations between the scales of the profile of Life values and ohio Work Values Inventory were reasonably consistent with a personal value system that extends into the world of work. Nevertheless, when students were grouped by selected biographic variables (type of educational institution, educational preparation, age, and job interests) significant differences were found on both instruments, indicating that these variables play some role in the values of nursing students.

\section{Values of student Nurses}

Being Considerate was found to be the most important personal value in the sample. Variation in the importance of this value was small. Intellectual and Achievement were found to be very important to the students, while Recognition, Creative, Artistic, and Integrity were seen as somewhat less in importance. The most important work values were Task Satisfaction, Self Realization, and Altruism. More moderate in importance were the values of Money, Security, Ideas/Data Orientation and Independence. Moderately lower in importance 
were Object Orientation, Control, and Prestige; particularly lower in importance was Solitude.

These results suggest that, when given a choice, self actualization values (Task Satisfaction and Self Realization), and Altruism are most important to student nurse; they like to work with people and choose not to work in Solitude. They prefer work that is interesting where they may utilize their skills/abilities in helping others. The importance placed on Considerate and Altruism suggests that the nature of the career choice with a social science orientation, that is directed toward helping, seems to be significantly related to the values of nursing.

The level of importance for Achievement suggests that there may be a relationship between Achievement and a sense of accomplishment on the part of students as they are nearing graduation. Also, the importance placed on Intellectual and Achievement suggests that being informed and competent are more important than what might be perceived to be traditional values in nursing. These values are more in agreement with recommended educational preparation for professional nursing practice (Edwards \& panel, 1986) and licensure for practice (Oregon Revised Statutes Chapter 678, 1987). It should be noted, however, that the values focusing on Creative and using ideas (Ideas/Data Orientation) were of only moderate importance. 
These results are compatable with the findings of Thurston, et al. (1989). Using Rokeach's (1973) instrument, they found a sense of accomplishment and "loving" to be the top choices of their student nurse sample. The high value placed on Considerate, Altruism, and Achievement is in disagreement with the earlier studies by O'Neil (1973), who found student nurses placing lesser value on Achievement, and Bloomquist, et al. (1980), in which their sample of baccalaureate nursing students valued Intellectual, Ambition, Freedom, and Self Respect the most; in the latter study, the value of being helpful decreased in importance during education. Recognizing that different instruments were used, these findings are somewhat different from the present study where Considerate and Altruism were highly valued. In particular, the stability across programs for Considerate and Altruism in the present study casts doubt on the decrease with education in the values of being helpful. These findings have implications for further study.

Values for Recognition, Prestige, Creative, and Artistic seem to be secondary in importance at this stage of the students' education, suggesting that other factors may be more related to the importance placed on these values. Generally speaking, these values are not presumed to be characteristics of the nurses' role; academic preparation is more science based, with emphasis on concern for other people. 
The relatively low importance placed on Integrity may be related to one's own moral values and opinions that occur during earlier stages of development. Values of this nature are believed to be fairly well established by adulthood (Kohlberg, 1981). From the psychological perspective, the importance of Integrity may suggest that the interpretation of this value varies with perceptions and flexibility towards right and wrong. This interpretation of the value may conceivably be related to the greater variation of importance for this value.

Money, Security, Ideas/Data Orientation, and Independence, while important, were not as important as personal satisfaction. Conceivably, the importance placed on Ideas/Data Orientation and Independence may increase in importance with experience and acceptance of more job responsibilities. Relatively speaking, it seems feasible that the importance placed on Security and Money could be increased, as the students are entering the work force with limited experience in the role for which they have prepared. The importance of the values, object Orientation, Control, and Prestige may be more directly related to particular jobs that entail use of objects or management of other people. The importance placed on these values have implications for further study.

Research by Hales (1977) supports these findings for nurses; intrinsic values such as Task Satisfaction, Self 
Realization, and Altruism were found to be the most important values for her sample of nursing students and practicing nurses. Money and Security were the most important extrinsic values, while less important than the above values. The values for Independence, Ideas/Data Orientation, Prestige, Object Orientation, and Control were more moderate in importance, while solitude was the least important. Garvin and Boyle's (1985) research indicated that students entering more recent nursing education programs placed more importance on Money than the students in their earlier study. Some support for this interpretation is found in comparing the value placed on Money in Hales' (1977) study with the values in the present study; the mean was higher in the present study, but the ranking of Money was about the same in both studies. Assuming that Money is receiving greater value today, one might question whether this change reflects the more materialistic 1980's, with a desire for improved economic status, or a struggle to maintain middle income status in a period of economic decline, locally and nationally. In either case, it may prove useful to monitor the relative positioning of intrinsic self-actualization variables (Self Realization and Task Satisfaction) with what may be seen as safety values (Security and Money).

The research by O'Neil (1973) also suggests a difference in work values in her sample of nursing students from the present study. While the value, Altruism did not differ 
significantly between the studies, Independence was more important; Achievement and Recognition were less important to O'Neil's sample. These difference in importance placed on the values may be more reflective of changes occurring with job responsibilities and the educational preparation for these jobs. The shift in responsibility from that of a team leader to that of a primary direct care provider has implications for further investigation.

While the current study only investigated the values of nursing students, it is interesting to note that similar importance was placed on Task Satisfaction, Self-Realization, and Altruism as the most important, with Solitude placed as least important in studies of Health Educators (Bohan, 1986), Teachers (Klampe, 1983), and School Administrators (Waggonner, 1986); these professions also have a social service orientation. The ranking of the work values for Health/Nurse Educators and Secondary Teachers were identical; with the exception that Control and Security were reversed in the rankings. Educational Administrators held similar values. In contrast to these professional groups, student nurses placed greater value on Money and Security and less on Independence and Ideas/Data Orientation. The uncertainity of employment opportunities for students entering the job market may be a factor here. The differences in importance placed on Independence and Ideas/Data may also suggest that those interested in teaching and administrative positions derive 
more satisfaction from roles that allows for more personal utilization of these values and has implications for further study. Table fuX presents the means and rank order for Bohan's, Waggoner's, and Klampe's scales on the OWVI.

TABLE LX

MEANS AND RANK ORDER ON OHIO WORK VALUES INVENTORY SCALES FOR EDUCATORS/ADMINISTRATORS

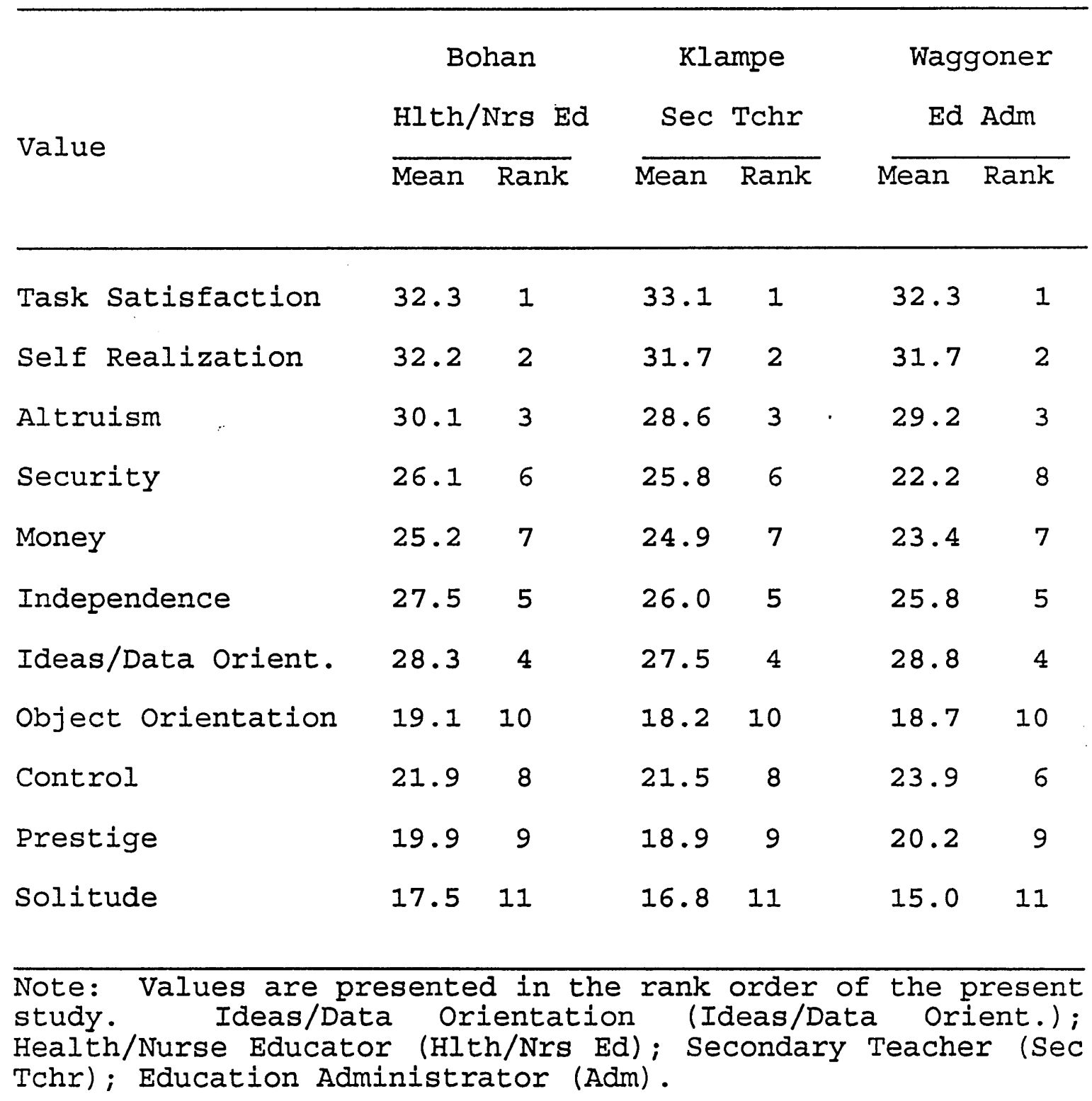


Values Examined by Educational Institution

Differences in the means for four personal values were statistically significant when examined by educational institution. The means for Creative, Recognition, Artistic, and Achievement were significantly higher for students enrolled in private institutions. When the means were ordered by rank, students enrolled in public institutions ranked Intellectual second and Recognition fourth; students enrolled in private institutions ranked Recognition second and Intellectual fourth, revealing differences in the two values.

Differences in the means of five work values were statistically significant when examined by educational institution. The means for Control, Independence, Solitude, Ideas/Data Orientation, and Prestige were higher for the students enrolled in private institutions. In general, the means for the work values tended to be moderately higher for students enrolled in private educational institutions. When ordered by ranking of means, differences were noteworthy. students enrolled in private institutions ranked the work values of Independence fifth, Money sixth, Prestige eighth, and Object Orientation tenth. Students enrolled in public institutions ranked Money fifth, Independence sixth, object Orientation eighth, and Prestige tenth. Prestige and Independence appeared to be more important to students enrolled in private institutions. 
It is evident that the values of students enrolled in private educational institutions differ from students enrolled in public institutions to a notable degree. Private school nursing students placed greater value on extrinsic values of Prestige, Recognition, and Control - all carrying implications of acquiring "status". In fact, when examining the ranks of the values, Prestige moved up two positions (exchanging positions with Object Orientation); Recognition also moved up two positions (exchanging positions with Intellectual). It is interesting to note that students in private schools also placed higher value on Independence, Ideas/Data Orientation, Creative, Artistic, and Achievement suggesting valuing greater control over the job setting and a personal value orientation toward cognitive activities which may suggest that different personal expectations exist, that these expectations may be related to differences in the norms for expression of values. Conceivably, the importance of Recognition, Prestige, and Control are in some way related to the environment of the educational institution and/or student and family expectations.

The other value differences may suggest that these students may be from families with somewhat higher incomes and their values may be more reflective of the values associated with a higher income; this is an interesting topic for future research. Nevertheless, the order of the profiles, as seen in the order of the means, on the two values instruments were 
similar: on the Profile of Life Values, five of the seven values were in the same ranking position, and on the ohio Work Values Inventory, seven of the eleven values were in the same position.

\section{Values Examined by Educational Preparation}

When values were examined by educational preparation, significant statistical differences were found on three personal values (Intellectual, Recognition, and Integrity) and five work values (Object Orientation, Money, Security, Control, and Independence). Graduate students placed more value on Intellectual and less value on Integrity, object Orientation, Money, and Security than did Associate Degree students. Graduate students also placed less value on object Orientation, Money, Security, and Control than did Baccalaureate Degree students. Perhaps, the focus of the education is related to the importance placed on these values. Educational preparation at the Associate Degree is directed towards applied practices, where issues are more absolute and less flexible. Baccalaureate and Graduate education examines the more abstract, examines the issues, and discusses differing viewpoints which may be viewed as having more flexibility. Being knowledgeable may also be viewed as being more important to Graduate students who chooses to be more autonomous in their practice. 
The integrity scale is somewhat bipolar, with low scores indicating that the situational context is the determinate of ethical decision-making and very high scores suggest an absolute code for determining right and wrong. Thus, the characteristics of four year and graduate education may be a factor in the lower Integrity values of these programs as compared with Associate Degree students. The even more abstract nature of graduate education may account for the difference observed on the Intellectual scale.

The relatively lesser value placed on Money, Security, and Object Orientation by Graduate Degree students may reflect value differences which motivated them to pursue graduate education. However, in regard to Security and Money, the degree being persued may be perceived as providing access to positions with greater financial benefits and security than the more entry level jobs of the Associate Degree or Baccalaureate Degree Registered Nurse. These students may be less impacted by the economic ambivalence of today. Of course, given their greater interest in the Intellectual value, as compared to Associate Degree, they may simply hold these values to be of lesser importance. The lower valuing of Object Orientation partially supports a view of a value system oriented more to the abstract than the concrete.

Students in Baccalaureate Degree programs placed more value on Recognition and Independence than Associate Degree students. The greater "status" associated with licensure as 
a Registered Nurse with a Baccalaureate Degree, rather than an Associate Degree, and the likelihood of greater control over the work environment may be factors in the selection of an educational program. The greater value placed by Baccalaureate Degree, as compared to graduate students, on Control supports the view of higher values of control in the work environment, both physically and in interpersonal relations.

Minor differences in the rank order of means for personal values occurred in the order of Intellectual and Achievement, wherein, both Associate and Baccalaureate Degree students ranked these the same, while students in Graduate programs ranked Intellectual second and Achievement third. The only other difference was in the ranking of Integrity in sixth place by the Associate Degree students. Both Baccalaureate and Graduate Degree students ranked Integrity seventh. More differences were observed in the rankings of the work values, particularly, in regard to Graduate Degree students. When ordered by rank, Independence was fifth and Money sixth for Baccalaureate Degree students while this order was reversed for Associate Degree students. For Graduate Degree students, Independence was fourth, Ideas/Data Orientation fifth, Money sixth, Security seventh, Prestige eighth, Solitude tenth, and object orientation eleventh. This differed from the order for Associate Degree students with Security being fourth, Money fifth, Independence sixth, Ideas/Data Orientation seventh, 
Object Orientation eighth, Prestige tenth, and Solitude eleventh.

Prior research does support the concept that values change with graduate education (Swanson and Wodarski, 1982; Varley, 1968; Wodarski, Pippin, and Daniels). In general, the ranking of values by students in various degree programs were similar; the differences noted may indeed reflect programmatic differences in nature and status.

When work values of Associate Degree students were compared with the work values of returning Registered Nurses in a Baccalaureate Degree program by Hales (1977), no statistical significant difference in the values of the two groups was found. Again, the findings of her research indicated that the sample placed their highest values on Task Satisfaction, Self Realization, and Altruism, with relatively lesser value given to Prestige, Object Orientation, and Solitude. In this respect, the findings of the two studies are reasonably associated. Only modest differences occurred in the order of values between Hales' two groups while only one difference was found in the ranking of values between Associate Degree students and Baccalaureate Degree students in the present study. (See Table IXI.)

In contrast with the Associate Degree and Baccalaureate Degree nursing students in the present study, Hales' study of Associate Degree and practicing Registered Nurses assigned more importance to Ideas/Data Orientation (over Money and 
TABLE LXI

MEANS AND RANK ORDER ON OHIO WORK VALUES INVENTORY BY EDUCATIONAL PREPARATION FOR HALES STUDY AND THE PRESENT STUDY

Hales

Value

NS

PRNS

AD

Present Study

$\longrightarrow$

Mean $\mathrm{R}$ Mean $\mathrm{R}$ Mean $\mathrm{R}$ Mean $\mathrm{R}$ Mean $\mathrm{R}$

$\begin{array}{lcccccccccc}\text { Task Sat. } & 33.3 & 1 & 32.8 & 1 & 33.2 & 1 & 33.6 & 1 & 33.3 & 1 \\ \text { Self Real. } & 33.0 & 2 & 32.2 & 2 & 32.2 & 2 & 32.4 & 2 & 32.1 & 2 \\ \text { Altruism } & 32.1 & 3 & 30.9 & 3 & 31.2 & 3 & 31.0 & 3 & 30.6 & 3 \\ \text { Security } & 27.6 & 4 & 25.1 & 5.5 & 28.6 & 4 & 27.7 & 4 & 22.9 & 7 \\ \text { Money } & 25.9 & 6 & 25.1 & 5.5 & 28.5 & 5 & 27.0 & 6 & 23.8 & 6 \\ \text { Independ } & 24.4 & 7 & 24.6 & 7 & 25.7 & 6 & 27.6 & 5 & 26.8 & 4.5 \\ \text { Ideas/Data } & 27.0 & 5 & 27.4 & 4 & 25.4 & 7 & 26.0 & 7 & 26.8 & 4.5 \\ \text { Obj. Orient } & 17.9 & 9 & 17.0 & 10 & 20.4 & 8 & 21.1 & 8 & 16.4 & 11 \\ \text { Control } & 20.9 & 8 & 21.5 & 8 & 19.5 & 9 & 20.9 & 9 & 18.2 & 9 \\ \text { Prestige } & 17.7 & 10 & 18.0 & 9 & 18.3 & 10 & 20.0 & 10 & 18.7 & 8 \\ \text { Solitude } & 15.6 & 11 & 15.8 & 11 & 17.6 & 11 & 18.7 & 11 & 17.0 & 10\end{array}$

Note: Task Satisfaction (Task Sat.), Self Realization (Self Real.), Independence (independ), Ideas/Data Orientation (Ideas/Data), object Orientation (Obj. Orient.), Associate Degree ( $A D)$, Practicing nurses (PRNS), Baccalaureate Degree (BSN), Graduate Degree (Gr), Rank Order (R)

Independence) and Control (over Object Orientation and Prestige). These modest differences may reflect the more materialist values of the American culture of the past decade, 
the technological changes, and/or the recent slide in the national and local economy.

\section{Values Examined by Age}

Differences in the means for values were statistically significant when examined by age. Students between the ages of 40-54 placed more value on Intellectual; students between ages 20-29 placed more value on Recognition, Prestige, Security, Control, and Money.

When personal values were rank ordered by the means, students between ages 20-29 differed the most, ranking Recognition second, Intellectual fourth, Integrity sixth, and Artistic seventh, whereas, students between ages 30-39 ranked Intellectual second, Recognition fourth, Artistic sixth, and Integrity seventh. The 30-39 year age group differed from the 40-54 age group in two respects. Students in the 40-54 age group ranked Creative fourth and Recognition fifth, while the 30-39 age group reversed the ranking of these values.

When the means for work values were ordered, differences were found in the order for security and Money for the three groups. Security ranked fourth for ages 20-29, whereas, Security ranked fifth for the 30-39 and 40-54 age groups. Money ranked fifth for the 20-29 age group, fourth for the 30 39 age group, and seventh for the 40-54 age group. Other rankings that were noteworthy were Independence which was ranked fourth by the 40-54 age group while being ranked sixth 
by the 20-29 and 30-39 age groups. Ideas/Data Orientation ranked sixth for the 40-54 age group and seventh for the 20-29 and 30-39 age group. The 20-29 age group ranked Control eighth and Object Orientation nineth while the 30-39 and 40-54 age groups reversed this ranking.

Intellectual, Independence, and Ideas/data Orientation were valued more by those between ages 40-54, while Money, Recognition, and Prestige were more important to those between ages 20-29. Because of their greater life experiences and probably greater financial stability, and lessening of family financial responsibilities, this age group may feel more comfortable in "valuing" intrinsic, cognitive activities and have less concern for valuing money and status when compared to younger students. Of course, it is possible that these older students acquired their value systems in a more idealistic society, while the younger students were at a more impressionable stage in value development in the period of the last decade. Nevertheless, work experience, status of employment, and income appear to be directly related to security and Money •

Ulrich's (1987) study of graduate faculty and graduate student nurse executives suggests that values may change over time; she found Task Satisfaction to be valued more by those over 45 years of age and security valued more by those under 45. While the sample of subjects were apparently employed, age was related to the importance of these work values. 


\section{Values and Job Interests}

Significant mean differences were found between values and job interests, particularly between students interested in Pediatrics, Geriatrics, and Medical/Surgical nursing. Students interested in Pediatrics placed more value on Considerate than the students interested in any of the other job areas. Students interested in Pediatrics also placed more value on Intellectual than did the student nurses interested in Medical/Surgical or Geriatric nursing. In addition, student nurses interested in Pediatrics placed more value on Achievement than the students interested in Medical/Surgical nursing. In the statistical analyses of the work values by job interests, object Orientation was more important to students interested in working in Specialty areas such as the operating room and emergency room. object orientation was also more important to student nurses interested in working in Critical Care than for students interested in working in Obstretrics, Mental Health, and as a Nurse Practitioner/ Clinical Specialist. In addition, object Orientation was more important to the student nurses interested in Pediatrics than to the student nurses interested in Mental Health.

When personal values were ordered by the means and job interests, differences in the ranking of personal values were greater for students interested in Geriatric and obstetrical nursing. No differences were found when personal values were 
ordered for Pediatrics and Nurse Practitioner/Clinical specialist. In ordering work values, the greatest difference occurred in Mental Health and Nurse Practitioner/Clinical Specialist, whereas, they was no difference in the order of work values of student nurses interested in Pediatrics and Medical/Surgical nursing. However, the values seen as ranking consistently among the three most important to job interests were Considerate (personal value), Task Satisfaction, Self Realization, and Altruism (work values).

Perhaps, student nurses values do not differ greatly from the values of employed American workers. As discussed in the research by England and Lee (1973) on managers values, individual values have a primary orientation that are directed towards Achievement and being successful, with a secondary orientation directed towards values such as Integrity.

These findings suggest that work values do differ with job interests. Students interested in jobs that require use of, or manipulation of equipment, placed more value on object Orientation than students interested in jobs where equipment is used less frequently. The research (Campbell, 1966; Strong, 1943, 1955) suggests that people may select occupations that are compatable with their values. The findings in this study suggests that the choice to specialize in a particular area within a special field are part of these values, an area for further research. 


\section{Educational Preparation and Job Interests}

The relationship of educational preparation to job interest indicated that students enrolled in Graduate Degree programs were most interested in the Nurse Practitioner or Clinical Specialist role. Only a few expressed an interest in administration and education. More students in baccalaureate nursing programs were interested in Critical Care and Pediatrics. Students in the Associate Degree programs expressed more interest in Medical/Surgical nursing. Geriatrics, and the Specialty areas such as the operating room and emergency room. These findings suggest that level of educational preparation is related to student interest in particular job areas, that in the higher level of educational preparation, students have fairly clear ideas regarding their interest in professional practice, that they engage in education at the level required to prepare themselves for a particular job.

\section{In Conclusion}

In conclusion, investigative research by Hales and Fenner (1972, 1973, 1975) on the nature of values suggests that values, including work values, begin to form at an early age, that the important values of students in elementary and secondary education are Self Realization and Altruism, that adolescents are more motivated by intrinsic values, and that values are associated with job requirements. Career choices 
are related to a set of values that are important to the person making the choice (Campbell, 1966; Hales \& Eenner, 1972, 1973, 1975; Strong, 1943, 1955; Super, 1957; Super et al., 1963). A career choice may be person oriented or nonperson oriented (Roe, 1957). A social science orientation is directed toward helping. Women place more importance on intrinsic values (Brenner, Blazini, \& Greenhaus, 1988). Time and control over problems influence values (Kluckhohn, 1961). A person seems to have a primary orientation towards Achievement or success, with a secondary orientation related to Integrity (England \& Lee, 1974). Standards for Integrity seem to be based on the recognition of one's own personal values and opinions.

While this investigation chose to describe the values of nursing students, one must recognize that students chose nursing as a profession, a career with a social science orientation. The sample of subjects were mostly woman. Data collection of the information for the study was collected at a time when students were near graduation. Job choices within the profession are people oriented and non-people oriented.

The results of this study indicate that student nurses had comparable personal values and work values, with certain intrinsic values being more important, to them. Extrinsic values were important to them; however, these values were of lesser importance. When values were examined by types of 
educational institution, educational preparation, age, and job interest, significant differences in values were found.

\section{IMPLICATIONS FOR NURSING EDUCATION}

In general, the differences in students' values in this study were moderate, yet significant, nevertheless, they have implications for nursing education. As the educational foundation for nursing is based on the fostering of personal well-being and continuing growth through interpersonal interactions, the nursing curriculum does need to be reviewed periodically for differientation, interpretation, and clarification of the values that are a part of the curriculum.

In order to continually provide an education that is conducive to recognition of values, the faculty need to be aware of their own values, be able to recognize how their values relate to their teaching, student learning, and professional practice, and periodically evaluate how they they use values in the process.

Teaching by relating values to subject matter, human differences, and practice enables student nurses to recognize and understand their own values as well as the values of other people. These teaching techniques have continual implications for further research, as values of faculty and students are in some ways related to age, specific interests, and educational preparation. 
Job interests seem to reflect the importance of certain values of people pursuing or working in a particular role. Clarification and/or recognition of these values may be beneficial to both an employee and employer. For the employer, staffing, retention, and quality of patient care may be related to values of the employees. For the practicing nurse, it seems that values are related to interests and performance with implications for further research in these areas.

\section{LIMITATIONS OF THE STUDY}

Several limitations must be taken into consideration with this study. First, the study was limited to a sample of student nurses in the final quarter/semester of their educational preparation in Oregon and Washington. Less responses to the survey from students in Washington suggests the findings may be less representative of student nurses in that state.

A second limitations was the response rate was lower from bigger schools of Nursing with larger classes. Therefore, the findings of the study may be less representative of student nurses enrolled in larger classes.

A third limitations in the study is the number of male student nurses in the sample in relation to the number of female students. With $11 \%$ of the sample male, the findings may be less representative of male nursing students in 
general. Contributing to this limitation is the prelevance of females in the nursing profession.

A fourth limitation is that the findings on job interests at the graduate level are primarily representative of the values of students interested in the Nurse Practitioner role. The values of graduate students interested in other job areas may differ.

A fifth limitation is that the values of student nurses interested in administration and education are questionable as only a few students in the sample expressed an interest in these areas.

A final limitation involves the nature of any survey. The study was limited to one period of time in the students' education. Longitudinal studies are needed to ascertain developmental and historical relationships on individual changes in values over time. Longitudinal comparisons of student values as they enter and progress through differing education programs in nursing are needed to ascertain the relationships between nursing curriculum, faculty values, and student values.

\section{RECOMMENDATIONS FOR FUTURE RESEARCH}

Future research could (1) replicate this study, (2) replicate this study with a more culturally diverse nursing student sample, (3) replicate this study in other states or nationally, even internationally, (4) compare values of 
student nurses with value of practicing nurses, (5) compare values with more areas of interests in practice, (6) compare value of nurses in clinical practice and management, (7) compare values of nurse educators and students, (8) compare values found in nursing curricula with the values of the faculty and students, (9) perform longitudinal studies on values of nursing students, (10) perform longitudinal studies on values of nursing faculty, (11) compare values of male and female nursing student and practicing nurses with a larger male sample, (12) explore the values of people with career changes, (13) examine changes in values with age, (14) compare work ethics with personal and work values, (15) explore the relationships between family members and student nurse values, (16) examine the relationships between peer pressure and student nurse values, and (17) investigate the relationship between values of nurses, the economy, and other external influences. Research of this nature has the potential to influence nursing curriculum, faculty decisions, student values and employment. 
REFERENCES

Allport, G., Vernon, P., and Lindzey, G. (1931). Study of values. Boston: Houghton Mifflin.

Allport, G., Vernon, P., and Lindzey, G. (1960). Patterns and growth in personality. New York: Holt, Rinehart, and Winston.

Bartol, K. M. and Manhardt, P. J. (1979). Sex differences in outcome preferences: Trends among newly hired college graduates. Journal of Applied Psychology, 64, 477-482.

Blau, P. M., Gustad, J. W., Jessor, R., Parnes, H. S., and Wilcox, R. C. (1956). Occupational choice: A conceptual framework. Industrial Labors Relations Review, 9, 531 543.

Blomquist, B. L., Cruise, P. D., and Cruise, R. J. (1980). Values of baccalaureate nursing students in secular and religious schools. Nursing Research, 29, 379-383.

Bloom, B. (1964). Stability and social change in human characteristics. New York: Wiley.

Bohan, J. F. (1986). Values of oregon community college faculty in selected instructional areas. (Doctoral Dissertation, Portland State University. 1986). Dissertation Abstract International, 47, $08 \mathrm{~A}$

Brenner, O. C., Blazini, A. P., and Greenhaus, J. H. (1988). An examination of race and sex differences in managerial work values. Journal of Vocational Behavior, 32, 336 344 .

Brenner, O. C., and Tomkiewicz, J. (1979). Job orientation of males and females: Are sex differences declining? Personnel Psychology, 32, 741-750.

Brenner, O. C., and Tomkiewicz, J. (1982). Job orientation of black and white college graduates in business. Personnel Psychology, 35, 89-101.

Bridges, C., and Priest, R. (1983). Development of values and moral judgements of West point cadets. Report No: USMA-OIR-83-002. 
Campbell, D. P. (1966). The stability of vocational interests within occupations over long time spans. personnel and Guidance Journal, 44, 1012-1019.

Campbell, D. P. (1969). The vocational interests of Dartsmouth College freshman: 1946-67. Personnel and Guidance Journal, 47, 527-530

Campbel1, D. P. (1974). Manual for Strong-Campbell interest inventory. Stanford, California: Stanford University Press.

Combs, A. W., and Snygg, D. (1949). Individual Behavior. New York: Harper and Row.

Crowley, J. E., and Shapiro, D. (1982). Aspirations and expectations of youth in the United States: Part I: Education and fertility. Youth and Society, 13, 391-422.

Darley, J. C., and Hagenah, T. (1955). Vocational interest measurements. Minneaspolis: University of Minnesota Press.

Donohue, P. J. (1984). Adolescents who work: Effects on work values, achievement, and basic living skills. Paper presented at the annual meeting of the American Educational Research Association.

Duttweiler, P. C. (1984). The internal control index: A measure of locus of control. Educational and psychological measurements, 44, 209-221.

Edel, A. (1955). Ethical judgement: The use of science in ethics. Glencoe, Illinois: The Free Press.

Edel, A. (1963). Method in ethical theory. New York: The Bobles-Merrill Co., Inc.

Edwards, H. J. and panel (1986). Essentials of college and university education for professional nursing: Final report American Association of Colleges of Nursing.

England, G. W. (1967). Personal values systems of American managers. Academy of Management, 3, 53-68. 
England, G.W., and Koike, R. (1970). Personal values system of Japanese managers. Journal of Cross-Cultural

Psychology, 1, 21-40.

England, G. W., and Lee, R. (1974). The relationship between managerial values and managerial success in the United States, Japan, India, and Australia. Journal of Applied Psychology, 59, 411-419.

Enoch, Y. (1988). Why are they different? Background, occupational choice, institutional selection, and attitudes of social work students. Journal of Social Work Education, 2, 165-174.

Erez, M., and Shneorson, Z. (1980). Personality types and motivational characteristics of academics versus professionals in the same occupational discipline. Journal of Vocational Behavior, 17, 95-105.

Eyde, I. D. (1961). Work values and background factors as predictions of women's desire to work. Research Monogram No. 108. Columbus: Ohio State University. Bureau of Business Research.

Fenner, B. J., and Hales, I. W. (1974). Ohio work values inventory: Manual. Athens, Ohio: Authors.

Fromer, M. J. (1981). Ethical issues in health care. St. Lewis: C. V. Mosby Co.

Galler, E. H. (1951). Influence of social class on Children's choice of occupations. Elementary School Journal, 51, $439-445$.

Garvin, B. J., and Boyle, K. K. (1985). Values of entering nursing students: change over ten years. Research in Nursing and Health, $8,235-241$.

Ginzberg, E., Ginzberg, S. W., Axelrod, S., and Herma, J. (1951). Occupational Choice: An Approach to a General Theory. New York: Columbia University Press.

Ginzberg, E., Ginzberg, S. W., Axelrod, S., and Herma, J. (1963). Occupational Choice. New York: Columbia University Press. 
Glee, U. S. (1975). Similarities between college students applying for financial aid and their parents.

(Doctoral Dissertation, University of Maryland, 1975). Dissertation Abstract International. 37, 02A.

Goodale, J. G. (1973). Effects of personal background and training on work values of hard-core unemployed. Journal of Applied Psychology, 57, 1-9.

Goodwin, L. (1972). Do the poor want to work? Washington, D. C. Brookings Institute.

Gordon, L. (1960). Survey of interpersonal values. Chicago, Illinois: Science Research Associates.

Gribbons, W. D., and Lohnes, P. R. (1965). Shifts in adolescents' vocational values. Personal and Guidance Journal, 44, 248-252.

Gruen, W. (1966). Composition and some correlates of the American core culture. Psychological report, 18, 483486 .

Hales, A. K. (1977). A comparative study of the work values of nurses versus the work values of nurse trainees. Unpublished master's thesis: Ohio University.

Hales, L. W., and Fenner, B. J. (1972). Work values of 5 th, 8th, and 11th grade students. Vocational Guidance Quarterly, 20, 199-203.

Hales, L. W., and Fenner, B. J., (1973). Sex and social class differences in work values. Elementary School Guidance and Counseling, $8,26-32$.

Hales, L. W., and Fenner, B. J. (1975). Measuring the work values of children. Measurement and Evaluation in Guidance, $8,22-25$.

Hales, L. W., and Hartman, T. P. (1978). Measuring the work values of technical college students: The ohio work value inventory. Measurement and Evaluation in Guidance, 11, 169-174.

Hales, I. W., and Yackee, K. (1974, April). Self-concepts sex, and work values. A paper presented at the annnual meeting of the American Educational Research Association. Chicago. 
Hall, R. V. (1969). The relationship between personality factors and the choice of selected major fields in education. (Doctoral Dissertation, North Texas State College, 1969). Dissertation Abstract International, 28, $06 \mathrm{~A}$.

Hardcastle, A. J. (1984). Work values and personality types: A comparative study of two occupational interest groups. Unpiblished Masters thesis, California State University, Long Beach.

Harrington, Thomas F., and Harrington, J. C. (1989). Values choices - - Similar or different. Paper presented at the Annual Meeting of the American Association for Counseling and Development.

Harris, C. T., and Earle, J. R. (1986). Gender and work values: Survey findings from a working class sample. Sex roles, 15, 487-494.

Havighurst, R. (1964). Youths in exploration and man emergent. In $\mathrm{H}$. Borow (Ed). Man in a World of Work. Boston: Houghton Mifflin.

Hayes, D. D., and Varley, B. K. (1965). Impact of social work education on student's values. Social Work, 10, 40-46.

Holland, J. L. (1959). A theory of vocational choices. Journal of Counseling Psychology, $\underline{6}, 35-45$.

Holland, J. L. (1965). Manual for the Vocational Preference inventory. Palo Alto, California: Consulting Psychologists Press.

Holland, J. L. (1973). Making vocational choices: A theory of careers. Englewood Cliffs, New Jersey: Prentice Hall, Inc.

Holland, J. L. (1977). The Vocational Preference Inventory (7th Revision). Palo Alto, Ca: Consulting Psychological Press.

Holland, J. L., and Nichols, R. C. (1964). Exploration of a theory of vocational choice. III. A longitudinal study of change in major field of study. Personnel and Guidance Journal, 43, 235-242.

Horney, K. (1945). Our inner conflicts. New York: Norton. 
Howard, A., Shudo, K., and Umeshima, M. (1983). Motivation and values among Japanese and American managers. Personnel Psychology, 36, 883-898.

Huntley, S. (1984, April 16). Yumpies, Yaps, yuppies: Who they are. U.S. News and World Report, p. 39 .

Ishii, S., and Klopf, D. W. (1987, August). Human values in intercultural communication: Japan compared to the U. S. A. Paper presented at the Biennial Meeting of the World Communication Association. Norwich, England.

Isralowitz, R. E., and Singer, M. (1986). Unemployment and its impact on adolescent work values. Adolescence, $21(81), 145-158$.

Izraeli, D., Krausz, M., and Garbor, R. (1979). Student selfselection for specialization in engineering. Journal of Vocational Behavior, 15, 107-117.

Johnson, B. S. (1986). Psychiatric mental health nursing: Adaptation and growth. Philadelphia, Pa.: J. B. Lippincott Co., p. 683 .

Judah, E. H. (1976). Aculturation to social work profession in baccalaureate social work education. Journal of Education for Social Work, $13(2), 65-67$.

Jurgensen, C. E. (1978). Job preferences: What makes a job good or bad? Journal of Applied Psychology, 63, 267276 .

Just, D. A, and Wircenski, J. L. (1984, June). The relationship between female delinguent behavior and work values, occupational aspirations, and labor market experience. Final Report: Vocational Technical Education Research Report, Volume 22, Number 2.

Kahle, L. R. (1985). Social values in the eighties: a special issue. Psychology and Marketing, 2 (4), 231-237.

Kane, J. (1961). Questions of value choice in education. In Barrett D. N. (Ed): Values in America. Notre Dame, In: University of Notre Dame. pp. 83-88.

Kane, R. (1985). Free will and values. Albany, N. Y.: State University of New York Press.

Katz, M. (1963). Decisions and values: A rationale for secondary school guidance. New York: College Entrance Examination Board. 
Kelly, L. Y. (1981). Dimensions of professional nursing: Fourth edition. New York: Macmillan Publishing Co., p. 141 .

Kenkel, W. F., and Gage, B. A. (1983). The restricted and gender-typed occupational aspirations of young women: Can they be modified? Eamily Relations, 32, 129-138.

Kirchner, John R., and Hogan, R. A. (1968). Values patterns of future teachers in three curricula. The Journal of Teacher Education, 19(3), 349-352.

Kirchner, J. H., and Hogan, R. A. (1972). Values of college seniors enrolled in teacher preparation four to five years later. Psychology in the Schools, 9 (1), 7983.

Klampe, C. E. (1983). The work values of secondary teachers: A comparative study by teaching assignment. Unpublished Master's thesis: Portland State University.

Kluckhohn, C. (1951). Values and value orientation in the theory of action: An exploration in definition and classification in T. Parson's and E. Shil's (eds). Toward a general theory of action. Cambridge, Ma.: Harvard University Press, pp. 388-433.

Kluckhohn, F. (1961). Variations in values orientation. New York: Row Peterson.

Kohlberg, L. (1981). The philosophy of moral development: Moral stages and the idea of justice. San Francisco: Harper and Row.

Kosier, B., and Erb, G. (1987). Fundamentals of nursing: Concepts and procedures. Menlo Park, California: Addison-Wesley Publishing Co., pp. 178-195, 280-288, 591 .

Kramer, M. (1986). Effects of faculty practices on student learning outcomes. Journal of professional nursing, Sep-Oct; 2(5), 289-301.

Krathwohl, D. R., Bloom, B. S., and Masia, B. B. (1964). Taxonomy of educational objectives. New York: David Mckay Co., Inc.

Leninger, M. (1984). Care: The essence of nursing and health. Thorofare, New Jersey: Charles B. Slack. 
Levine, A. (1980). When dreams and heroes died: A portrait of today's college student. San Francisco: Jossey-Bass Publishers.

Lindsay, P., and Knox, W. E. (1984). Continuity and change in work values among young adults: A longitudinal study. American Journal of Sociology, 89, 918-931.

Loscocco, K. A., and Kalleberg, A L. (1988, December). Age and the meaning of work in the United States and Japan. Social Forces, 67(2), 337-356.

Lusk, E. J., and Oliver, B. I. (1974). American managers personal value systems - revisited. Academy of Management Journal, 17, 549-554.

Manhardt, P. J. (1972). Job orientation of male and female college graduates in business. Personnel Psychology, $\underline{25}, 361-368$.

Maslow, A. H. (1954). Motivation and personality. New New York: Harper Publishing Co.

Maslow, A. H. (1968). Toward a psychology of being. New York: D. Van Nostrand Company.

Mckibbin, R. D. (1990). The nursing shortage and the 1990s: Realities and remedies. Kansas City: American Nurses Association.

Mills, C. J. (1981) Sex roles, personality, and intellectual abilities in adolescents. Journal of Youth and Adolescence, 10 (2), 85-112.

Morgan, R. G., Brenser, W. G., and Chou, C. (1980). Are expectations realistic? Woman CPA, $42(4), 13-17$.

Morris, C. (1948). Individual differences and cultural patterns. In C. Kluckholm \& H. A. Muray (Eds). Personality in Nature, Society, \& Culture. New York: Knopf, pp. 131-143.

Munsterberg, H. (1913). Psychology and Industrial Efficiency. Boston: Houghton Mifflin and Co.

Neuman, Y., and Neuman, L. (1982). Faculty work orientation as predictors of work attitudes in the physical and social sciences. Journal of Vocational Behavior, 21 , $359-365$. 
Newstrom, J. W., and Ruch, W. (1976, Apri1). The ethics of business students: Preparation for a career. AACSB Bulletin, 12, 21-29.

Norusis, M. J. (1991). Statistical program for social science SPSS. Chicago, Il., SPSS, Inc.

Omery, A. (1989). Values, moral reasoning, and ethics. The Nursing Clinics of North America. 24 (3), 499-509.

O'Neil, M. (1973). A study of baccalaureate nursing students values. Nursing Research, 22, 437-439.

Parsons, P. R. (1988, July). Student values and professional self-selection. Paper presented at the annual meeting of the Associatjon for Education in Journalism and Mass Communication. Portland, OR.

Pearson, H. M., and Kahn, Sharon E. (1989). Women clerical workers: sex role socialization, work attitudes, and values. The Career Development Quarterly, 37, 249-256.

Perrone, P. A. (1965). Values and occupational preferences of junior high school girls. Personal and Guidance Journal, 44, 253-257.

Perrone, P. A. (1967). Stability of values of junior high school pupils and their parents over two years. Personnel and Guidance Journal, 46, 268-274.

Perrone, P. A. (1973). A longitudinal study of occupational values in adolescents. Vocational Guidance Quarterly, $\underline{22}(2), 116-123$.

Perry, R. B. (1954). Realms of value. Cambridge, Ma.: Harvard University Press.

Perrucci, C. C. (1968). The female engineer and scientist: Factors associated with pursuit of a professional career. (Final Report of Manpower Policy). Washington, D. C., Department of Labor.

Posner, B. Z., and Schmidt, W. H. (1984). Values and the American manager: An update. California Management Review, 26, 202-216. 
Pratt, C. B., and McLaughlin, Gerald W. (1988, July). Ethical inclinations of future public relations practitioners. Paper presented at the Annual Meeting of the Association for Education in Journalism and Mass Communication, Portland, OR.

Raths, L., Harmon, M., and Simon, S. (1965, 1978). Values and teaching. Columbus, Ohio: Charles E. Merrill Publishing Co.

Ravlin, E. C., Meglino, B. M., and Adkins, C. L. (1988). Stability of work values: Individual differences and relationship with decision making. Paper presented at the Annual Meeting of the American Psychological Association. Atlanta.

Rescher, N. (1969). Introduction to values theory. Englewood Cliffs, N. J.: Prentice Hall, Inc.

Rescher, N. (1982). Introduction to values theory. Washington, D. C.: University Press of North America.

Robb, I. H. (1900). Nursing ethics for hospitals and private use. Cleveland, Ohio: E. C. Koeckert. p. 16 .

Rodriguez, J. F. (1980). Youth unemployment: A needs assessment. In B. Lindu \& R. Taggert (Eds). A review of youth employment problems, programs, and policies. The youth employment problems: Causes and dimensions. (Vol 1). Washington, D. C.: Vice Presidents' Task Force on Youth Employment. (ERIC Document Reproduction Service No ED 195 665).

Roe, A. (1956). The psychology of occupations. New York: John wiley Publishing Co.

Roe, A. (1957). Early determinants in vocational behavior. Journal of Behavioral Psychology, 4, 212-217.

Rokeach, M. (1968). Beliefs, attitudes, and values. San Francisco: Jossey-Bass Inc.

Rokeach, M. (1973). The nature of human values. New York: Free Press.

Rosenberg, M. (1957). Occupations and values. Glencoe, Il: Free Press. 
Rosenberg, M. (1965). Society and the adolescent self-image. Princeton University Press.

Rosenberg, M. (1973). The nature of human values. New York: Free Press.

Sarason, J. G., and Sarason, B. R. (1973). Modeling and role playing in the schools: A manuel with special reference to disadvantaged students. Washington, D. C.: Office of Education.

Schank, M. J., and Weis, D. (1989). A study of baccalaureate nursing students and graduate nurses from a secular and nonsecular program. Journal of Professional Nursing, $\underline{5}(1), 17-22$.

Schulenberg, J. E., and Vondracek, F. W. (1987, April). Differientation of work values during adolescence. Paper presented at the Biennial Meeting of the Society for Research in Child Development. Baltimore.

Scott, W. (1960). International ideology and interpersonal ideology. Public Opinion Quarterly, 24, 419-435.

Sheahan, J. (1983). Occupational values of senior nurses. Nursing Times, $79(16), 43-44$.

Shorr, J. (1963). The development of a test to measure the intensity of values. Journal of Educational Psychology, 44, 266-274.

Sitaram, K. S., and Cogdell, R. T. (1976). Foundations of intercultural communication. Columbus: Chas. E. Merrill.

Snygg, D., and Combs, A. W. (1949). Individual behavior. New York: Harper and Brothers Publishers.

Spranger, E. (1928). Types of men. Translated from the 5 th German edition of Lebensfarmen by P. J. Pigois: Max Niemeyer Verlag. American agent. New York: StechertHafner, Inc.

St. John, C. H., Blumenfeld, W. S., Angelidis, John P., and Young, S. T. (1989). An attempt to predict career intentions of business administration doctoral students. Journal of Education for Business, 4, 315-318. 
State of Oregon (1987). Laws regulating the practice of nursing: oregon revised statutes, chapter 678 as Amended.

Strong, E. K., Jr. (1943). Vocational interests of men and women. Palo Alto: Stanford University Press.

Strong, E. K., Jr. (1955). Vocational interests 18 years after college. Minneapolis: University of Minnesota Press.

Strong, E. K., Jr., and Campbell, D. P. (1974). StrongCampbell interest inventory. Stanford: Stanford University Press.

Super, D. E. (1957). The psychology of careers. New York: Harper.

Super, D. E. (1970). Manual for the work values inventory. Boston, Mass.: Houghton Mifflin Co.

Super, D. E., Stanshevsky, R., Matlin, N., and Jordan, J. P. (eds) (1963). Career development: self concept theory. New York: College Entrance Examination Board.

Sverko, B. (1989). Origin of individual differences in importance attached to work: A model and a contribution to its evaluation. Journal of Vocational Behavior, 34, 28-39.

Swanson, S. K., and Wodarski, J. S. (1982). Analysis of attitudinal rigidity in social work students. Journal of Applied Social Studies, $6(2), 99-110$.

Thomas, R. E.., Murrell, P., and Chickering, A. W. (1982). Critical role of value development in student development. NASPA Journal, 20, ISS 1.

Thompson, J. E., and Thompson, H. O. (198). Ethics in Nursing. New York: Macmillan Co.

Thurston, H. I., Flood, M. A., Shupe, I. S., and Gerald, K. B. (1989). Values held by nursing faculty and students in a university setting. Journal of Professional Nursing, $\underline{5}(4), 199-207$.

Toffler, A. (1980). The third wave. New York: Morrow Publishing Co. 
Tyson, J. C., and Carroll, M. A. (1970). Conceptual tools for teaching in secondary schools. Boston, Mass.: Houghton Mifflin, Co.

Ulrich, B. T. (1987). Value difference between practicing nurse executives and graduate educators.... who teach aspiring executives. Nursing Economics, $\underline{5}(6), 287-$ 291.

United States Department of Labor, Employment Service. (1965) Dictionary of occupational titles, volume I: Definitions of titles.

Varley, B. K. (1968). Social work values: Changes in value commitment of students from admission to MSW graduation. Journal of Education for Social Work, $4(2), 67-76$.

Vien, D. C. (1989). A history of nursing's code of ethics. Nursing Outlook, 37 (1), 45-49.

Vodanovich, S. J., and Kramer, T. J. (1989). An examination of the values of parents and their children. The Career Development Ouarterly, 37, 365-374.

Vroom, H. V. (1964). Work and motivation. New York: Wiley.

Waggoner, J. C. (1986). Metropolitan school administrators work values, role perceptions and burnout. (Doctoral Dissertation, Portland State University and University of Oregon, 1986). Comprehensive Dissertation Index. 44, $11 \mathrm{~A}$.

Walker, J. E., Tausky, C., and Oliver, D. (1982). Men and women at work: work values within occupational groups. Journal of Vocational Behavior, 21, 17-36.

Ward, M. J. and Fetler, M. E. (1979). Instrument for nursing education research. Boulder, Co.: Western Interstate Commission for Higher Education.

Wax, A. S. (1982). The development of an instrument for measuring administrator burnout: An investigation of internal characteristics. (Doctoral Dissertation, Portland State University, 1982). Comprehensive Dissertation Index. 44, 03A. 
Winters, J. J. (1981). The influence of perceived parental work values and parental environment upon the development ofthe work values of male college students. Dissertation Abstracts International: The Catholic University of America, 42, 1611A.

Wodarski, J. S., Pippin, J. A., and Daniels, M. (1988). The effects of graduate social work education on personality, values, and interpersonal skills. Journal of Social Work Education, 3, 266-277.

Yankelovich, D. S., and White, T. (1977). Raising children children in a changing society. Minneapolis: General Mills. 
APPENDIX A

BIOGRAPHIC DATA 


\section{BIOGRAPHIC CHARACTERISTICS}

1. Date of Birth: Month Day Year Sex: Female _ Male Month Day Year Sex: Female _ Male Month Day Year Sex: Female _ Male

3. Present educational program

( ) Community College Associate Degree Program

( ) Program for Bachelor of Science in Nursing

( ) Program granting a Master's Degree in Nursing

4. Form of educational institution
( ) Public
( ) Private

5. Previous highest level of education PRIOR to entering your present program

( ) High school diploma

( ) Associate degree in

( ) Diploma in nursing

( ) Bachelor's degree in

( ) Master's degree in

( ) Doctorate in

6. Previous employment: FULL TIME Number of years

( ) As a Registered Nurse

( ) As a Licensed Vocational Nurse, Paramedic, or Nursing Assistant

( ) In another field

7. Previous employment: PART TIME Number of years

( ) As a Registered Nurse

( ) As a Licensed Vocational Nurse, Paramedic, or Nursing Assistant

( ) In another field 
8. In what setting do you plan to work when you finish your present program? (CHECK ONLY ONE.)

( ) Hospital

( ) Home Health

( ) Community Health

( ) Industrial

( ) Public Health

( ) Clinic/Doctor's office
( ) Nursing Home

( ) Private Practice

( ) Hospice

( ) College/University

( ) School

( ) Other

9. In what ONE AREA OF INTEREST do you plan to seek employment upon graduation? PLEASE CHECK ONLY ONE.

( ) Medical/surgical nursing

( ) Geriatrics

( ) Critical Care Nursing
( ) Adults
( ) Children
( ) Neonates

( ) Obstetrical Nursing

( ) Pediatric Nursing

( ) Mental Health
( ) Adults
( ) Children

( ) Nurse Practitioner

( ) Family Practice

( ) Adults

( ) Midwife

( ) Other

( ) Administration

( ) Education/Staff Development

( ) Speciality in

( ) Emergency Room ( ) Flight Nursing

( ) Operating Room ( ) Other

( ) Clinical Specialist in Please state. 
APPENDIX B

OHIO WORK VALUES INVENTORY 


\section{OHIO WORK VALUES INVENTORY}

People have their own reasons for choosing the work they will do for a living. The work that a person chooses often depends upon what is important to him or her. If you know what you value about work, it may be easier for you to make plans and choices which are right for you.

There are no right or wrong answers to these questions because no one knows better than you what is good for you.

DIRECTIONS; There are five empty boxes after each question. Draw an $\mathrm{X}$ in the one box you decide for your answer. For example, one person marked two questions this way:

HOW MUCH WOULD

YOU LIKE TO HAVE;

a job where you work out doors most of $\begin{array}{ccccc}\text { Not } & \text { A } & \text { Fairly } & \text { A } & \text { Very } \\ \text { much } & \text { little } & \text { much } & \text { lot } & \text { much }\end{array}$ the time?

$\begin{array}{lllll}() & (1) & (1) & (x) & (1)\end{array}$

a job where you work at night?

$(x)$ ( ) ( ) ( ) ( )

You can see that this person values working outdoors a $\underline{\text { lot }}$. And, work that is done at night the person values a little. 


\section{HOW MUCH WOULD YOU LIKE TO HAVE;}

1. a job that helps people?

2. a job where you put things together?

3. a job that is easy for you to keep?

4. a job where you can tell others what to do?

5. a job where you do many of the things you are able to do?

6. a job where you come and go as you please?

7. a job that pays you a lot of of money?

8. a job where you do things you like to do?

9. a job that you do mostly by yourself?

10. a job where you often work with facts, ideas, and opinions?

11. a job where a lot of people in your state know what you do?

12. a job where you help people to have a better life?

13. a job where you make or build things?

14. a job that is yours as long as you want it?

15. a job where you would be the boss?
Not A Fairly A very much little much lot much
()$\quad() \quad() \quad(\quad) \quad(1)$

$(1)(1)(1)(1)$

()()()$\quad(1)$

()()()()$\quad(1)$

( ) ( ) ( ) ( ) ( )

()()()$\quad() \quad(1)$

()()$\quad()(1)$

()$(1)(1) \quad(1)$

( ) ( ) ( ) ( ) ( )

$(1)(1)(1)(1)$
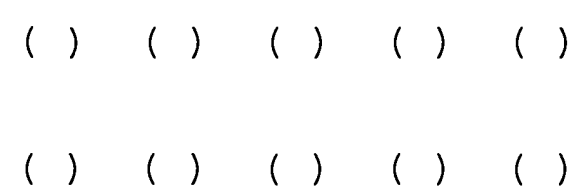

( ) ( ) ( ) ( ) ( )

( ) ( ) ( ) ( ) ( )

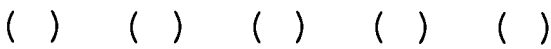


HOW MUCH WOULD YOU LIRE TO HAVE;

16. a job where you can use the skills you have?
Not A Fairly A Very much little much lot much

17. a job where you choose what you ( ) ( ) ( ) ( ) ( ) will do each day?

18. a job where you can earn all the money you need or more?

19. a job that gives you a lot of enjoyment?

20. a job where you work very little with other people?

$\left(\begin{array}{llllll} & (1) & (\end{array}\right)(1)$ a job where you sometimes think ( ) of new ways to do things?

22. a job that will make you well known?

23. a job where you do good things for others?

24. a job where you can see how and ( ) why parts of things fit together?

25. a job you are sure of having year after year?

26. a job where you give direction ( ) ( ) ( ) ( ) ( ) to other workers?

27. a job that lets you use your abilities?

28. a job where no one tells you what to do?

29. a job where there is a chance to get rich?

30. a job that makes you feel happy ( most of the time? 


\section{HOW MUCH WOULD YOU LIRE TO HAVE;}

31. a job that is done mostly by one person?

32. a job where having ideas is important?

33. a job where people admire you for your work?

34. a job where you can help people ( ) who have problems?

35. a job where your main work is to make or fix things?

36. a job where no one will take your place unless you decide to leave the job?

37. a job where you are in charge of a group of workers?

38. a job that helps you to keep on improving as a person?

39. a job where you decide what hours you will work?

40. a job where you can earn a lot of money?

41. a job that you look forward to doing each day?

42. a job where you are on your own ( in doing the work?

43. a job where you try to make sense out of several ideas?

44. a job where many people will know you because of your work?

45. a job where you can help people ( who don't have a very easy life?

46. a job where you take things apart to see why they don't work?
Not A Fairly A Very much little much lot much 
47. a job that you know is always yours?

48. a job where it is up to you to see that others do their work?

49. a job where you do the things you are good at doing?

50. a job where you can take time off when you want?

51. a job where you may sometimes make a lot of extra money?

52. a job that seems fun to do?

53. a job where you work by yourself( ) most of the time?

54. a job where it is important that ( ) others understand your ideas?

55. a job where you have a chance ( ) ( ) ( ) ( ) ( ) to be famous?

56. a job where doing something for ( ) other people is your main work?

57. a job where you often handle things?

58. a job you can keep as long as you like?

59. a job where you plan and direct ( ) ( ) ( ) ( ) ( ) the work of others?

60. a job where you can develop your abilities?

61. a job where you decide how you ( ) ( ) ( ) ( ) ( ) will do your work?

62. a job that will make you a rich ( ) ( ) ( ) ( ) ( ) person? 
HOW MUCH WOULD YOU LIKE TO HAVE;

63. a job that you enjoy doing?

64. a job where you are not near other people much of the time?

65. a job where putting ideas together is important?

66. a job where you will be well known for the work you do?

67. a job that makes living easier and happier for other people?

68. a job where you use tools in
Not A Fairly A Very much little much lot much 


\section{APPENDIX C}

PROFILE OF LIFE VALUES 


\section{PROFILE OF LIFE VALUES}

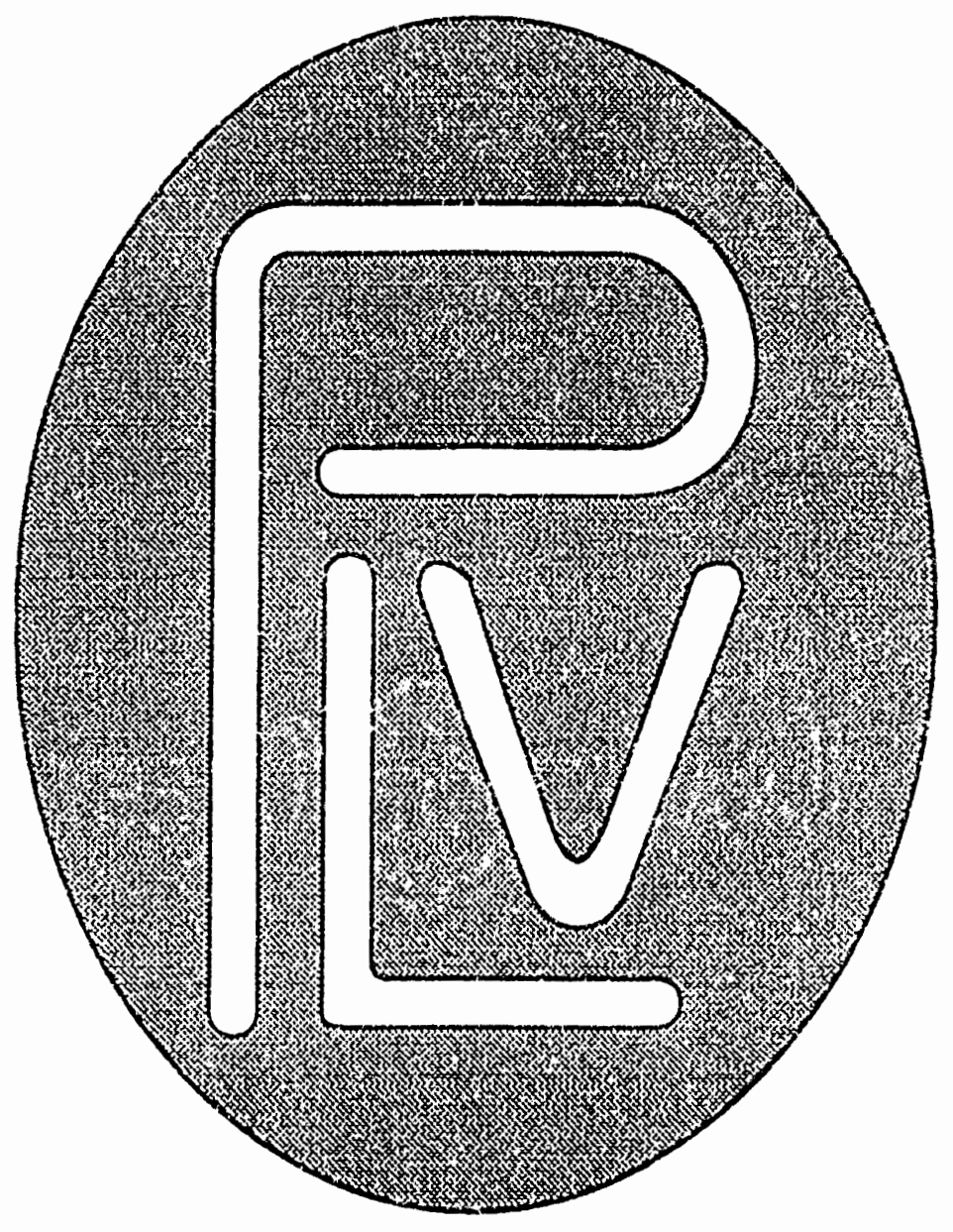

Copyright (c) 1992 by Loyde W. Hales and Stella B. Bellarts 
INSTRUCTIONS; In this section are statements representing things that you may consider important to you. please read each of the statements. Decide if the statement represents something you value by indicating if you strongly agree, agree, neither agree nor disagree (are neutral), disagree, or strongly disagree. Indicate your choice by placing an $x$ in one of the brackets next to the statement. 
HOW MUCH DO YOU AGREE?

Strongly

Disagree

1. I have a strong intellectual curiousity.

2. I show concern when other people are upset.

3. I use unique ideas to solve problems.

4. I like to receive recognition for the work I do in organizing group activities.

5. I have an appreciation for the fine arts, music, drama, ballet and literature.

6. I do a good job when I take on added responsibilities.

7. A person should stick to the truth regardless of the circumstances.

8. I have an active interest in scholarly activities.

9. I show concern for the welfare of my colleagues.

10. I like to develop new and different techniques for doing things.

11. I like to be rewarded for the support I give to those who work with me.

12. I have many cultural interests.

13. I do a good job in solving problems.

14. I stick to the truth even if it is unnecessary to do so.
Strongly Agree

$($ ) ( ) ( ) ( ) ( )

()$\quad(1)(1) \quad(1)$

( ) ( ) ( ) ( ) ( )

( ) ( ) ( ) ( ) ( )

( ) ( ) ( ) ( ) ( )

()()$(1)(1)$

()$\quad(1) \quad(1) \quad(1)$

( ) ( ) ( ) ( ) ( )

()$\quad(1)(1)(1)$

( ) ( ) ( ) ( ) ( )

( ) ( ) ( ) ( ) ( )

( ) ( ) ( ) ( ) ( )

( ) ( ) ( ) ( ) ( )

( ) ( ) ( ) ( ) ( ) 
HOW MUCH DO YOU AGREE?

Strongly

Disagree
Strongly

Agree

15. I like to be involved in activities that challenge my abilities and skills.

16. I am considerate of other people's feelings.

17. I like to develop new solutions ( ) ( ) ( ) ( ) ( ) to problems.

18. I like to be in a position where I can recognize people for what they do.

19. I like to express myself artistically.

20. I look for ways to increase my responsibilities.

21. To make a situation more comfortable, it is all right to tell a white lie.

22. I strive to gain new knowledge about the world.

23. I go out of my way to help someone feel at home.

24. I like to discover alternative methods for doing things.

25. I like to have others respect me for the work I do.

26. I enjoy visiting museums and art gallerys.

27. Others look to me for advice.

28. In some situations it is permissable to deceive others. 
HOW MUCH DO YOU AGREE?

29. I read articles that are a

Strongly

Disagree
Strongly

Agree challenge to understand.

30. I help people feel more comfortable in new places.

31. When looking for a solution to an issue, I use creative approaches.

32. I like others to notice and appreciate what I do.

33. I like to design things that are artistic.

34. When there is a hard job to do, ( ) I get it done.

35. Some delay in presenting the truth is permissable in easing a difficult situation.

36. I investigate ideas that influence changes in our society.

37. When I am pleased with others, I show it in my behavior.

38. I look for novel ways to get the job done.

39. People respect me for the things I do.

40. I like to create beautiful and artistic objects.

41. When there is a hard job to be done, I see that it gets finished.

42. If withholding information will ( ) ( ) ( ) ( ) ( ) make the job easier, it is all right to do so. 
HOW MUCH DO YOU AGREE?

Strongly

Disagree

43. I enjoy searching for new ways ( ) ( )

to approach life.

44. I am sensitive to hurting other ( ) people's feelings.

45. I use original ideas when doing ( things.

46. I like to be acknowledged for my accomplishments.

47. I arrange my time so that I may ( ) ( participate in cultural activities.

48. Achieving what I am capable of doing is important to me.

49. Stretching the truth is all if it helps a friend get out of a tight place.

50. I like to read literature that gives me insight into a problem.

51. I see that other people are fair treatment.

52. I like to take a problem and and study different ways to solve it.

53. Being recognized for the work I do is important to me.

54. I appreciate unusual works of art.

55. Providing the leadership needed to solve a difficult task is important to me.

56. Some compromise of the truth is ( ) permissible if it helps other people.

Strongly Agree

) ( ) ( ) ) 
APPENDIX D

SAMPLE LETTER SENT TO COLLEGES AND UNIVERSITIES 
SAMPLE LETTER

TO: Deans, School of Nursing

FROM: Stella B. Bellarts

I am a graduate student in postsecondary Education at Portland State University working on my dissertation. My advisor is Dr. Loyde Hales in the School of Education. My area of research is on personal values, work values, and job interests of nursing students. My research proposal has been reviewed and approved, so I may begin data collection.

I am requesting permission to obtain data for this study in your institution. The data for this study should be provided by nursing students who are in their last year of their educational program. A survey questionnaire is be used to collect biographic data on age, sex, education, employment, area of interest for future employment, values that are important to the person as an individual, (i.e., achievement, altruism, creativity), and values that are important in the world of work, (i. e., self realization, prestige, interest orientation using the Ohio Work Values Inventory by Hales and Fenner).

The research questions to be answered are:

1. What are the work values of nursing students in the final year of their nursing program?

2. What are the personal values of nursing students in the final year of their nursing program?

3. Do personal values of nursing students differ with level of educational preparation? With job interests?

4. Do work values of nursing students differ with level of educational preparation? With job interests?

The survey takes approximately 15 minutes to complete. It contains no right or wrong answers. Confidentiality will be maintained as no college, university, or student will be identified. Names or some means of personal identity are not part of the survey questionnaire. Surveys are to be placed in an envelope and sealed before being returned to the investigator. 
I have chosen to study the values of student nurses as values seem to receive more attention in the curriculum. A section in the American Association of Colleges of Nursing Report on Essentials of College and University Education for Professional Nursing (1986) discussed values with the significance to nursing education. Theories support the assumption that behavioral responses are influenced by our internal personal values. The advances in science and techology and the need for a broader knowledge base are said to have an effect on a person's values.

I feel that the survey will answer questions for nurse educators on values that are important in curriculum planning, teaching, student development, and work.

For your convenience, I am enclosing a response form and a self-addressed stamped envelope.

I will be contacting you or your designated contact person within the week by telephone to further discuss this study and to make arrangements for collecting the data.

Thank you for your assistance.

Sincerely,

Stella Bellarts

Graduate student

Postsecondary Education

Portland State University 
TO; Stella Bellarts, RN, MN Graduate student

Portland State University

In reply to your request to obtain data for your investigative study on personal values, work values, and job interests of nursing students, I (do)_ (do not) consent to your request.

Date study .
Signature

Institution

Person to contact for further coordination of your Name 
TO: Presidents of Community Colleges

FROM: Stella B. Bellarts

I am a graduate student in Postsecondary Education at Portland State University working on my dissertation. My advisor is Dr. Loyde Hales in the school of Education. My area of research is on personal values, work values, and job interests of nursing students. My research proposal has been reviewed and approved, so I may begin data collection.

I am requesting permission to obtain data for this study in your institution. The data for this study should be provided by nursing students who are in their last year of their educational program. A survy questionnaire is to be used to collect biographic data on age, sex, education, employment, area of interest for future employment, values that are important to the person as an individual, (i.e., achievement, altruism, creativity), and values that are important in the world of work, (i. e., self realization, prestige, object orientation using the Ohio Work Values Inventory by Hales and Fenner).

The research questions to be answered are:

1. What are the work values of nursing students in the final year of their nursing program?

2. What are the personal values of nursing students in the final year of their nursing program?

3. Do personal values of nursing students differ with level of educational preparation? With job interests?

4. Do work values of nursing students differ with level of educational preparation? With job interests?

The survey takes approximately 15 minutes to complete. It contains no right or wrong answers. Confidentiality will be maintained as no college, university, or student will be identified. Names or some means of personal identity are not part of the survey questionnaire. Surveys are to be placed in and envelope and sealed before being returned to the investigator.

I have chosen to study the values of student nurses as values seem to receive more attention in the curriculum. Theories support the assumption that behavioral responses are influenced by our internal personal values. The advances in 
science and technology and the need for a broader knowledge base are said to have an effect on a person's values.

I feel that the survey will answer questions for nurse educators on values that are important to curriculum planning, teaching, student development, and work.

For your convenience, I am enclosing a response form and a self-addressed stamped envelope.

I will be contacting you or your designated contact person within the week by telephone to further discuss this study and to make arrangements for collecting the data.

Thank you for your assistance.

Sincerely,

Stella B. Bellarts

Graduate student

Postsecondary Education

Portland State University 
APPENDIX E

SAMPLE LETTERS FROM RESEARCHER TO STUDENTS 
Dear Colleague:

This survey has been designed to allow you to describe what is important to you as you finish your present educational program and seek employment in your particular area of interest. Your responses will be combined with those of other nursing students to yield a picture of what is important to many nursing students. This should help the next generation of nursing students to better understand their values. Your answers will remain anonymous while being a very important contribution to this study. Please choose to complete this survey. Place the survey in the envelope; seal the envelope; place the envelope in the box furnished by the investigator.

Thank you for being a participant. 
Dear Colleague:

I am a graduate student in Postsecondary Education at Portland State University working on my dissertation. My area of research is on values and job interests of nursing students in the last year of their present educational program.

I would like you to consider being a participant in this study. The enclosed survey has been designed to allow you to decribe what is important to you as you finish your present educational-program and seek employment in your particular area of interest. Your responses will be combined with those of other nursing students to yield a picture of what is important to many nursing students. this should help the next generation of nursing students to better understand their values. Your answers will remain anonymous while being a very important contribution to this study. Please choose to complete the survey. Place the survey in the stamped addressed envelope and mail the envelope to me.

Thank you and congratulations to you on your upcoming graduation. Hope you find the job that really interests you.

Sincerely,

Stella Bellarts, R. N., M. N. Graduate Student

Portland State University 